\title{
AMBIENTE ADECUADO PARA LA FORMACIÓN TECNOLÓGICA UNIVERSITARIA
}

AUTOR: HÉCTOR H. THOMPSON

DIRECTOR EXTERNO: ING. HILARIO FERNANDEZ LONG DIRECTOR INTERNO: LIC. GUSTAVO ROSSI

\author{
TESIS PRESENTADA PARA OBTENER EL \\ GRADO DE MAGISTER EN TECNOLOGIA \\ INFORMATICA APLICADA EN EDUCACION
}




\section{CAPITULO 1}

LA CIENCIA COMO SOPORTE DE LA TECNOLOGÍA, CASO DE LA FÍSICA 4

La ciencia como base del conocimiento 5

El conocimiento progresivo de nuestro planeta $\quad 6$

Actividad científico-tecnológica desde el renacimiento en adelante 6

$\begin{array}{ll}\text { Positivismo lógico y las revoluciones científicas } & 7\end{array}$

$\begin{array}{ll}\text { Método científico } & 7\end{array}$

Filosofía y política $\quad 8$

$\begin{array}{ll}\text { Los sistemas, sus límites } & 8\end{array}$

Otras visiones. El legado de oriente 9

Conocimiento científico confiable 9

Evolución de distintos conocimientos en el camino de la ciencia 10

$\begin{array}{ll}\text { Críticas a la ciencia } & 11\end{array}$

Límites naturales de la tecnología $\quad 12$

$\begin{array}{lr}\text { Límites cuantitativos } & 12\end{array}$

Límites cualitativos $\quad 14$

Caso de la máquina a vapor $\quad 14$

La automatización $\quad 15$

$\begin{array}{ll}\text { Experimentos científicos y la enseñanza de la física } & 15\end{array}$

\section{CAPITULO 2}

CONOCIMIENTO CONECTADO

Obstáculos en el camino del aprendizaje de la ciencia $\quad 19$

$\begin{array}{lr}\text { Tiempos y caminos comunes } & 19\end{array}$

$\begin{array}{ll}\text { La cuestión semántica } & 19\end{array}$

$\begin{array}{lr}\text { Lenguaje y comunicación } & 20\end{array}$

Pedagogía y patética $\quad 21$

Conocimiento conectado $\quad 22$

Acceso a información ordenada $\quad 23$

Información $\quad 24$

Información y conocimiento conectado $\quad 24$

La fuerza del conocimiento conectado $\quad 24$

Soportes físicos de la información $\quad 25$

Desarrollo de habilidades mediante la producción $\quad 25$

Experiencia y conocimiento conectado $\quad 26$

La imitación y los ejemplos $\quad 26$

$\begin{array}{ll}\text { Los patrones } & 27\end{array}$

Lenguaje de patrones $\quad 28$

Formación integral. $\quad 28$

Los receptores de la actividad académica $\quad 28$

Velocidad de avance individual $\quad 28$

Avance personalizado y adelantados $\quad 29$

Universo de los que aprenden $\quad 29$

¿Es posible personalizar la capacitación tecnológica? 30 
CAPÍtULO 3

CONTEXTO IDEAL PROPUESTO PARA EL ACCESO TEÓRICO

EL DESARROLLO DE HABILIDADES Y LA FORMACIÓN 31

Tres ámbitos de actividad académica

Acceso a información ordenada

Superficie de representación del conocimiento 33

Características de la superficie de representación del conocimiento 33

$\begin{array}{ll}\text { Representación gráfica } & 34\end{array}$

Dinámica de la superficie de conocimiento $\quad 35$

Localización inicial del alumno $\quad 35$

Itinerario sobre la superficie de conocimiento $\quad 35$

Optimización del itinerario $\quad 35$

Acceso a la información ordenada $\quad 35$

Las fuentes informativas $\quad 36$

La teoría correcta. Los errores $\quad 36$

Historia de los soportes físicos de la información $\quad 36$

$\begin{array}{ll}\text { El tiempo y la extensión de los contenidos } & 37\end{array}$

$\begin{array}{ll}\text { Las metáforas. Sus límites } & 37\end{array}$

Ámbito para el desarrollo de las habilidades $\quad 38$

Contexto físico ideal $\quad 38$

Contexto ideal para el desarrollo de habilidades. Límites de la idealización $\quad 39$

Contexto afectivo ideal. El rol de los adelantados

La conducción del proceso educativo $\quad 39$

Composición de la conducción $\quad 40$

Evaluación del avance $\quad \mathbf{4 0}$

Elementos naturales de evaluación $\quad 41$

Planilla de seguimiento $\quad 41$

La continuidad del crecimiento académico

La formación integral. $\quad \mathbf{4 2}$

Contexto afectivo ideal para la formación humana 4

CAPÍTULO 4

LA TECNOLOGÍA DE OBJETOS Y SU APRENDIZAJE

Paradigma $\quad 44$

Paradigma informático tradicional $\quad 44$

Tecnología informática tradicional $\quad 44$

Herramientas y Técnicas tradicionales $\quad 45$

Primera crisis del software $\quad 46$

Búsqueda de paliativos a la primera crisis $\quad 46$

Parametrización $\quad 46$

Modularización $\quad 46$

Encapsulamiento de comportamiento 46

Componentes $\quad 46$

$\begin{array}{ll}\text { Arquitecturas } & 47\end{array}$

Cambios en las aplicaciones $\quad 47$

La segunda crisis del software $\quad 48$

Tecnología de objetos $\quad 49$

Objeto 49 
Mensaje $\quad \mathbf{5 0}$

Interfaz de un objeto

Clase $\quad \mathbf{5 0}$

Sistema compuesto por objetos

Ejemplo que permite apreciar la diferencia entre los dos paradigmas

Aprendizaje de la tecnología de objetos $\quad \mathbf{5 2}$

Dificultades en el aprendizaje de la tecnología de Objetos $\quad 52$

Ventajas de aprender la tecnología de objetos $\quad 53$

Los caminos para aprender tecnología de objetos $\quad 54$

Ambiente de objetos (un camino)

Constructivismo en el dominio informático $\quad 55$

Ambiente $\quad 55$

El profesional informático en un ambiente de objetos 56

Smalltalk $\quad \mathbf{5 6}$

Lenguaje Logo y ambiente Smalltalk $\quad 57$

Diseño (un camino) $\quad 57$

Patrones de diseño $\quad 58$

Elementos que identifican un patrón $\quad 58$

Beneficios $\quad 58$

Comparación con otro cambio de paradigma informático 59

Uso y Re-uso

Precisión semántica $\quad 59$

El universo de los que aprenden $\quad 60$

El código, los patrones de implementación y la documentación

Contexto físico ideal $\quad \mathbf{6 1}$

CAPITULO 5

APLICACIÓN DE LA FORMACIÓN PERSONALIZADA EN UN ÁMBITO
DE APRENDIZAJE REAL

Aplicaciones iniciales de los conceptos relevantes de esta tesis 63

Actividad previa. Encuesta $\quad \mathbf{6 4}$

Planilla de conocimiento: concreción de la superficie de conocimiento 65

$\begin{array}{ll}\text { Extensión del tiempo disponible } & 67\end{array}$

$\begin{array}{ll}\text { Necesidad } & 67\end{array}$

$\begin{array}{ll}\text { Propuesta } & 68\end{array}$

Extensión del alcance físico de actividad académica $\quad 69$

Contexto informativo para el acceso a la tecnología de objetos 70

$\begin{array}{ll}\text { Contenidos del Sitio (o CD) } & 70\end{array}$

Semántica $\quad \mathbf{7 0}$

Clases teóricas $\quad \mathbf{7 0}$

Materiales de soporte de la actividad práctica $\quad 71$

Soporte bibliográfico $\quad 71$

Desarrollo de la actividad práctica $\quad \mathbf{7 1}$

Actividad de desarrollo de un sistema a realizar por los cursantes 72

Especificación de requerimientos del sistema $\quad 72$

Cuidados a tener en cuenta cuando se escribe la especificación $\quad 73$

$\begin{array}{ll}\text { Diseño } & \mathbf{7 3}\end{array}$

Casos de uso $\quad 73$

Análisis y diseño $\quad 74$ 
Relación entre objetos del problema (análisis) y objetos de la solución (diseño) 74

El diseño y las interfaces de los objetos

Diseño e implementación $\quad \mathbf{7 5}$

Implementación de los desarrollos $\quad \mathbf{7 5}$

Contexto afectivo real y adelantado en el taller de aprendizaje de Objetos $\quad 75$

Conexión adicional: Modelado E/R del paradigma de TO $\mathbf{7 6}$

Optimización de los desarrollos $\quad \mathbf{7 6}$

Evaluación del acceso al conocimiento $\quad 78$

$\begin{array}{ll}\text { Carpeta individual de seguimiento. } & \mathbf{7 8}\end{array}$

CAPITULO $6 \quad 79$

APORTES, CONCLUSIONES Y ACTIVIDAD A FUTURO 79

$\begin{array}{ll}\text { Aportes } & 79\end{array}$

Conclusiones y actividad a futuro $\quad 79$

Objetivos del ambiente académico propuesto $\quad \mathbf{8 0}$

Continuidad en el desarrollo de e-learning $\quad 81$

$\begin{array}{ll}\text { Sitio evolutivo de la cátedra } & 81\end{array}$

Red conceptual del sitio $\quad 81$

Contenido del sitio

Ámbito virtual de publicación de la producción de los cursantes $\quad 82$

Inscripción de los cursantes $\quad \mathbf{8 2}$

Comunicación a los alumnos en el momento de inscripción $\quad 82$

Red de actividad con los alumnos y ex alumnos $\quad 82$

$\begin{array}{lr}\text { BIBLIOGRAFIA } & 83\end{array}$ 


\section{PRÓLOGO}

La impronta de esta tesis la estableció mi apreciado maestro Hilario Fernandez Long. Nos conocimos a principios de la década de 1980, en Buenos Aires compartiendo el ámbito común de la informática aplicada a la enseñanza. En esos años apareció con claridad la potencia del lenguaje Logo para el desarrollo de un aprendizaje, aprovechando las ventajas de los aparatos informáticos personales (también me habló de otras formas de acceso al conocimiento a través de la cultura oriental). Aquella experiencia -Logo- tuvo sus límites, pero dejo en mi una dinámica que, en parte, queda reflejado en este trabajo

Luego al comenzar mi trabajo en esta tesis tuvimos varias reuniones en la casa de Fernandez Long en Necochea, donde pasó sus últimos años.

Fernandez Long dirigió esta tesis y conoció su primera versión completa. Un punto culminante de esta relación -mantenida principalmente mediante el intercambio de e-mails - se dio cuando encontré y comuniqué a Fernandez Long que aquellos objetos de software (tortugas) con las que trabajábamos en Logo hoy tenían su versión en el Lego controlado por Smalltalk o sea por la tecnología de objetos.

Mi reconocimiento a la influencia de Gustavo Rossi, quien durante sus cursos en la maestría de Ingeniería de Software, en nuestro trabajo académico común y en la revisión de este trabajo ha sido una ayuda paciente y definitoria de la conclusión del mismo.

En la década de 1980, Fernández Long, me hablo del libro "El Tao de la física" que he despertó mi atención a principios del 2004 y terminó de internalizar en mí la concepción limitada de lo percibido por nuestros sentidos, esa metáfora de la realidad que traducimos en palabras e imágenes. La física cuántica comenzó a plantear la imposibilidad de la percepción sensorial nivel de la física de las partículas, por eso, al conocerse los fenómenos cuánticos, comienza a aparecer la realidad no percibible, y el observador comienza a involucrarse en los fenómenos, aparece un cuestionamiento de la objetividad. Hay entonces, otras formas de relacionarse con el mundo, o sea que el conocimiento es relativo, lo que hace incierto el concepto de una versión única y objetiva. En nuestro espacio-tiempo podemos tener una visión de la realidad que traducimos en teorías científicas. La humildad de la ciencia esta dispuesta a rectificar esas teorías, en cuando no respondan prediciendo la realidad (esa realidad subjetivamente observada por esta cultura en este espacio tiempo).

Un filósofo no tiene el patrimonio de la reflexión y trabaja con una determinada noción del sujeto. La reflexión es una característica del pensamiento, los naturalistas ven al sujeto con conciencia plena y cuerpo presente lo que tiene que ver más con la biología del conocimiento (no con la filosofía), no tiene que ver con una posición de orden epistemológico (cómo se genera una teoría). Cuando miramos desde distintos puntos de vista obviamente no vemos lo mismo, pero las múltiples miradas generan, en el campo del aprendizaje, múltiples caminos. Esta tesis busca encontrar entre las múltiples miradas del aprendizaje, un conocimiento de base científica admitiendo la relatividad de esta visión. Cualquier percepción nos muestra una cara del absoluto inaccesible. Toda percepción que nos hace co-partícipes de lo que estamos percibiendo, de otro modo las cosas son en la medida de nuestros sentidos. El observador forma parte integrante de la experiencia en la que se encuentra necesariamente incluido (desde un punto de vista matemático si el fenómeno a explicar es $\mathrm{N}$, cuando lo explicamos es $\mathrm{N}+1$ )

Aunando lo expresado en el párrafo anterior la lectura del libro Connected Knownledge de Cromer -recomendada por Fernández Long en una de nuestras primeras 
entrevistas- tome la decisión de apoyarme en mi camino previo asociado al método científico y a una plausible objetividad. El libro de Cromer resultó un hito en mi camino de búsqueda. Se concreta en él una expresión del modelo científico de aprendizaje e investigación que contextualiza mi actual actividad docente, reconociendo que la ciencia goza de las ventajas que no poseen los otros métodos de explicación de la realidad: si se basa en una sabia humildad, aprende de sus errores.

Mi aprendizaje en relación a la pedagogía y la matética comenzó también en los '80. La concreción de muchos talleres de aprendizaje asociados a la informática permitió conocer errores, rectificarlos y volver a probar, este camino se ve reflejado en el contenido de esta tesis, que busca optimizar el ámbito de aprendizaje tecnológico, redefiniendo las actividades teóricas y prácticas y personalizando la actividad individual de cada alumno.

Al asociar el método científico con el aprendizaje tecnológico, se desarrolla una pedagogía para las materias tecnológica con una aplicación particular en el área de la informática: la tecnología de objetos, tomando en cuenta el particular desafío a las capacidades intelectuales de quien aprende Tecnología de Objetos,

Algunos instrumentos que propongo -como aporte a la actividad universitariatanto en su expresión teórica como en su concreción práctica, son

$>$ Superficie de conocimiento

$>$ Tiempo variable de cursada

$>$ Concepto de adelantado

Quienes se ocupan de lo pedagógico en conexión con la tecnología de base científica podrán conocer un enfoque que propone una transición, desde la tradición universitaria a un futuro que nos pide más y mejor capacitación para mayor cantidad de ciudadanos.

Para quienes trabajan del área de la ingeniería de software quedan planteadas las bases para llegar a lograr, en el futuro, la estabilidad de otras ingenierías más maduras.

Se plantea la necesidad de una red terminológica hipermedia y una propuesta de acceso al conocimiento que estimule la personalización del aprendizaje de cada cursante, buscando una transición que permita simultáneamente expandir los límites el espacio tiempo universitario (hoy acotado por razones edilicias y administrativas).

El concepto de adelantado, resulta imprescindible para recorrer los caminos de aprendizaje y tener la posibilidad de ampliar sin límites la capacidad de formación terciaria, reclamo social que debe satisfacerse en momentos que él único ámbito de crecimiento de actividad laboral es aquel basado en el conocimiento.

El párrafo anterior, conecta este trabajo con la época que nos toca vivir. Por eso al concretar esta publicación, su desarrollo se vio influenciado también por las manifestaciones que ha tenido en nuestro medio la coyuntura internacional, rotulada como "globalización". La tecnología de base científica está produciendo transformaciones que afectan la vida cotidiana a una velocidad como nunca lo hiciera antes. No son los cambios en la comunicación o las novedades de cualquier tipo lo que la tecnología está produciendo sino, y fundamentalmente, un cambio de paradigma de la forma de distribución de la riqueza. 
Hoy -como el resto de los habitantes de este planeta- los universitarios estamos sometidos al acelerado cambio que llevará a la automatización de la provisión de bienes y servicios. Tan corto es el lapso de transformación que requiere de mucha inteligencia sinergicamente manejada para encontrar otro modo de compartir el planeta que -a pesar de las guerras y algunas otras barbaries- logró cierto equilibrio social durante siglo XX. En el siglo pasado la producción de bienes y servicios era remunerada masivamente mediante los salarios. Hoy, el empleo laboral disminuye creando una población excedente creciente para ese paradigma distributivo. El planeta requiere respuestas inteligentes que preserven a la humanidad. El mercado no puede conducir el cambio, pues el consumo fruto de salarios pagados- no es posible sin la existencia de empleo laboral, los correspondientes salarios y sin el crecimiento del número de asalariados. Por eso aparecen en esta tesis una propuesta de un tercer ámbito de actividad académica: reflexión sobre el presente y futuro (además del planteo de una reformulación los tradicionales ámbitos de actividad teórica y práctica)

El cambio que vivimos hace necesario conectar la actividad académica con lo político-social de un modo diferente al que aconteció el siglo pasado. Desde la reforma de principios del siglo XX, la actividad política se refería fundamentalmente a la democratización de la enseñanza en el tercer nivel. En el estado actual de la universidad, existen responsabilidades mayores que tendremos que afrontar los integrantes de esta comunidad: prever un futuro, hoy sin certezas.

Como síntesis, esta tesis se busca:

- Optimizar el ámbito de aprendizaje tecnológico, redefiniendo las actividades teóricas y prácticas.

- Asociar el método científico con el aprendizaje tecnológico

- Mejorar la eficiencia del aprendizaje mediante un ámbito que personalice el aprendizaje tecnológico en sus fases teóricas y prácticas según el perfil de de cada educando.

- Analizar el caso particular de la tecnología de objetos, su historia y situación actual para luego poder evaluar en teoría y en práctica los efectos de la aplicación de los conceptos desarrollados en la tesis, incluida la transición desde la situación actual al ámbito planteado.

- Describir las experiencias del autor en un caso particular en el ámbito de postgrado en el área informática

- Generar un ámbito universitario que analice los efectos del cambio tecnológico en el presente y el futuro. 


\section{CAPITULO 1}

\section{LA CIENCIA COMO SOPORTE DE LA TECNOLOGÍA EVOLUCIÓN CIENTÍFICA EN EL ÁMBITO DE LA FÍSICA}

\section{Resumen}

Se establece la relación entre ciencia y tecnología en distintos momentos de la historia, para situarnos en los límites cuantitativos y cualitativos de la tecnología en alguna de sus aplicaciones.

Se buscan los ejemplos en el campo de la física donde aparecen con claridad los limites del conocimiento científico y la aplicación de la tecnología: limites cuantitativos y cualitativos que la tecnología tiene y limites que la tecnología provoca en formas de convivencia vigentes en el siglo $X X$

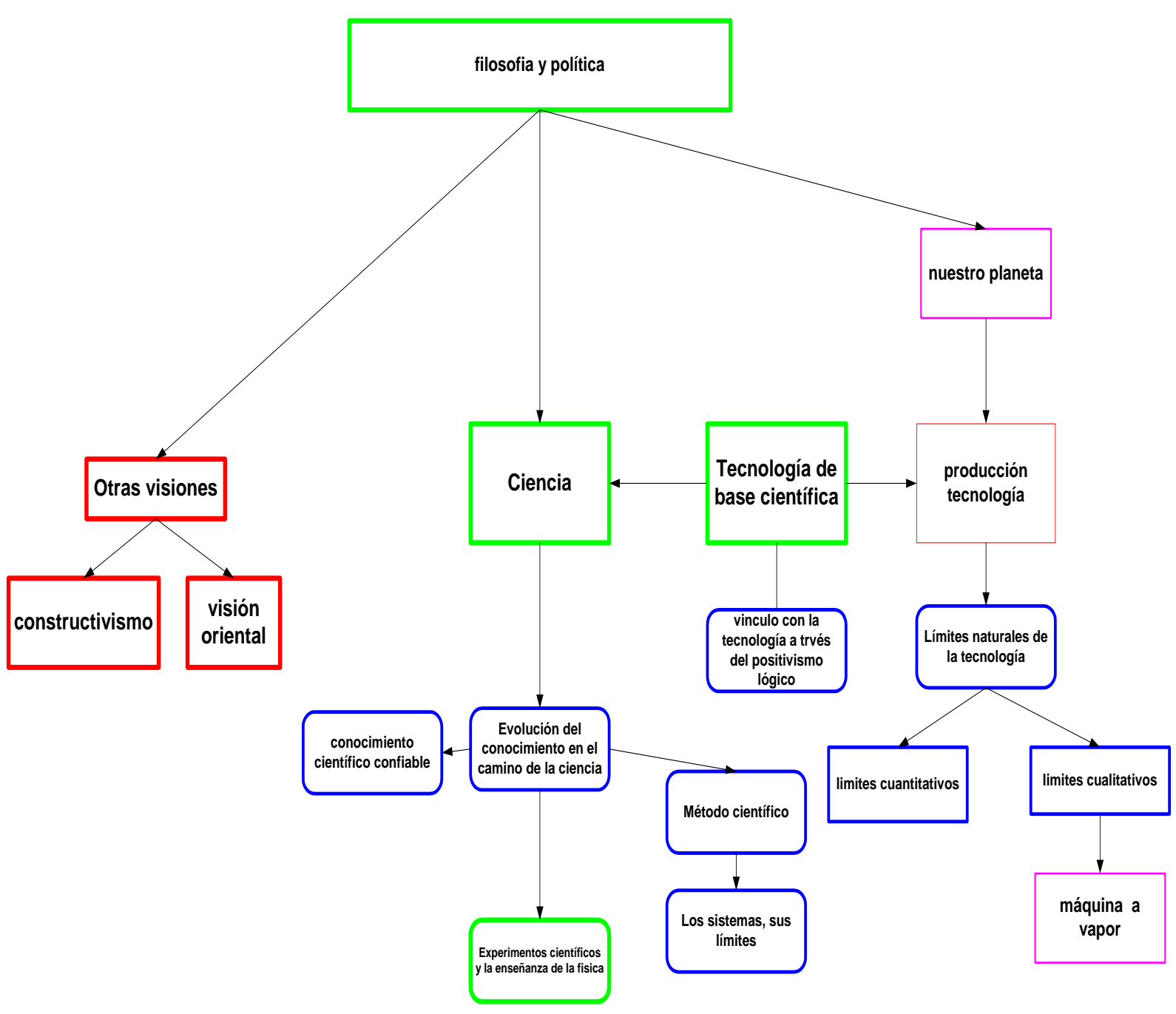




\section{La ciencia como base del conocimiento}

Hoy, todos los ámbitos están influenciados por la ciencia, sobre todo a través de sus aplicaciones tecnológicas.

La tecnología que a veces hace mejor nuestras vidas y otras las destruye; produce -con su presencia física y mercantil- efectos políticos, sociales, culturales y epistemológicos. Por otra parte las investigaciones en el campo de las partículas elementales, permiten generar nuevas e interesantes discusiones que parecían abandonadas por la privilegiada posición de la ciencia hasta el siglo XX.

¿Cómo fue que la ciencia se abrió paso hasta tener la importancia de hoy?

¿Hubo y hay otros caminos para llegar al conocimiento?

Son preguntas que nos hacemos, en algún momento, quienes estamos en el ámbito académico.

La primera pregunta podemos comenzar a responderla con la siguiente tabla cronológica, desde que el conocimiento -además de desarrollarsecomenzó a registrarse.

Momento histórico

Siglo VI antes de Cristo

Siglo V antes de Cristo.

Siglo IV antes de Cristo

Desde fines del siglo XV. Renacimiento,
Aristóteles

\section{Actores}

Sabios de la escuela de Mileto

Heráclito de Efeso

Parménides de Elea

Demócrito

Descartes (pienso, luego existo)

\section{Criterio dominante}

No separación entre ciencia, filosofía y religión. Fisis: naturaleza esencial de las cosas

Logos: pares de opuestos que dan lugar a la unidad Ser: único e invariable. Los cambios son ilusiones de los sentidos

El ser se manifiesta en partículas indivisibles. Átomo: materia separada del espíritu Importancia mayor de la perfección espiritual sobre el conocimiento del mundo material, lo que provoco la permanencia del modelo aristotélico apoyado por la Iglesia Católica

Separación entre la mente controladora del cuerpo y entre lo interno y el mundo exterior. Modelo mecanisita newtoniano impuesto por Dios.

Fragmentación del todo social 


\section{El conocimiento progresivo de nuestro planeta}

Los antiguos griegos conocían dos datos importantes acerca de la tierra: primero, que es esférica, y segundo que Europa, África y Asia forman una masa conectada de tierra, completamente rodeada de agua. La astronomía y la geografía griega alcanzaron su cúspide con Ptolomeo en el siglo II a.c., y de esta forma fue transmitida a la Europa medieval en el siglo XII, donde permaneció incuestionable hasta la travesía transatlántica de Colón.

El descubrimiento de continentes desconocidos para los antiguos, abrió el legado de los griegos para revisión. En particular, Copérnico cuestionó la astronomía de Ptolomeo, centrada en la tierra. Esto fue el comienzo de la ciencia moderna, pues para encontrar las reglas correctas del movimiento fue necesario desestimar la cosmografía geocéntrica de Aristóteles y Ptolomeo. Este cambio en la cosmografía fue tan abrumador que es llamado adecuadamente, Revolución Científica.

\section{Actividad científico-tecnológica desde el renacimiento en adelante}

Desde el renacimiento hasta principios del siglo XX, la actividad científica, creció junto con la producción tecnológica asociada. También comenzó a manifestarse el cientificismo, a veces con tintes de nueva religión, tomando lo sensorialmente medible como si fuera la realidad.

El camino de la actividad científica, que en algún momento, parecía fluir sin interferencias, ha sufrido las contradicciones propias asociadas a toda forma de actividad del pensamiento.

Las contradicciones, lejos de ser un obstáculo, incentivan la búsqueda que el ser humano comenzó en sus orígenes cuando trató -todavía sin lenguaje- de explicar la realidad.

Es claro que, lo percibido sensorialmente cubre solo una parte del espectro que le corresponde, así hay un intervalo de sonidos, de radiación visible, de olores, etc. que son percibidos y traducidos a nuestra mente. Esta limitación generó siempre contradicciones en el pensamiento científico, particularmente en la búsqueda de los componentes últimos de la materia. Estas partículas elementales se comportan en formas notablemente diferentes a las que la física clásica podía prever cuando pudo explicar el comportamiento de los cuerpos macroscópicos.

La teoría cuántica junto con la teoría relativística han cambiado los conceptos clásicos de espacio, tiempo, causa y efecto.

\section{Positivismo lógico y las revoluciones científicas}

"En Viena, a principios del siglo XX, un grupo de filósofos y científicos se encontraron para discutir asuntos de la ciencia que habían sido planteadas por los extraordinarios descubrimientos de la relatividad y la mecánica cuántica." [Crommer, 1997]

El denominado positivismo lógico, había colocado -aparentemente- la certidumbre del conocimiento científico sobre fundaciones filosóficas de una solidez nunca antes alcanzada. Esto permitió creer que todo el conocimiento 
científico estaba asentado y permitía dar los pasos necesarios para describir la realidad y que la realidad podría ser descripta integralmente.

La unicidad del camino recorrido hacia el conocimiento asentado fue cuestionada. Julios Robert Oppenheimer dijo "Las ideas generales sobre el entendimiento humano... ilustradas por los descubrimientos ocurridos en la física atómica, no constituyen cosas del todo desconocidas, de las que jamás se oyera hablar, ni tampoco nuevas. Incluso en nuestra propia cultura tiene su historia y en el pensamiento budista e hindú ocupan un lugar muy importante y central. Lo que hallaremos es un ejemplo, un desarrollo y un refinamiento de la sabiduría antigua" [Oppenheimer,1954], Niels Bohr planteo "De un modo paralelo a las enseñanzas de la teoría atómica... al tratar de armonizar nuestra posición como espectadores y actores del gran drama de la existencia (tenemos que considerar) ese tipo de problemas epistemológicos, con los que pensadores como Buda y Lao Tse tuvieron ya que enfrentarse [Bohr, 1958], y Werner Heisemberg declara "La gran contribución a la física teórica llegada de Japón, desde la última guerra puede indicar cierta relación entre las ideas filosóficas tradicionales del lejano Oriente y la sustancia filosófica de la teoría cuántica“ [Heisemberg, 1963]. En los tres casos, estos científicos, encontraron ciertos paralelismos entre la física moderna y las concepciones del misticismo oriental. Por otro lado, debido en gran parte a la notable influencia de Thomas Kuhn, se cuestionó el aparente logro del positivismo en el libro The Structure of Scientific Revolutions (La estructura de las revoluciones científicas) presentando a la ciencia como una sucesión sin fin de nuevas teorías revolucionarias. Kuhn supuso que la creación de nuevas teorías fundamentales modifican totalmente los conceptos de la ciencia, y presentó a la teoría de la relatividad y la teoría cuántica como dos ejemplos del siglo veinte [Kuhn, 1962]. De otro modo, presentó al conocimiento humano acerca de la ciencia no como definitivo, sino como preliminar.

Es cierto -como dice Popper- que la naturaleza, la realidad, nunca dice rotundamente " $s i$ " a las propuestas teóricas, hay que resaltar igualmente que raramente proporciona un "no" taxativo [Popper, 1965]. El papel de la evidencia empírica es limitado pero eficiente -en tanto repetible- y permite que la observación y la experimentación sean una posibilidad de pisar tierra firme. Cuando esa firmeza es suficiente, resulta posible soportar estructuras articuladas y cerradas del pensamiento.

\section{Método científico}

La forma de acceder al conocimiento del mundo físico es a través del proceso de investigación científica que, precedidos por la idea creativa o la hipótesis, presenta los siguientes pasos:

a) Reunir evidencia experimental

b) Descripción mediante un modelo matemático (o teoría, si es más amplio)

c) Predicción de los resultados de experimentos posteriores. 
Esta la práctica racional -donde las tres etapas no se desarrollan siempre en ese orden ni en esa secuencia- constituye la base de la investigación científica y es complementada por la intuición que es la que les da a los científicos creatividad y nuevas ideas.

Los conocimientos se expresan con modelos matemáticos, pero cuando es necesario hablar de los logros a quienes no conocen el lenguaje matemático se necesita recurrir a modelos verbales. Los modelos matemáticos son rigurosos y congruentes pero alejados de nuestra experiencia. Por su parte los modelos verbales -inexactos y ambiguos- no se diferencian mucho de los modelos filosóficos de la realidad.

Queda claro, que la base empírica de la ciencia no tiene nada de absoluta, pero al resultar accesible al espíritu y pensamiento humano, nos permite aspirar a la coherencia de las representaciones entre sí. Esas representaciones son, acuerdos entre los humanos, para poder comunicarnos. Son el mapa, no el territorio.

\section{Filosofía y política}

¿Es necesario plantear las controversias científicas en los ámbitos filosóficos y políticos para progresar en el desarrollo integral del ser humano?

Mi respuesta es afirmativa. Observando la situación mundial actual vemos la necesidad vital de una rápida evolución humana, que haciendo predominar la inteligencia, nos libere de las guerras y permita compartir nuestro planeta como el hogar común. Sin embargo la inteligencia planetaria no se ha manifestado y cunden las catástrofes sociales y ecológicas, sumándose -bajo el manto de la automatización tecnológica- un futuro sin ninguna certeza ni seguridad, sin que se perciba desde las conducciones políticas una propuesta alternativa para convivir en la sociedad postindustrial, donde la desaparición del empleo laboral solo es cuestión de tiempo. Junto con el empleo desaparece el paradigma de distribución de la riqueza de la era industrial, basado en un ciclo de producción, remuneración a la producción y consumo.

\section{Los sistemas, sus límites}

La ciencia no se ocupa de la realidad en general, sino de sistemas, esos sistemas surgen de un "recorte" que se genera respecto de la realidad: un punto de vista, una teoría, un paradigma. No hay duda que sólo construimos un mapa de la realidad

Todos los modelos y teorías son aproximados, por eso decía Einstein "en lo que las leyes matemáticas se refieren a la realidad, no son ciertas y en lo que son ciertas, no se refieren a la realidad". Por eso hay conciencia en los científicos que este método de análisis y razonamiento lógico, nunca podrá explicar la totalidad de los fenómenos naturales en su conjunto. Al aislar sistemas se descuidan otros fenómenos y por ello los modelos no proporcionan una descripción completa de la situación real. Los fenómenos no tomados en cuenta pueden tener un efecto despreciable o ser omitidos pues se desconoce su existencia en el momento de plantear la teoría. Así el modelo newtoniano es útil para describir fenómenos en los que estén 
involucrados objetos de gran número de átomos y que se desplacen a velocidades pequeñas respecto de la velocidad de la luz. Ese modelo debe ser reemplazado por el modelo cuántico cuando tratamos con partículas elementales y por el modelo relativístico cuando los desplazamientos de lo observado lo hace a velocidades próximas a la de la luz. Esto no quiere decir que el modelo newtoniano sea "incorrecto" y el cuántico o relativístico sean "correctos", sencillamente corresponden a sistemas diferentes. Respecto del principio de incertidumbre, Einstein insistía en la existencias de variables ocultas que una vez que se encontraran permitirían dar con certeza la posición y momento de las partículas elementales, el teorema de Bell [Bell, 1990] y el experimento de Aspect [García del Cid, 2004], concretados sobre fines del siglo XX, aseguran que no hay tales variables ocultas y que todo se relaciona con todo, a partir el big bang.

El método de abstracción científica es muy eficiente y poderoso, pero a medida que aumenta la precisión, se paga el precio de alejar la descripción del sistema del mundo real.

Existe una asimetría clara entre las lógicas de la verdad y la objetividad que, al no ser tenida en cuenta, oscurece la mayoría de los debates epistemológicos. La asimetría puede ser expuesta brevemente así: la cuestión de la objetividad de nuestras creencias se resuelve, sin duda, desde el punto de vista de la causalidad que ejerce la realidad sobre nuestros constructos teóricos, pero la verdad no puede ser decidida fuera del plano del discurso, del consenso, de la coherencia de nuestras representaciones entre sí. Para realizar ese recorte, los científicos usan términos y operan con esos términos resultando verdades teórico-dependientes, no lingüísticas, esto es, hay un acuerdo semántico entre el conjunto de interlocutores para aceptar los mismos significados y significantes de los términos, en un lapso de tiempo determinado (resultando una simulación limitada de lo ontológico en cada materia de estudio).

La capacidad de aprender de los errores y poder predecir de la ciencia aplicada al desarrollo tecnológico, son la frontera que separa a la ciencia de los simples relatos verbales. En lo concreto: si se puede crear una vacuna o cualquier producto tecnológico es porque de algún modo hemos conectado la teoría y la realidad percibible directamente.

\section{Otras visiones. El legado de oriente}

Fritjof Capra -en su libro "El Tao de la Física" -refleja su compromiso con el método científico, pero no deja de lado es la que denomina "visión oriental del mundo" y conecta ambas formas de acceder al conocimiento. Plantea que en las investigaciones sobre partículas elementales y a través de un riguroso y consistente formalismo matemático, permite obtener respuestas teóricas que acercan de una manera menos prejuiciosa al pensamiento de los antiguos griegos y las filosofías orientales, comparando la naturaleza del conocimiento íntimo de la materia y el lenguaje con que esta comparación se realiza. La filosofía oriental siempre ha señalado la naturaleza complementaria de lo intuitivo y lo racional. Lo intuitivo es hábil en moverse en el mundo natural, mundo de infinitas variedades y complejidades, multidimensional, no secuencial, donde todo 
sucede simultáneamente. El pensamiento racional se ve enfrentado al mismo problema que el cartógrafo, siempre tenemos una imagen de la realidad, nunca la realidad misma ("el mapa no es el territorio"), finalmente la realidad última nunca podrá ser descripta por la palabra, pues está más allá del reino de los sentidos y del pensamiento de donde derivan nuestras palabras y conceptos. [Capra, 1973]

\section{Conocimiento científico confiable}

Mucho del conocimiento científico actual es reciente y completo. Completo, pues -por ejemplo- no se va a descubrir un nuevo elemento, así como tampoco se va a descubrir un nuevo continente. Aún así, la inteligente humildad de la ciencia permitiría rectificar lo que fuera necesario en el caso que la experimentación contradiga en algún momento, alguna teoría (hasta entonces aceptada como cierta).

Hubo una época, hace no mucho tiempo, en la que se conocía poco acerca de estas cosas, pero ahora no solo sabemos eso, sino que además sabemos que nuestro conocimiento de los continentes y de los elementos está bastante completo. Conocimiento asentado y comprobable. Este es uno de los mensajes importantes de la ciencia: conocemos algunas cosas importantes.

\section{Evolución de distintos conocimientos en el camino de la ciencia}

Caso I: La teoría del flogisto (sobre el calor) del siglo XVIII fue substituida sucesivamente por teorías de química y termodinámica, mas precisas, desarrolladas en el siglo XIX. Nadie puede afirmar con certeza, que la teoría moderna del calor, basada en el comportamiento de los átomos, permanecerá sin modificaciones.

Caso II: Antes del descubrimiento de América, no había conocimiento de otros continentes, mientras que inmediatamente después se tornó obvio que con el tiempo que todos los continentes de la tierra serían conocidos.

Caso III: Es particularmente destacable en el caso de los elementos químicos o sea de los materiales que componen el universo.

La Europa medieval heredó de los griegos la noción de que todo es una combinación de un pequeño número de sustancias más simples o elementales. Usualmente eran nombradas como aire, agua, tierra y fuego. Fue Lavoisier, quien publicó en 1789, la propuesta de la definición operacional de un elemento, como una sustancia que no podía ser descompuesta más. Fue, para la época una idea bastante sofisticada. Solo con el desarrollo de técnicas para la manipulación de gases y pesado de la materia de modo preciso, pudo llegarse a la definición de Lavoisier, quien era un experto es estas técnicas. Lavoisier llegó a nombrar veintitrés substancias como elementos. En los siguientes cien años se logró encontrar nuevos elementos. Entre 1790 y 1830, fueron descubiertos treinta y un 
elementos nuevos, casi uno por año. No había ninguna estimación en esa época de cuantos elementos podía haber, ni tampoco si el número era finito. Con el trabajo de Mendeleiev en 1869, basado en los sesenta elementos conocidos comenzó a saberse que los elementos seguían algún orden o patrón. En la primera década del siglo XX, con el desarrollo de la teoría atómica, se volvió claro que los elementos forman una secuencia precisamente ordenada que depende del número de protones en el núcleo atómico. Este número puede ser 1, 2, 3,..., hasta 98. Un núcleo con más de noventa y ocho neutrones puede crearse momentáneamente, pero no se obtienen cantidades de los elementos correspondientes, capaces de ser pesadas. De modo que hay exactamente noventa y ocho elementos, como "elemento" fue definido por Lavoisier, una sustancia capaz de ser pesada que no puede ser descompuesta más. Actualmente se conocen todos, también sus isótopos han sido estudiados con gran detalle. Por ende, en el sentido en que tenemos conocimiento completo del número de continentes, tenemos conocimiento completo de los elementos. Además, nuestro conocimiento de las propiedades de los elementos es más completo que nuestro conocimiento de las propiedades de los continentes, dado que la estructura de los átomos es más simple que las estructuras de ríos, montañas y cañones.

Caso IV: Similarmente, antes de que la estructura de ADN fuese descubierta por James Watson y Francis Crick en 1953, la base químicas de la herencia era desconocida. Después del descubrimiento, la estructura aseguró que el diseño genético de la mayoría de los organismos estaba codificado por el orden de sus pares base ADN. El genoma humano está codificado por unos millones de pares base, dispuestos en veintitrés pares de cromosomas. A pesar de que el número de pares base es grande, es finito y hasta manejable, haciendo que la estructura del genoma humano sea hoy conocida.

El profundo entendimiento dentro de la naturaleza de la materia y organismos vivientes que la investigación científica nos ha dado, también nos dice lo que no es posible. A pesar de que se pueden hacer infinitas combinaciones de elementos, todos los materiales, a temperatura y presión normal, tienen un límite en sus propiedades de densidad, extensibilidad, punto de fusión, límites dados por la máxima masa de núcleo y la fuerza intrínseca del vínculo químico entre átomos. Similarmente, los pares base de ADN pueden formar una ilimitada serie de organismos vivientes, todos los cuales existen dentro de una limitada gama de temperatura dado que ellos están todos hechos de carbono, oxígeno e hidrógeno.

\section{Críticas a la ciencia}

En la filosofía idealista, asociada con Emmanuel Kant (1724-1804), las explicaciones son en términos de conceptos a priori, verdades absolutas que se nos hacen conocidas a través del pensamiento puro. Así, los postulados de la geometría Euclidiana habían sido pensados como ejemplos de esas verdades, hasta el desarrollo de geometrías no-euclidianas, realizada por Nikolai Lobachevski y Georg Friedrich Riemann. En la 
"nebulosa metafísica" de Kant, hasta las leyes de mecánica Newtoniana podían ser derivadas por razón pura.

El gran trabajo de Newton, "Philosophiae Naturalis Principia Mathematica o los Principia como siempre se han conocido fue escrito en Latín y publicado por primera vez en 1687. Los críticos de Newton deploraban la infundada e irrazonable naturaleza de sus leyes, especialmente la ley de gravitación universal. Ellos sentían que era no científico introducir una fuerza "mística" invisible que actuaba a través del ilimitado espacio vacío, mientras que sus admiradores la aclamaban por descubrir una ley tan contraria a nuestros sentidos (probando de esa manera que Dios existe).

Pero en el nombre de Kant, las leyes de Newton han sido elevadas al estatus de verdades evidentes en sí mismas por filósofos que nunca tuvieron que enseñarlas a incrédulos principiantes. El desarrollo de la relatividad y de la mecánica cuántica en las primeras dos décadas del siglo XX causó que la filosofía idealista de la explicación sea reconsiderada por los positivistas lógicos, quienes tomaron como su líder a Ernst Mach. El objetivo de este esfuerzo era el de desarrollar una teoría de la explicación que no tuviese que ser enmendada con cada nuevo descubrimiento en la ciencia.

Todos los filósofos inclinados hacia la ciencia están de acuerdo en que la ciencia está basada en experiencia, pero cada uno usa terminología diferente. Mach escribió acerca de hechos, conocimiento instintivo, y percepciones de los sentidos para enfatizar su creencia de que la base filosófica y psicológica de la ciencia era las experiencias inmediatas de todos los días. Nuestro entendimiento del movimiento planetario, por ejemplo, descansa a fin de cuentas en nuestra primitiva experiencia con el modo en el que los objetos pesados se comportan cuando son arrojados. Para estar seguros, se requiere una larga y abstracta cadena de razonamiento para relacionar una experiencia con otra, pero eso no quiere decir que la teoría está describiendo el funcionamiento invisible de la naturaleza. Para Mach la teoría era solo un modo económico de relacionar experiencias, y no era ella misma un elemento de conocimiento. Esta filosofía se libra exitosamente de la ciencia kantiana de las verdades en si mismas y los conceptos metafísicos no relacionados a la experiencia directa, pero es incapaz de hacer frente a los conceptos de relatividad y mecánica cuántica que están fundamentalmente peleados con la experiencia ordinaria.

En su vínculo con la tecnología, recién en el siglo veinte ha habido tecnologías, como la vinculada a la energía nuclear y dispositivos semiconductores, que requieren inevitablemente análisis teórico antes de la fabricación.

Los positivistas lógicos concluyeron que la ciencia podía permitir explicaciones basadas en conceptos abstractos y principios generales, siempre y cuando estos conceptos y principios se conecten lógicamente a consecuencias comprobables. Hasta los conceptos bizarros y antinaturales de la relatividad y de la mecánica cuántica son aceptables dado que sus predicciones son verificables con los sentidos humanos (a través de los instrumentos adecuados). Psicológicamente, la discontinuidad de la 
mecánica cuántica con la experiencia primitiva es un problema para los aprendices.

$\mathrm{Al}$ discutir estos asuntos, se puede plantear que la costumbre de usar términos como "experiencia", "observación" y "observado" ha creado un hábito que ha llevado a algunos a la conclusión de que la ciencia puede subjetivarse, la respuesta es volver a los límites de la ciencia usando palabras menos antropomórficas, como "detectores" y "lectura del instrumento", al usarlas en lugar de "observador" y "observación", se podría evitar un poco de confusión a expensas de un estilo muy afectado. La ciencia se ocupa de una realidad objetiva observador-independiente, o por lo menos, esta es la premisa metafísica de la mayoría de los científicos.

Quizá no existe una realidad objetiva después de todo, y todas las experiencias son el resultado de una conspiración para que se piense que existe tal realidad objetiva. Apenas valdría la pena discutir semejantes pensamientos infantiles, si no fuesen el tema de una seria disputa filosófica.

¿Cómo podemos saber cualquier cosa, declaran los filósofos, si no podemos distinguir lógicamente entre una realidad objetiva observadorindependiente y un mundo conspirador subjetivo? Una respuesta es, que no hay necesidad de distinguir entre ellos. Siempre y cuando sea asumido que los conspiradores imitan perfectamente una realidad observadorindependiente, las dos premisas son lógicamente idénticas; están diciendo lo mismo en diferentes palabras. Después de analizar, los positivistas lógicos hallaron que los argumentos filosóficos más tradicionales podían estar tan vacíos de sustancia como este.

Los seres humanos son necesarios para interpretar le lectura de instrumentos, a ellos mismos y a otros seres humanos. Es así necesario distinguir entre lo que ocurre dentro de un detector (lo cual puede ser una cabeza humana) y la interpretación de estos sucesos o experiencias. La experiencia no depende de intelecto activo, mientras que la interpretación ciertamente lo hace. En otras palabras, la experiencia es el resultado de una realidad observador-independiente, en tanto que la teoría es una creación humana.

\section{Límites naturales de la tecnología Límites cuantitativos}

Nunca habrá un modo de conocer -aún en principio- la estructura y propiedades de todas las posibles sustancias u organismos, precisamente como no hay modo de conocer todas las novelas que puedan ser escritas. Esto es solo para decir que los modos de combinar aún unas pocas entidades básicas puede ser inimaginablemente vasto, a pesar de ser finito. La cuestión es narrada por J. L. Borges en "La biblioteca de babel". Por su lado, George Gamow [Gamow, 1961], muestra que el número de líneas diferentes de sesenta y cinco caracteres de longitud, que puede ser tipeada usando solo cincuenta caracteres del teclado (veintiséis letras, diez números, y catorce signos de puntuación) es $50^{\wedge} 65$. Esto es dado que el carácter en la primera posición puede ser cualquiera de los cincuenta caracteres del teclado, de modo que hay cincuenta posibilidades. El carácter en la segunda posición también puede ser cualquiera de los cincuenta caracteres, de modo que son 50 x $50=50^{\wedge} 2=2.500$ 
posibilidades para los caracteres en las dos primeras posiciones. Continuando el argumento, hay 50 x 50 x $50=50^{\wedge} 3=125.000$ posibilidades para los caracteres en las primeras tres posiciones, y $50^{\wedge} 65=$ $10^{\wedge} 110$ posibilidades para los caracteres en una línea completamente tipeada de sesenta y cinco caracteres.

Por comparación, la tierra está compuesta por menos de $10^{\wedge} 50$ átomos. El sistema solar entero -el sol y todos los planetas- tiene a lo sumo, un millón $\left(10^{\wedge} 6\right)$ de veces tantos átomos, o sea que el sistema solar en su conjunto tiene $10^{\wedge} 56$ átomos. Continuando el argumento, la galaxia Vía Láctea contiene $10^{\wedge} 11$ estrellas, cada una con aproximadamente $10^{\wedge} 56$ átomos, de modo que la galaxia entera contiene $10^{\wedge}(56+11)=10^{\wedge} 67$ átomos. Y el universo entero tenga quizá $10^{\wedge} 11$ galaxias, o sea que en conjunto tendrán $10^{\wedge}(67+11)=10^{\wedge} 78$ átomos. Aún si hay error por un factor de diez, o hasta cien, el número de átomos en el universo es solo $10^{\wedge} 80$, el cual es mucho más pequeño que $10^{\wedge} 110$, el número de posibles líneas de sesenta y cinco caracteres que pueden ser escritas con cincuenta caracteres. De este modo el número de combinaciones de incluso unos pocos ítems es impensablemente inmenso.

Una computadora puede fácilmente almacenar billones de números, pero ninguna computadora podría guardar $10^{\wedge} 110$ números, incluso si cada celda de memoria fuese un único átomo y la computadora usara todos los átomos en el universo. Este límite universal tira por tierra una noción común: que un mono, tipeando lo suficiente, podía producir un soneto de Shakespeare. Lo opuesto es justamente el caso. Si cada mono sobre la tierra tipeara una línea por segundo desde que los monos evolucionaron hace cincuenta millones de años, ninguna de las $10^{\wedge} 24$ líneas producidas sería gramaticalmente inglesa, ni que decir, de Shakespeare. Entonces, aunque se pueden conocer todos los caracteres en una máquina de escribir, y hasta catalogar todas las palabras de un idioma, en un diccionario íntegro, no se puede conocer todas las historias y los libros que pueden ser escritos.

Del mismo modo, se puede tener conocimiento completo de cosas que se pueden contar razonablemente: los continentes, los elementos, aún los genes humanos, porque números como 7, 98, 100,000, hasta 3 billones, son manejables dadas las técnicas de computación. Pero el número de combinaciones de noventa y ocho elementos, aunque todavía finito, es tan grande como para estar más allá de la enumeración. Así, mientras se tiene conocimiento completo y certero acerca de los átomos de los cuales toda la materia está compuesta, nunca se van a conocer todas las formas en la que los átomos se pueden combinar para formar moléculas y sustancias.

\section{Límites cualitativos}

A pesar de todo, se pueden decir algunas cosas con absoluta certeza acerca de todas las sustancias que pueden sintetizarse en la tierra. Por ejemplo, ninguna sustancia permanecerá sólida por encima de una temperatura de $5000{ }^{\circ} \mathrm{C}$, dado que hay una fuerza máxima cohesiva que los electrones pueden mantener entre átomos. La temperatura de derretimiento de los sólidos limita la máxima temperatura operacional de turbinas y por consiguiente la máxima propulsión de los motores del cohete. 
Todo esto es permite asegurar que aunque puede no haber límites al número de nuevos materiales existentes que llegará de la ciencia material, esta plétora de maravillas no debería conducir a la falsa suposición de que cualquier cosa es posible. Lo que la tecnología sí hace, es ver cada vez más cerca los límites inherentes de los materiales.

\section{Caso de la máquina a vapor}

Un importante ejemplo de los límites físicos de la tecnología es la eficiencia de las máquinas a vapor. Con dicho fluido, la máquina moderna es la turbina a vapor, la cual impulsa los generadores eléctricos en las usinas en base a energía nuclear o al combustible fósil. La máquina de vapor de principios del siglo XVIII de Thomas Newcomen tenía una eficiencia del uno por ciento (1\%), lo que significa que por cada unidad de trabajo útil que la máquina hacía al levantar agua de una mina, consumía cien unidades de calor. La máquina de James Watt -que revolucionó la minería y la manufactura- tenía una eficiencia del cuatro por ciento (4\%).

Estimulados por la necesidad de máquinas aun más eficientes, los científicos en el siglo diecinueve desarrollaron la moderna teoría de termodinámica, la cual brinda la precisa relación entre trabajo, calor y temperatura. Más importante aun, muestra como la eficiencia puede ser aumentada al aumentar la temperatura operacional de la máquina. Dado que el agua hierve a $100{ }^{\circ} \mathrm{C}$, a presión atmosférica, para aumentar más la temperatura del vapor es necesario presurizar el sistema, como en una olla a presión. El uso de vapor presurizado comenzó a principios del siglo diecinueve para operar trenes y barcos, un desarrollo al que fuertemente se oponía Watt dado el peligro de explosiones de caldera.

Las estaciones modernas de energía hierven agua a presiones de 165 a 218 atmósferas y sobrecalientan el vapor resultante a temperaturas de 537 ${ }^{\circ} \mathrm{C}$. Este vapor con presiones extremadamente altas y temperaturas elevadas impulsa grandes turbinas, convirtiendo calor en trabajo con una eficiencia cercana al 40 por ciento, o sea diez veces la eficiencia de Watt. Pero este es el límite: eficiencias mayores no son posibles dado que la mayor temperatura a la que hierve el agua $\left(374{ }^{\circ} \mathrm{C}\right)$ ocurre a 218 atmósferas. Las usinas eléctricas han estado operando cerca o a la máxima eficiencia la mayor parte del siglo XX. [Cromer, 1997]

\section{La automatización}

En este caso más que encontrar un límite de la tecnología, la tecnología esta limitando el paradigma de distribución de la riqueza vigente durante el siglo XX. Durante el siglo pasado la producción basada en capital y mano de obra, generó un sistema de remuneración a esos factores de la producción, que luego permitía el consumo y de este modo realimentaba la necesidad de producción, de otro modo existía un modo de lograr la distribución de la riqueza

A fines del siglo XX este paradigma de distribución de la riqueza comenzó a resquebrajarse al disminuir la mano de obra necesaria y aumentar la productividad. La disminución de mano de obra necesaria disminuye el valor de lo producido según la óptica marxista, por otro lado 
la productividad creciente -esta vez desde el punto de vista capitalista- al disminuir el costo, también disminuye el valor de las cosas.

Se puede predecir que en un tiempo limitado la producción automática de bienes y servicios hará caer a valores muy pequeños la mano de obra necesaria y consecuentemente el desempleo laboral se incrementará indefinidamente.

Nos encontramos esta vez con un límite para el paradigma de distribución de la riqueza y deberíamos desde los ámbitos académicos pensar en una alternativa. [Thompson, 2000]

\section{Experimentos científicos y la enseñanza de la física}

Si se mira hacia atrás y se ve lo que los físicos estaban enseñando hace 100 años se observa que en laboratorios de física de las escuela secundaria o de las universidades, se llevan a cabo hoy día -en su mayoríalos mismos experimentos,

La ciencia, en pocos siglos, ha revelado -a través de su particular visión- una discreta, modular y jerárquica organización del mundo. Por ejemplo, todos los organismos vivientes están compuestos por células idénticas y similares; todas las células están compuestas por moléculas de proteína idénticas y similares; todas las moléculas de proteínas están compuestas por aminoácidos idénticos y similares; hacia abajo aparecen los electrones, protones, y neutrones. Es por esta modularidad, y las matemáticas de combinaciones, que el mundo es conocible, y dado que la ciencia tiene algunas llaves para este conocimiento, la sociedad valora a la ciencia y la educación científica.

Esta manera de ver las cosas limita lo posible, por las características de la materia que forma el universo.

Kuhn, en su teoría de la revolución se opone a la noción de que la ciencia sea acumulativa o progresiva. Para él, las revoluciones no eran necesariamente avances hacia más altos entendimientos, sino el reemplazo completo de un conjunto de ideas por otro.

El constructivismo aparece a consecuencia de una posición subjetiva de la ciencia, que no considera que el conocimiento sea una objetiva representación del mundo. Pareciera que la ciencia moderna no nos brinda la verdad y ofrece un modo para que nosotros interpretemos los eventos de la naturaleza.

Dado que todas las ideas científicas dependen en confirmaciones experimentales y de observación, todo conocimiento está, en principio, sujeto a cambio en la medida que se vuelve accesible evidencia nueva. Las ideas centrales de la ciencia como ser la conservación de la energía o las leyes de movimiento han sido sujetas a una amplia gama de confirmaciones y por ende probablemente no van a cambiar en las áreas en las cuales han sido probadas.

El constructivismo (debe recalcarse el extremo que conlleva la palabra) es ineficaz para el aprendizaje en cuanto se torna una forma de empirismo subjetivo que pone su énfasis en los pensamientos del alumno aunque se fundamente en la que la búsqueda de lo que es la verdad. 
Es casi imposible encontrar una forma que permita a los estudiantes construir sus propias teorías de átomos y electrones, de estrellas y galaxias, de ADN y genética. Los educadores están empezando a reconocer las limitaciones de la ideología constructivista, al tiempo en que comienzan a hablar del problema de implementar estándares.

Si se desvaloriza el conocimiento científico, bajándolo, al nivel del conocimiento diario no se puede lograr ni la pedagogía ni la matética de la formación tecnológica de base científica.

Arquímedes (287-212 a.c.), quizá el mayor intelecto de la antigüedad, logró descubrir su famoso principio. La mayoría de los mortales comunes tienen suerte si pueden entenderlo, muy difícilmente pueden descubrirlo, cómo pretenden algunos constructivistas. A pesar de que el vivió solo cien años después de Aristóteles y 1800 años antes que Galileo, Arquímedes fue un miembro notable de la Revolución Científica. En su libro Cuerpos Flotantes I, deriva el principio de flotación de un único postulado de hidrostática. Una traducción al latín de ese y otros de sus trabajos, fue publicado en Venecia en 1543, el año en que Copérnico murió y veintiún años antes de que Galileo naciera. El trabajo de Arquímedes tuvo una gran influencia en Galileo, quién también desarrolló principios físicos de la idealización matemática, usando experimentos para propósitos de demostración y verificación- no para descubrir.

En un sentido histórico, el constructivismo es una forma de encarar la ciencia pre-newtoniana. La mayoría de las leyes de Newton de movimiento son desarrolladas al nivel de abstracción pre- newtoniano. [Cromer, 1997]. El ordenado desarrollo de los conceptos y principios de la ciencia física sigue, a grandes rasgos, una secuencia naturalmente histórica. Usada con cautela, la historia puede ser una guía para la enseñanza de la ciencia. Durante los años de escuela secundaria, cuando el estudiante debería estar desarrollando modos más abstractos de pensar, la ciencia pre-newtoniana de Arquímedes y Galileo es apta para describir un mundo idealizado, pues no tiene las notables dificultades conceptuales y matemáticas de la física Newtoniana y pos-Newtoniana (ciencia que requiera un nivel correspondiente de razonamiento abstracto para un entendimiento apropiado, esto es una ciencia completa en el sentido de usar abstracciones y matemáticas). 


\section{CAPITULO 2}

\section{CONOCIMIENTO CONECTADO}

\section{Resumen}

Se propone el conocimiento conectado como el instrumento a utilizar para el acceso al conocimiento nuevo en cualquier área y se plantea la pregunta que esta tesis pretende responder ¿Es posible personalizar la educación tecnológica?

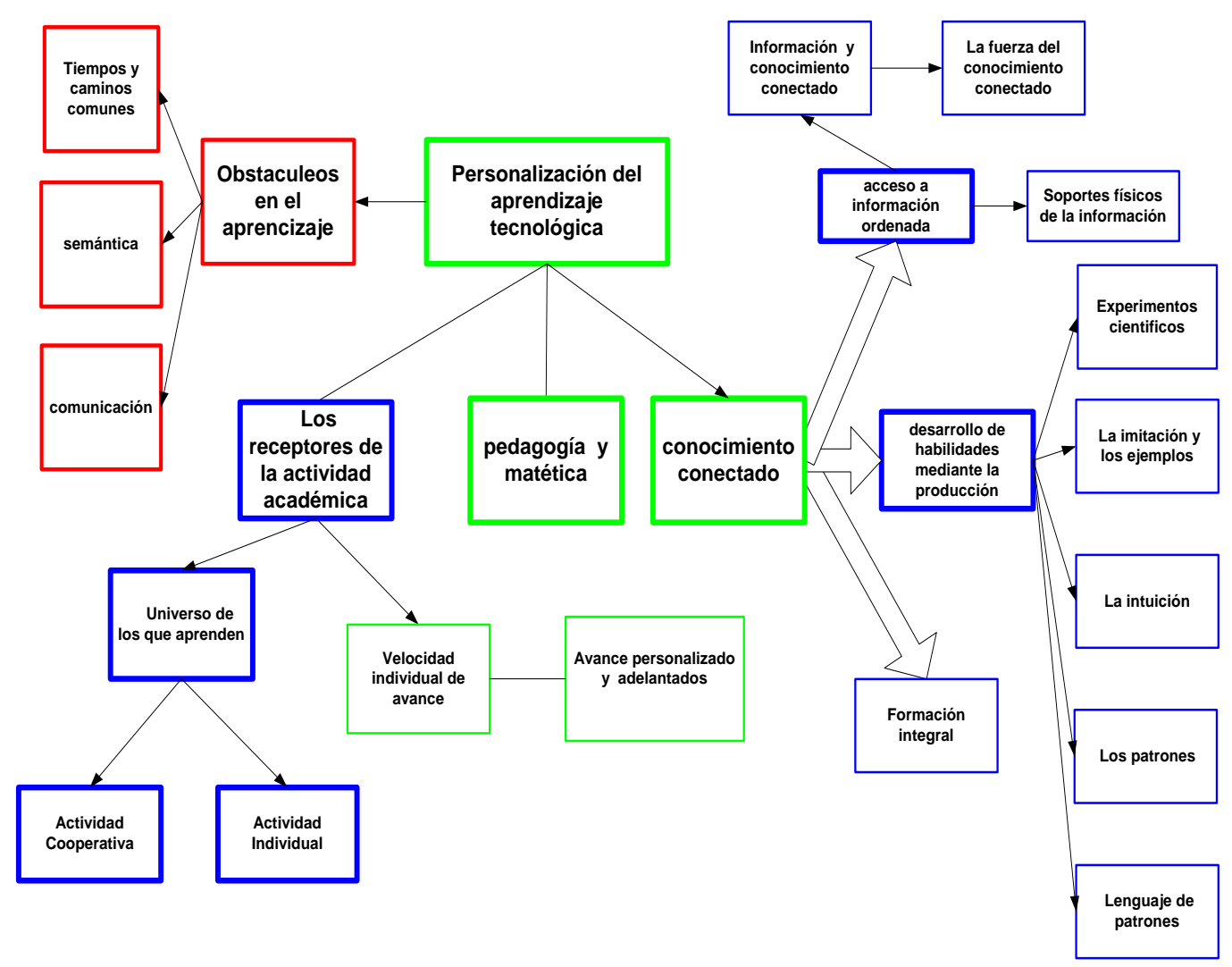

Esta tesis propone para el aprendizaje de tecnologías de base científica mediante acceso a información ordenada, el desarrollo de habilidades y la formación integral, con preponderancia de contenido de base científica, y el mínimo constructivismo agregado. El contexto adecuado personaliza el aprendizaje de los educandos, según el perfil matético de los cursantes. 


\section{Obstáculos en el camino del aprendizaje de la ciencia}

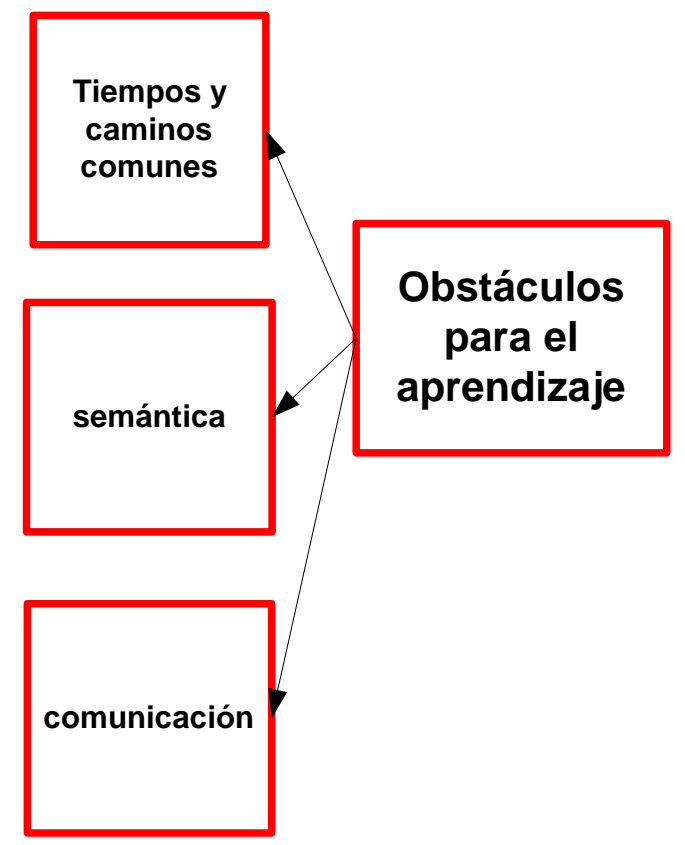

\section{Tiempos y caminos comunes}

El primer obstáculo que se puede encontrar en la enseñanza de la ciencia y la tecnología, asociada en los ámbitos académicos formales, se refiere al intento de asignar tiempos y caminos de aprendizaje iguales a todos los alumnos.

Se establece el mismo espacio-tiempo (por razones administrativas, en general), y se supone que se pueden seguir un camino único para todos los alumnos con soportes de información secuencial y prácticas dirigidas. Esta generalización supone individuos muy parecidos -desde un punto de vista metal y psíquico- que pueden percibir y comprender con igual velocidad los conocimientos a los que necesitan acceder. La duración de los cursos no esta definida por sus alcances y necesidades. Son los cuatrimestres u otras arbitrariedades en el uso del tiempo lo que determina cuanto se enseñará, con que frecuencia habrá contacto entre docentes y alumnos, quedando a la buena voluntad de los primeros (superando las reglamentaciones) el establecer tiempos vinculados con las necesidades temáticas tratadas, la característica individual de cada alumno y los objetivos a alcanzar.

\section{La cuestión semántica}

Un problema común a todo aprendizaje, es acceder al significado de los términos de uso común del área tecnológica en cuestión. Este problema se debe, en parte, a la definición circular de los términos, lo que obliga a una conexión gradual del vocabulario en la mente de los alumnos y un cuidado especial del docente para mantener la precisión semántica, respetando el significado de cada término y no realizando simplificaciones en el uso del lenguaje.

La precisión semántica es conveniente, en virtud de la potente economía que adquiere la comunicación cuando condensa muchos 
significados conectados. Simultáneamente el significante debe ser el mismo para emisor y receptor. El límite de esta síntesis, esta dado por la búsqueda de la claridad que surge de la extensión del lenguaje.

Aparece un problema recurrente: dificultad en la comunicación cuando se usa un dialecto técnico. Este problema se agrava en el caso habitual de ser -quienes desarrollan tareas docentes- miembros de una comunidad tecnológica en evolución, caso típico en la comunidad informática. [Bosch, 1999]

\section{Lenguaje y comunicación}

Como en muchas otras actividades vitales aparece la incompetencia del lenguaje para discutir ciencia. Una vez que un concepto es entendido, encontrar un medio adecuado para expresarlo no es un gran problema. El problema más grande es reconocer el concepto antes de expresarlo en palabras. De hecho, comúnmente se cree que el significado de una palabra puede ser hallado en la palabra misma.

Volviendo al campo de la física, cuando se presenta el concepto físico de trabajo, una buena estrategia es la de mezclar cualquier discusión con demostraciones y experimentos involucrando máquinas simples: palancas, poleas, planos inclinados, etc., hasta comprender que en cada máquina simple una pequeña fuerza de entrada moviéndose a través de una gran distancia causa que una gran fuerza de salida se mueva a través de una distancia pequeña. Trabajo es el nombre dado al número obtenido al multiplicar una fuerza por la distancia a través de la cual se movió. Para cada máquina simple, el trabajo hecho por la fuerza de entrada es igual a, o mayor que, el trabajo hecho por la fuerza de salida. Solo los estudiantes más brillantes pueden entender esta última generalidad, pero la mayoría de los estudiantes pueden aprehenderlo, utilizando el tiempo y la experimentación individual necesaria.

Una demostración resulta mucho más efectiva para provocar el interés de los estudiantes que los juegos de palabras que algunos maestros usan al comienzo de un tema. Se ha expresado ya que, a veces, se comete el error fatal de confundir al nombre que le damos a algo con la cosa misma. Este error es común en la enseñanza de la ciencia, y universal en la enseñanza de las demás materias. Por ejemplo, los académicos discuten interminablemente sobre el significado de "constructivismo" como si la palabra tuviese un significado objetivo que puede ser descubierto por argumentación.

El lenguaje parece haber evolucionado separadamente del intelecto, lo cual puede explicar su poder seductor. Unos pocos eslóganes patrióticos, y miles de personas marchan a la guerra. En el discurso racional, las palabras no resisten por sí solas, ellas deben relacionarse con algo real. El propósito del laboratorio de ciencias es mostrar a los estudiantes la realidad detrás de las palabras y símbolos que están en sus libros de texto. La experiencia les brinda una mejor comprensión de conceptos abstractos como ser trabajo y fuerza, mientras inculcan un escepticismo sano hacia abstracciones vacías como pueden ser la identidad nacional y los valores tradicionales.

El objetivo de la educación democráticamente desarrollada debería ser la aproximación al pensamiento objetivo. Las bases comunes para este tipo 
de pensamiento son un respeto por las opiniones de otros y un deseo de resolver desacuerdos con más investigación, que aspire a alcanzar consenso informado. [Cromer, 1997]

\section{Pedagogía y matética}

Tradicionalmente no se han desarrollado métodos para enseñar. Esta situación es coherente con una imagen tradicionalmente activa del profesor y pasiva del alumno

Así como existe la palabra pedagogía para el arte de enseñar es necesaria una palabra para el arte de aprender.

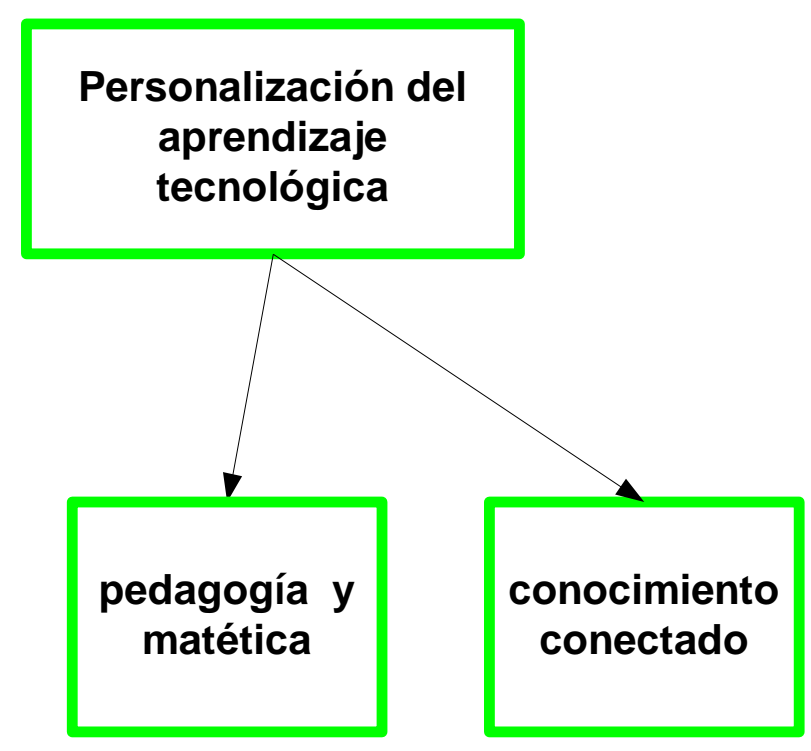

Seymour Papert ha propuesto llamar matética al arte de aprender, término que se utiliza en esta tesis. [Papert, 1981]

El arte de aprender incluye al profesor, él es una fuente de formación, información y habilidades que fundamentalmente puede crear un ámbito de elaboración de ideas. Asimismo conduce el proceso de acceso al conocimiento eliminando los obstáculos semánticos y operativos de cualquier tipo.

\section{Conocimiento conectado}

La filosofía moderna interpreta al conocimiento científico como la conexión de la teoría y la experiencia. El filósofo ha comparado la teoría científica con una red suspendida sobre el mundo de la experiencia (observaciones y experimentos). Los nudos de la red son los términos y los hilos son las relaciones -definiciones y leyes- entre los términos. La red está conectada a las experiencias por reglas de interpretación, las cuales Hempel comparaba con cuerdas fluyendo, desde puntos en la red a experiencias en el mundo debajo. Una experiencia en un lugar está relacionada a una experiencia en otro lugar al ir hacia arriba, hasta la red a lo largo de la cuerda en la primera experiencia, viajando a lo largo de la red 
hacia la cuerda sujeta a la segunda experiencia, y yendo hacia abajo en esta última cuerda. En este punto de vista, el encuadre teórico no es simplemente un dispositivo económico para relacionar diferentes experiencias, sino que es una parte indispensable de un todo conectado. . [Cromer, 1997]

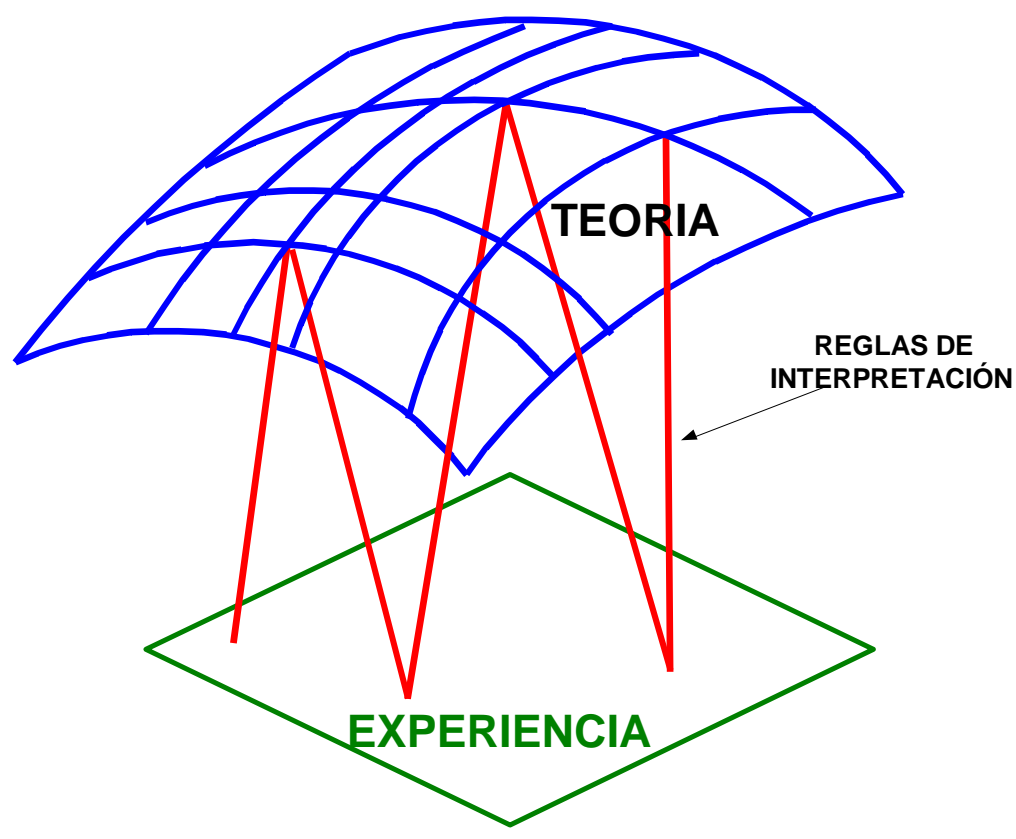

Una teoría científica debe especificar los factores relevantes de una experiencia y cómo los cambios en estos factores cambian el resultado de la experiencia. En términos del diagrama de Hempel, la teoría conecta lógicamente muchas experiencias específicas diferentes, de modo que sean ellas equivalentes desde el punto de vista de la repetición.

La teoría puede ser exacta, desde un punto de vista científico si, al pasar al campo de la tecnología (de la aplicación) aparecen disonancias poco relevantes. Dicha aproximación puede ser llamada un "modelo," dado que, como un modelo, representa los factores relevantes. Con cada refinamiento, y cada vez más experiencias diversas, se pueden considerar repeticiones que una y otra vez tienen un propósito no declarado de probar el modelo, e indirectamente, la teoría.

Existen dos puntos que relacionan esta filosofía directamente con la educación. Primero, se puede hacer muy poca ciencia, si el individuo se queda solamente en el mundo de la observación. Los estudiantes deben hacer algo de viaje entre las observaciones y la teoría a lo largo de las cuerdas de conexión para experimentar ciencia auténtica. Segundo, los hilos de la red teórica no son directamente observables. Así, no hay posibilidad de que los estudiantes los descubran a través de la experimentación exclusivamente, como los educadores constructivistas parecen creer. A los estudiantes se les debe enseñar la teoría, utilizando demostraciones, experimentos, búsqueda dirigida, y métodos tradicionales para resolver problemas. Aunque la búsqueda dirigida es usualmente 
denominada constructivista, asume -como lo hacen todos los educadores tradicionales- que hay algo que los maestros saben y que los estudiantes pueden aprender.

El mejor ejemplo es la ley de inercia, o la primera ley de movimiento de Newton: "Cada cuerpo continúa en su estado de reposo, o de movimiento uniforme en una línea (recta), a menos que sea obligado a cambiar ese estado por fuerzas impresas sobre el."(Newton 1686). Anteriormente en Principia, Newton definió una fuerza impresa como "una acción ejercida sobre un cuerpo, para cambiar su estado, ya sea de reposo, o de movimiento uniforme en una línea recta," de modo que la ley de inercia es inherentemente circular. Adicionalmente, la ley es nocomprobable, dado que no hay manera de observar un cuerpo sin fuerzas "impresas en el" moviéndose por siempre en una línea recta con velocidad constante. Esto no lo molestaba a Newton, quien nos dice que "en disquisiciones filosóficas, debemos abstraernos de nuestros sentidos, y considerar las cosas mismas, aparte de lo que son solamente medidas sensibles de ellas." Este es, los principios fundamentales de la teoría deben ser obtenidos por un proceso de abstracción de la observación; no son observables en si mismos. . [Cromer, 1997]

Para ayudar a los estudiantes con el proceso de abstracción, los maestros les deben proveer demostraciones y experimentos relevantes.

El centro de cualquier instrucción científica debe ser, desarrollar algún entendimiento de la estructura teórica del tema y relacionarlo con la observación.

En el campo de la ciencia informática no ha habido un proceso histórico semejante al de Galileo - Newton - Einstein.

En el campo de aplicación de la segunda parte de esta tesis se trata de introducir la informática como una tecnología de base científica. Es la misma tecnología la que va creando el "mundo" donde vive o va a vivir la ciencia informática. No es ya el mundo real de los físicos, es el mundo virtual de los objetos básicos de software que empezó a crecer hace más de tres décadas en el ambiente Smalltalk o similares.

Considero el ámbito adecuado de aprendizaje, aquel donde se materializa la analogía de Hempel, siguiendo una pedagogía y una matética adecuada que permiten acceder a la información, desarrollar las habilidades contextualizado por la formación integral.

\section{Acceso a información ordenada}

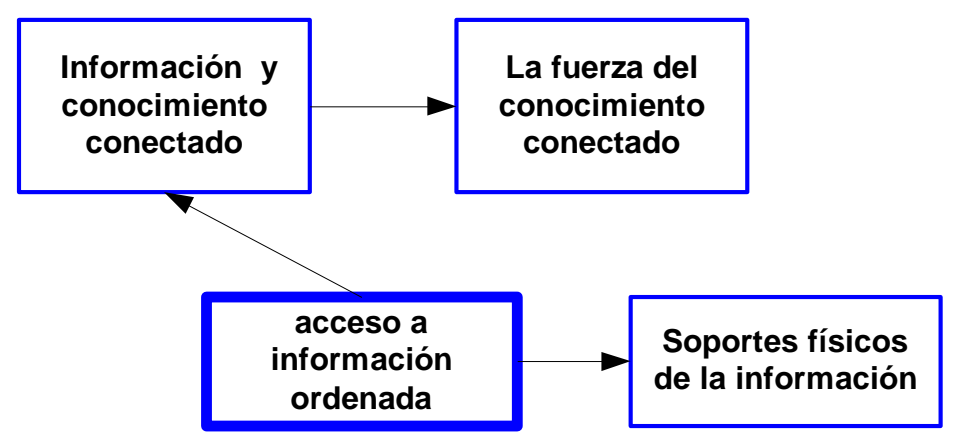




\section{Información}

En el proceso de enseñanza-aprendizaje, hay teoría que pueden transmitirse como información soportada en cualquier medio.

La información es el legado de quienes nos antecedieron en el camino de la ciencia. Dijo Newton "vi más lejos pues estaba parado sobre los hombros de gigantes" Se refería a Nicolás Copérnico, Tycho Brahe y Johannes Kepler y Galileo Galilei. Su genialidad le permitió -sobre la base de la información disponible- lograr un avance sustantivo en el desarrollo de la ciencia.

\section{Información y conocimiento conectado}

Como se expreso al plantear el concepto de conocimiento conectado, la ciencia requiere una interrelación dinámica entre la información teórica disponible y la actividad de experimentación. Sin una teoría disponible no es posible extraer de la multitud de factores presentes en cada situación, aquellos que son relevantes.

Aparentemente, la naturaleza de la ciencia -cargada de teoría- le roba a la misma ciencia su demanda de objetividad. El científico vería solo lo que busca, y busca solo lo que su teoría le dice que busque. Si esto fuera cierto, la ciencia sería entonces una empresa convencional, no sería diferente en estructura de la teología o del criticismo literario. Sus practicantes compartirían convenciones y creencias comunes, y solo emprenderían actividades que fortalecerían sus prejuicios, dándoles así un falso sentido de la objetividad de su trabajo.

Lo diferente de la ciencia es que nada es absoluto, nada es permanente, y el científico esta dispuesto que aprender de sus errores, reflexionando sobre los mismos. La fe real del científico es su práctica.

\section{La fuerza del conocimiento conectado}

Sin duda quien posee conocimiento conectado tiene mayores posibilidades de ver donde otros no pueden.

A los científicos les gusta contar la historia de William Crookes, el inventor del tubo de rayos catódicos (rayo de electrones), en el siglo diecinueve. Crookes, había encontrando que algunas películas fotográficas sin exponer en su laboratorio estaban empañadas, las envió de nuevo al fabricante. El punto es que Crookes no pudo ver la importancia del empañado, porque no era parte de su entendimiento teórico. Por su lado, Wilhelm Roentgen en 1895 investigó la débil fosforescencia que él notó provenía de una pantalla fluorescente cerca de su tubo de rayos catódicos, y descubrió los rayos X. En un año, los rayos X estaban siendo usados para diagnosticar fracturas y localizar balas en heridas, y han sido una parte indispensable de la ciencia y de la medicina desde entonces. El que otro científico fracasara en investigar un empañado misterioso de su película fotográfica no es muy importante. No importa cuantos científicos fracasan en seguir un indicio importante, siempre y cuando uno lo logre.

El gran descubrimiento de Roentgen, el cual ha tenido consecuencias revolucionarias para la medicina y la física, era parte de su práctica científica normal. Roentgen estaba realizando experimentos normales con 
el rayo de electrones y encontró algo inusual. Lo inusual es la parte de la ciencia normal con la que cada científico sueña toparse. Algunos científicos lograr apresar ese inusual que se presenta, como lo hizo Roentgen. [Cromer, 1997]

La objetividad de la ciencia no está establecida por cualquier observación única o teoría, sino por la totalidad de sus teorías y observaciones. Aunque sería apetecible que los estudiantes adquieran un entendimiento unificado de la ciencia, es dudoso que pueda ser aprendido de algún modo.

La repetitividad es la esencia del conocimiento científico, sin embargo la repetitividad es solo posible, si hay un conocimiento teórico previo concerniente los factores relevantes a ser repetidos. Hasta el simple proceso de medir con una regla tiene una base teórica: no es intuitivo. Pero dado que la teoría debe estar basada en experiencias repetibles, el completo proceso de la ciencia aparece siendo circular o conectado. En realidad, es espiral, el intercambio cíclico entre teoría y experiencia elevándose y refinando el alcance y precisión de los conceptos y prácticas es proceso difícil de llevar adelante por lo que hay muchas teorías que simplemente no lo hacen. Lo que científicamente sobrevive ha encontrado rigurosas pruebas de repetición, consistencia y validez, y puede ser llamado conocimiento científico objetivo, quedando apartado el constructivismo pos-modernos que ve a la ciencia como un esfuerzo puramente empírico.

\section{Soportes físicos de la información}

El acceso de información de ha tenido diversos soportes físicos desde la oralidad al DVD- a lo largo de la historia. El libro será la herencia informativa permanente de la humanidad, debido a la desaparición paulatina de otros tipos de soportes informativos producto de la obsolescencia tecnológica (por ejemplo se va perdiendo la información soportada en disquetes de 51/4)

Los nuevos soportes masivos, han mejorado el registro de la información y la facilidad de su acceso, pero junto con estas ventajas ha crecido la dispersión.

Históricamente, podemos hablar de una etapa oral -origen del aula actual y de la clase magistral- seguida de una etapa textual y la introducción en este momento (principios del siglo XXI) de la etapa hipermedia.

La preponderancia de las aulas como ámbito físico educativo mostraría cierta autoconservatividad del sistema educativo. Sigue teniendo vigencia la imprescindible comunicación docente-alumno. Sin embargo nos encontramos que esa comunicación se podría potenciar, si las nuevas tecnologías hubieran sido aplicadas adecuadamente a la educación.

\section{Desarrollo de habilidades mediante la producción}




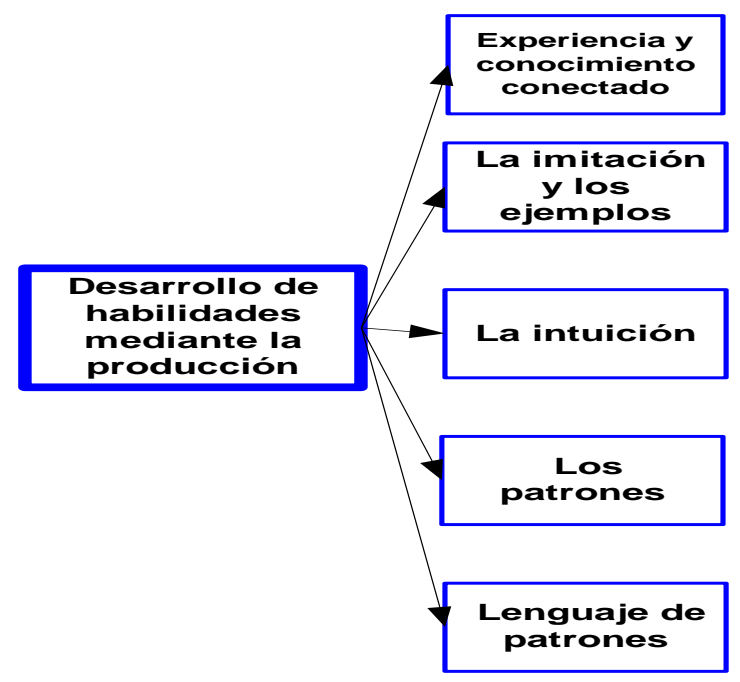

\section{Experiencia y conocimiento conectado}

Es conveniente aclarar que las experiencias que se observan tienen los límites de observación de nuestros sentidos. En base a esas experiencias se generan conocimientos y teorías que tienen la misma limitación: la imposibilidad de lograr una percepción directa de la realidad. Desde el punto de vista filosófico este planteo es relevante.

Desde el punto de vista del aprendizaje y aplicación de la tecnología -donde no tienen otra opción que percibir mediante los sentidos- los estudiantes realizan viajes entre las observaciones y la teoría -esquema de Hempel- que la explica a efectos de experimentar ciencia auténtica

\section{La imitación y los ejemplos}

La imitación es la forma primitiva de aprender de los animales y de los niños. La enseñanza es exitosa, si se logra compartir una heurística adecuada. El ámbito natural para compartir heurísticas es el taller de aprendizaje donde los que comienzan interactúan con la producción con los expertos

En el ámbito tecnológico, como una forma de comenzar a trabajar, se pueden presentar ejemplos simples que funcionen adecuadamente; luego se puede pasar a algo parecido a esos ejemplos iniciales, con pequeñas variaciones.

Si es posible, los ejemplos no deberían ser arbitrariamente definidos por el docente, sino que el educando debería sentir la necesidad de consultarlos (los ejemplos), a efectos de despertar su interés, esencia del placer de aprender.

\section{La intuición}

Ya se ha mencionado la intuición, aquella forma de la inteligencia que les da a los científicos creatividad y nuevas ideas.

La intuición, forma artística -no científica ni analítica- de entender algo, es considerada una cualidad inherente a la mente.

El término intuición se ha empleado en sentidos distintos, a veces opuestos, por numerosos autores, con lo que no puede definirse más que en referencia a las obras de algún filósofo en particular. El concepto de 
intuición surgió al parecer de dos fuentes: del concepto matemático de axioma (proposición obvia que no necesita ser demostrada) y de la idea mística de la revelación (verdad que supera las capacidades del intelecto).

La intuición era importante en la filosofía griega, en particular en el pensamiento de filósofos como Pitágoras y sus seguidores, que poseían formación matemática. El concepto tuvo también mucha importancia en gran parte de la filosofía cristiana como una de las maneras en que podía llegarse a conocer a Dios. Los filósofos que más se apoyaron en la noción de intuición fueron Baruch Spinoza, Immanuel Kant y Henri Bergson.

En la filosofía de Spinoza, la intuición es la forma más elevada de conocimiento que existe por encima del saber empírico que se deriva de los sentidos.

Kant consideraba la intuición como la parte de una percepción que proporciona la mente por sí sola. Clasificó lo perceptible o phenomena, en dos tipos: la sensación causada por el objeto externo percibido y la forma, o la comprensión de esa percepción en la mente, que proviene de la intuición. Percepciones como el espacio y el tiempo son variedades de la intuición pura.

Bergson oponía el instinto a la inteligencia y consideraba la intuición como la forma más pura de instinto. La inteligencia es para él adecuada al objeto de tratar las cosas materiales, pero no puede entender la naturaleza esencial de la vida o el pensamiento. Bergson definió la intuición como "el instinto sin objetivos, consciente y capaz de reflexionar sobre sí mismo y acrecentarse indefinidamente". Por otro lado, la inteligencia sólo puede analizar y la función del análisis es la de determinar qué es relativo a un objeto, más que lo absoluto o individual. Sólo a través de la intuición, pensaba Bergson, puede alcanzarse lo absoluto.

Algunos filósofos éticos, como Spinoza, han sido llamados intuicionistas por su creencia de que los valores morales son intuitivos e inmediatos. Este punto de vista se opone al de los empíricos, que sostienen que los valores morales nacen tan sólo de la experiencia humana, y al de los racionalistas, que creen que los valores morales vienen dados por la razón.

\section{Los patrones}

Un patrón especifica la solución de un problema que aparece una y otra vez, en un contexto determinado [Alexander, 1997]. Cada patrón registra un problema recurrente, establece como se construye la solución para el problema y explica porqué la solución es apropiada.

Hasta mediados del siglo XX la velocidad de desarrollo de la tecnología de base científica permitió -en ámbitos como los de la industria automotriz y las radiocomunicaciones- que los patrones acumularan la solución de problemas recurrentes, especificándose las soluciones en manuales de simple acceso.

El desarrollo de tecnologías nuevas, por ejemplo la del software, sobre todo en el área de la codificación no ha acumulado patrones. Esto se debe en parte a la velocidad del cambio de la industria asociada al software y también al desarrollo de una tecnología de limitada base científica. En 
caso particular del software, la mayoría de los desarrollos de sistemas ha sido realizada aisladamente, empezando de cero, con una tecnología que impidió la acumulación de patrones en la mayoría de los pasos de un desarrollo.

\section{Lenguaje de patrones}

El lenguaje de patrones es una colección de patrones que forman un vocabulario para entender y comunicar ideas. Si un patrón es una solución recurrente a un problema en un dado contexto establecido por diversas fuerzas, un lenguaje de patrones es una solución colectiva -que integra patrones individuales- para resolver problemas complejos.

\section{Formación integral}

\section{Formación}

integral

La educación debe tender a la formación integral de las personas, y este elemento es el que hace irremplazable la función docente. Esa formación está compuesta de conceptos éticos y estímulos para pensar.

Una de las principales actividades la formación integral es facilitar el acceso democrático al continuo descubrimiento de cuestiones conocidas por otros, para lograr que el crecimiento cultural del conjunto, permita una pendiente positiva en la evolución humana y logre que el conjunto pueda disfrutar del planeta, en otras palabras tender a -la no lograda aúnpreponderancia de la inteligencia sobre la estulticia.

\section{Los receptores de la actividad académica}

Se refiere a los alumnos, destino del esfuerzo pedagógico.

\section{Velocidad de avance individual}

Disponer de tiempo ante cualquier problema -aprender es un problema- da la oportunidad de enfrentarlo con la tranquilidad de no estar acotado externamente por los plazos (cuando consideramos un conjunto de educandos, la forma práctica dichos plazos tendrían la extensión de tiempo del más lento). 


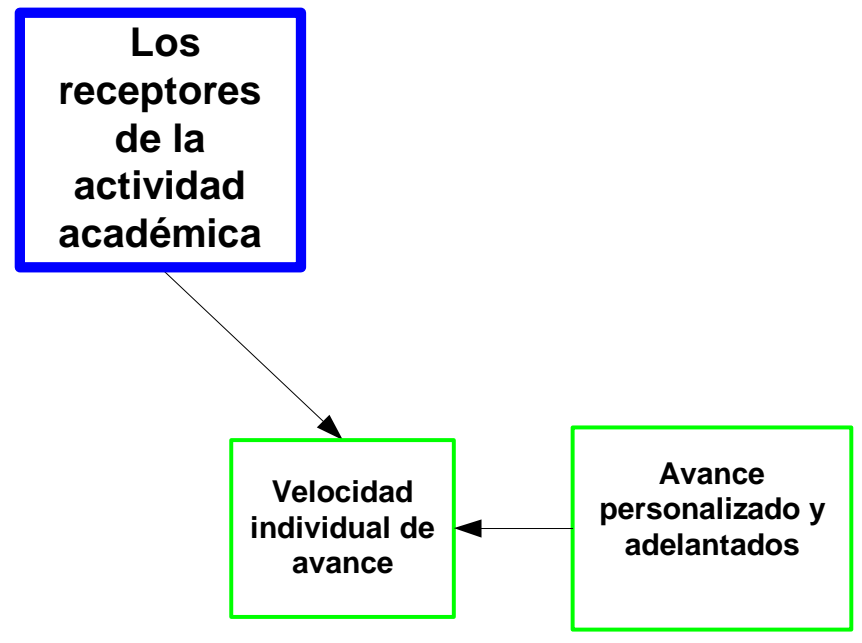

Cada uno de nosotros tiene, para cada ámbito de la formación una velocidad de avance diferente, que depende de muchas variables. Surge de inmediato la imposibilidad de establecer una velocidad única de avance para un conjunto de alumnos (procedimiento habitual cuando se limita el tiempo disponible). El ámbito físico del aula impone tal avance uniforme, muy difícil de concretar. [Thompson, 1984] Es conveniente buscar la forma de lograr que cada educando avance a su propia velocidad.

\section{Avance personalizado y adelantados}

La necesidad de una velocidad de avance individual (del párrafo anterior), requiere una atención personalizada, que desarticularía la mayoría de los presupuestos docentes. Sin embargo, quien escribe, ha realizado en distintos ámbitos experiencias asociadas a la formación de adelantados.

Esta formación de adelantados, consiste en una capacitación breve un taller previo con pocos alumnos elegidos de acuerdo a capacidades personales de conocimientos y comunicación- para colaborar con el profesor en el desarrollo del taller amplio. También pueden ser personas con distinto grado de experticia en la tecnología en cuestión (por ejemplo, cursantes de años anteriores).

La menor experiencia de los adelantados es reemplazada por la mejor relación afectiva entre adelantados y alumnos, que se transforma en un aporte para la formación, tanto de los alumnos como de los propios adelantados. La interacción entre alumnos y adelantados ayuda a salvar, entre otros problemas, la carencia inicial de una semántica adecuada, por parte del alumno. De otro modo, la conformación de grupos de experticia diferente, ayuda a aplicar gradualmente el lenguaje de patrones.

Los adelantados, con su menor diferencia de conocimiento con los alumnos logran que los educando superen amablemente el miedo de mostrar una mente sin los conocimientos ante profesores (relación general con quienes tienen cierto poder).

Si fuera imprescindible mantener una velocidad de grupo entre los alumnos, los más avanzados deberían compensar la menor velocidad de los más atrasados, quienes a su vez deberán dedicar mayor cantidad su propio tiempo a la materia de estudio. 
Universo de los que aprenden

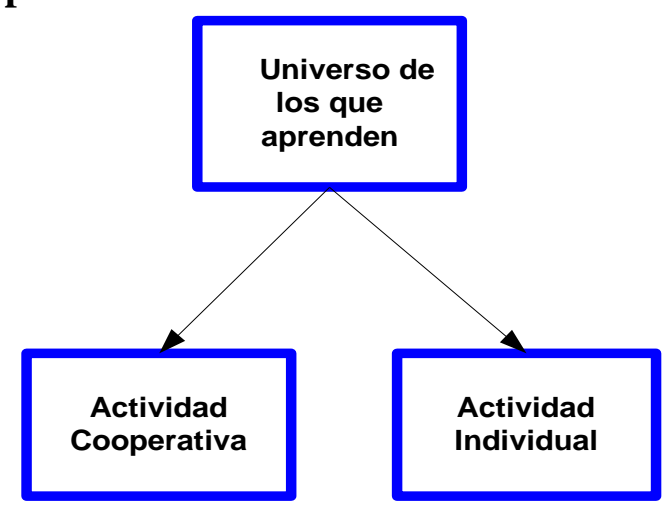

Asumida una distribución normal de la velocidad de aprendizaje en el universo de los que aprenden, habrá quienes por diversos motivos, como puede ser el conocimiento de paradigmas anteriores, tengan un conocimiento y una habilidad mayor para desplazarse a mayor velocidad en el aprendizaje, en el otro extremo están quienes tienen el primer contacto con la temática y con su práctica para quienes -salvo excepciones- la velocidad de aprendizaje estará en el extremo inferior de la distribución normal

En base a esta población -adecuadamente evaluada mediante encuestas- pueden definirse actividades individuales y cooperativas. En estas últimas se puede seguir el criterio de agrupar por nivel, lo cual implica un mayor trabajo docente o mezclar distintos niveles con lo que aparece naturalmente la figura del adelantado. La conformación de estos grupos es conveniente proponerla al conjunto. Puede suceder que, en ámbitos demasiado competitivos los más capacitados, muchas veces, no deseen colaborar.

¿Es posible personalizar la capacitación tecnológica?

Esta tesis pretende establecer que si se logra el contexto adecuando para lograr que cada educando avance a su propia velocidad individual, el educando puede recorrer un conjunto de caminos para el desarrollo de:

- Conocimiento teórico a través de la información

- Habilidades

- Formación integral

Ese contexto permite que cualquier persona -que pueda y quiera dedicar tiempo y aplicar su voluntad- acceda al conocimiento tecnológico de base científica, para luego tener la oportunidad de aplicarlo virtuosamente en su ámbito de actividad.

En los siguientes capítulos de esta tesis se establecerán las bases de ese contexto adecuado, propuestas efectuadas para concretarlo y las experiencias realizadas. 


\section{CAPÍTULO 3}

\section{CONTEXTO IDEAL PROPUESTO PARA EL ACCESO TEÓRICO, EL DESARROLLO DE HABILIDADES Y LA FORMACIÓN}

\section{Resumen}

Se plantean los ámbitos para el desarrollo de actividad académica para: la actividad de acceso a información ordenada, desarrollo de habilidades mediante la producción y la formación integral.

Se define la superficie de representación del conocimiento y a partir de la misma se abstrae el denominado itinerario óptimo del aprendizaje. Luego se establecen las características de un contexto ideal analizando a distintos aspectos que hacen a la conformación del ámbito de concreción de estas tres actividades: el contexto físico y social, la cuestión afectiva, el contexto informativo, la estructura y composición de la conducción académica, etc.

Se analiza la situación actual de la universidad argentina para conectarla con la necesidad de la formación humana de los futuros graduados.

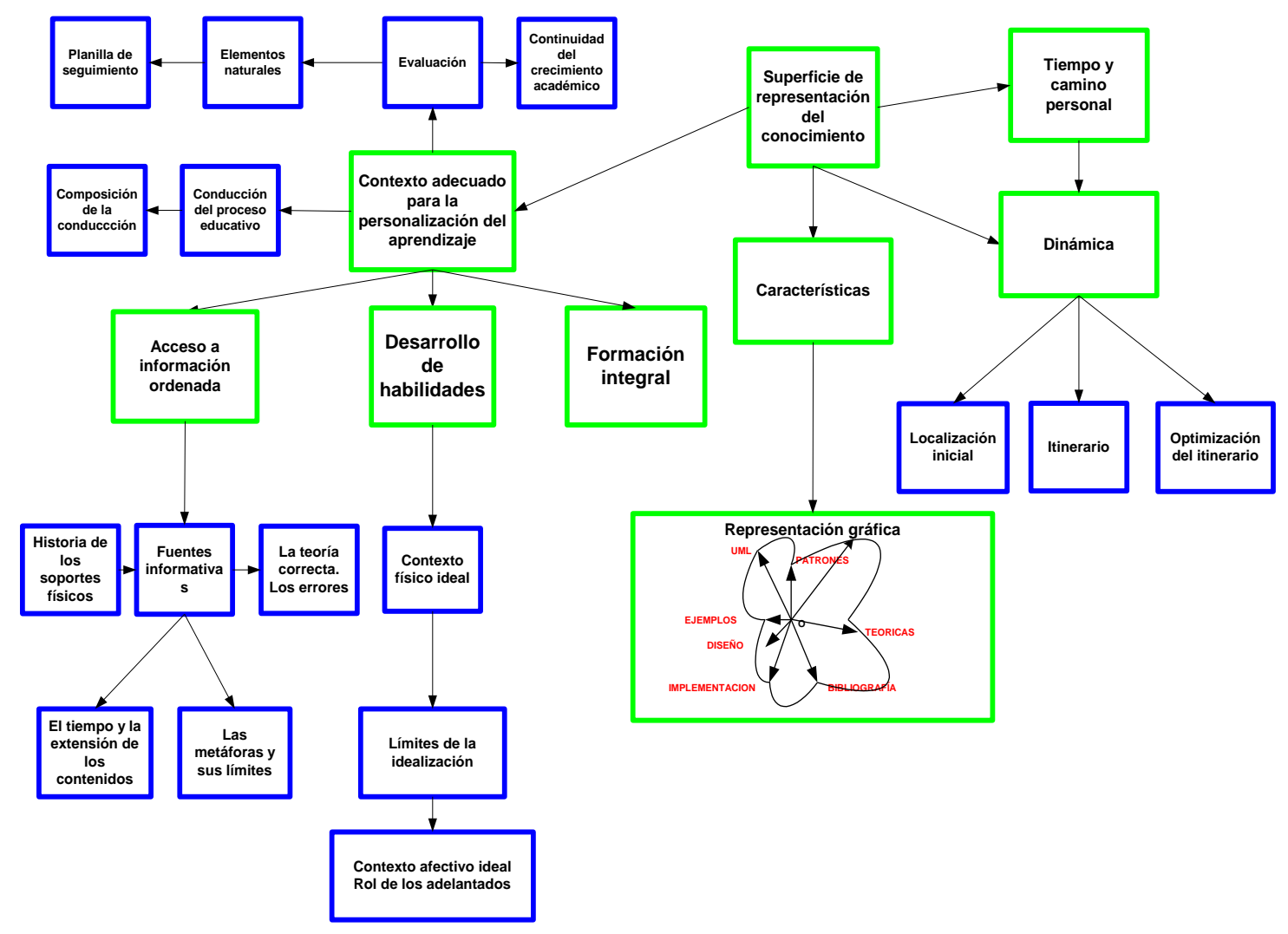


Tres ámbitos de actividad académica

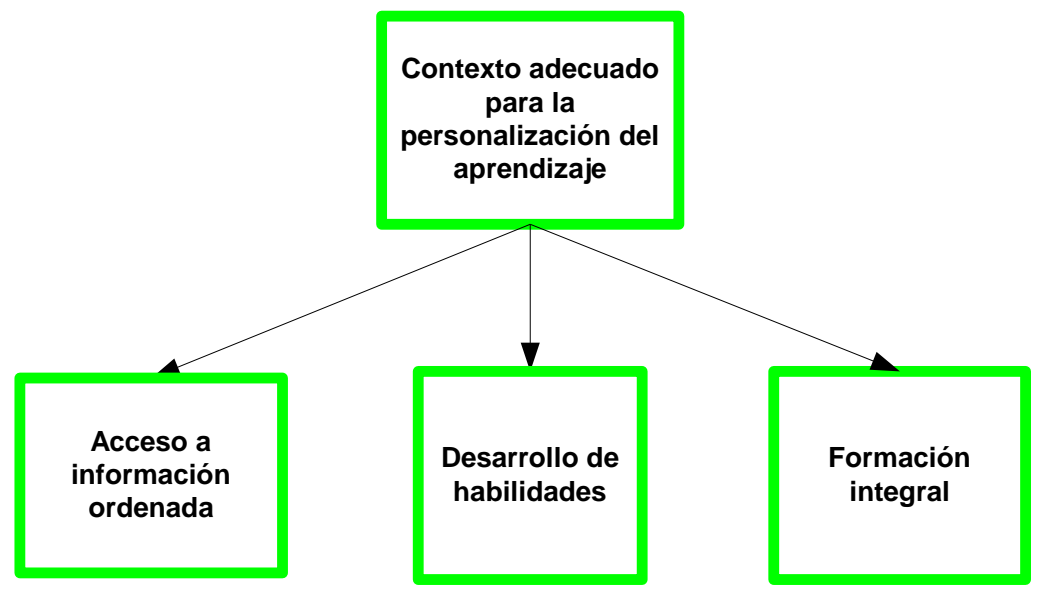

Como se estableció en el capítulo anterior esta tesis propone la enseñanza personalizada de tecnologías de base científica para lo cual se plantean tres ámbitos de desarrollo -sobre todo a nivel universitario- de dicho aprendizaje:

a) Acceso a información ordenada

b) Desarrollo de habilidades mediante la producción

c) Formación integral

El estudio teórico permite ver más lejos "sobre los hombros" de quienes nos precedieron en el desarrollo de los conocimientos bajo estudio. Compendiar y actualizar esa teoría, es una tarea que, aprovechando los soportes informáticos actuales, permitiría aproximarse al corpus teórico conocido de la materia de estudio.

En lo que respecta al desarrollo de habilidades, las personas aprenden de sus experiencias cuando están totalmente inmersas en ellas. El lugar físico de inmersión deberá tener características que permitan "vivir" en un micromundo de contacto multisensible con la expresión práctica de los conocimientos [Papert, 1981].

Finalmente es necesario recuperar actualizándola, una actividad que es la esencia histórica de las universidades: un ámbito formador de las personas en aspectos que exceden la materia de estudio. Las experiencias sociales y políticas vividas en nuestro país (genocidio, malversación de la democracia, aplicación fuera de contexto de recetas neoliberales, etc.), hace necesario revisar el rol de la actividad académica y su relación con la sociedad. Debemos preguntarnos si se le ha dado la suficiente atención a la formación humana o es necesario revalorizarla. Por otra parte la situación internacional ha impulsado -en parte a través de la tecnología- la ruptura de un esquema de distribución de la riqueza fundamentado en la remuneración a los factores de producción, en particular haciendo desaparecer paulatinamente el empleo laboral.

\section{Acceso a información ordenada}

Como ya se expresó, un número creciente de psicólogos e investigadores cognitivos han adoptado la visión del conocimiento conectado, dentro del contexto en el que se construye y actualiza los saberes, donde el crecimiento cognitivo consiste en una progresión bidireccional entre lo concreto y lo abstracto, tornándose el educando en un activo participante en la multiplicidad de prácticas en una comunidad de conocimiento específico

Se propone en el desarrollo de esta tesis, una base de información teórica completa, semánticamente coherente y con localizaciones de comienzo variables según 
la formación previa del educando. Esta base debería lograr estabilidad en el conocimiento asentado y que permitir una actualización permanente.

\section{Superficie de representación del conocimiento}

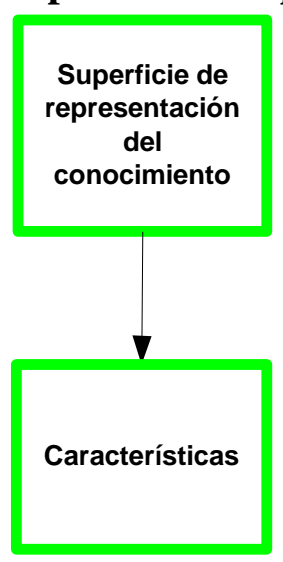

Previo análisis de la base teórica y sus posibilidades resulta conveniente realizar una abstracción -superficie de representación del conocimiento- como ayuda a la comprensión de las posibilidades de actividad pedagógicas y matéticas en un ámbito adecuado.

La superficie de conocimiento se construye mediante semirrectas que representan -alegóricamente- los distintos caminos teóricos y de experimentación práctica, para acceder al conocimiento. Estos caminos son, una representación de los recorridos que realiza cualquier persona para aprender. Algunos recorridos pueden ser formalmente provistos por la cátedra, otros se recorren informalmente, otros han sido recorridos inconscientemente por el educando

\section{Características de la superficie de representación del conocimiento}

Aceptado que el camino de acceso a cualquier expresión de un conocimiento tecnológico se puede representar por una semirrecta, cuyo punto de origen $\mathbf{O}$ representaría el desconocimiento y cuyo extremo representa el máximo desarrollo de dicha forma de expresión del conocimiento, se puede definir como superficie de representación del conocimiento al conjunto de esas semirrectas con origen en $\mathbf{O}$ y extremo correspondiente al límite conocido y aceptado del conocimiento actual. De otro modo, los extremos de cada semirrecta van definiendo el contorno de esta superficie, contorno que representa el estado actual de conocimiento de esa tecnología.

Esta representación puede resultar útil para la comprensión de cómo se desarrolla la formación tecnológica fundamentada en teorías científicas. Luego se usará para el caso de la tecnología de objetos que se basa en la ciencia informática en pleno desarrollo.

\section{Representación gráfica}

A efectos de ir conectando esta primera parte del trabajo con el caso específico de la Tecnología de objetos se concretan, dentro de la superficie de conocimiento, algunos caminos posibles para dicha tecnología. 


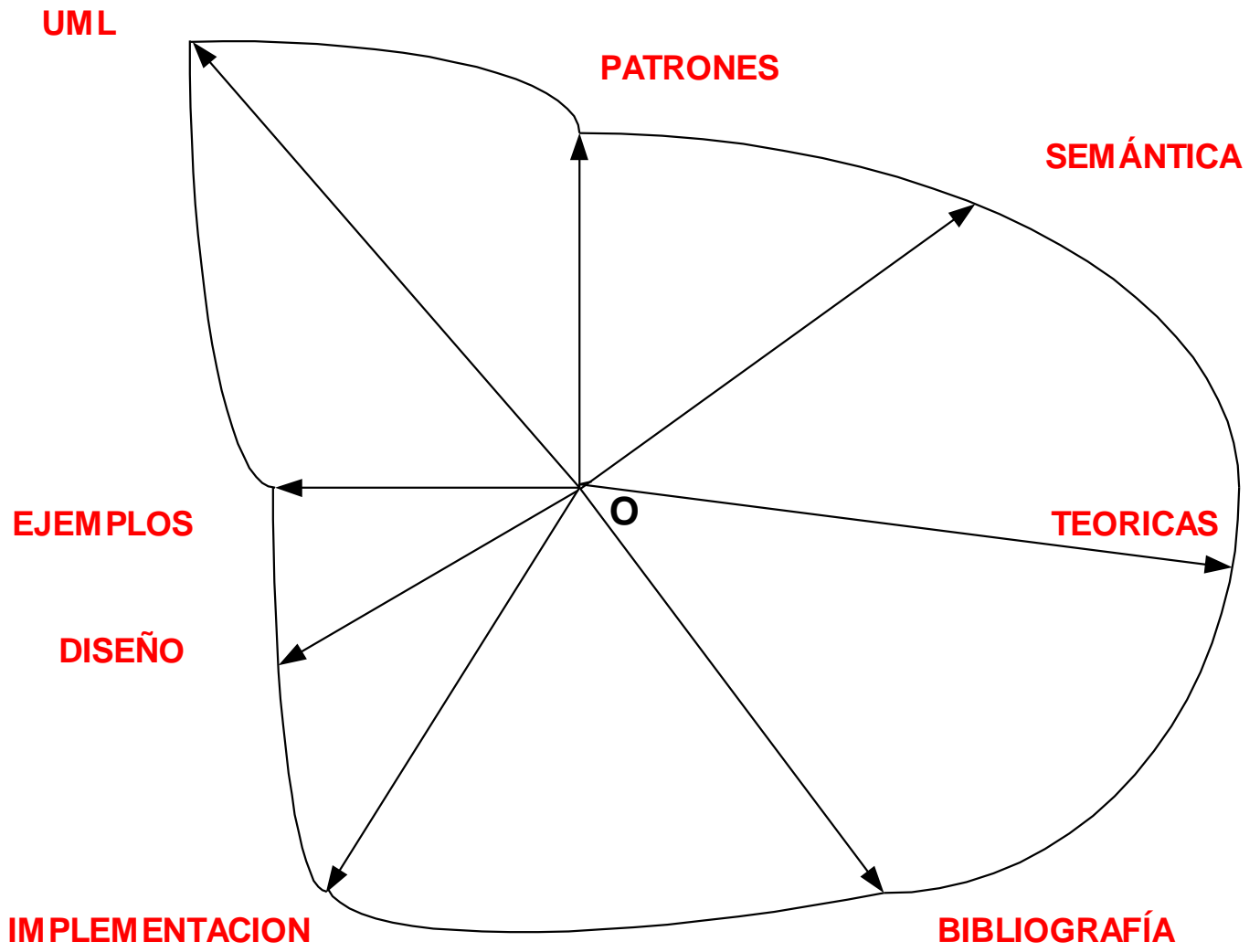

El centro $\mathrm{O}$ de la superficie corresponde al caso de conocimiento nulo de la tecnología de objetos. El contorno representa el estado actual de conocimiento de la tecnología de objetos.

Hay dos sectores en que se puede separar la superficie, sector de teoría (en sus distintos soportes: texto, sonido e imágenes) y prácticas en el taller de aprendizaje. Para el caso particular de la tecnología de objetos se muestran en el ejemplo de la figura estarían presentados mayoritariamente en la base teórica, la semántica asociada, los criterios de diseño y los patrones de diseño. Se asociarían a la actividad práctica o de desarrollo de habilidades, los ejemplos, el diseño, la graficación UML, la implementación en Smalltalk, etc. En este caso particular de la tecnología de objetos es posible ir recorriendo la teoría a partir de las clases teóricas, acceso a la semántica base, lectura de la abundante bibliografía existente, teoría asociada a diagramación UML (recién normalizada en 1999). En la actividad de taller práctico aparecería desde la implementación en el ambiente Smalltalk (ambiente que en si mismo en un ámbito de experimentación que permite mediante las reglas de interpretación conectar la teoría con la práctica) hasta el uso de los patrones de diseño de reciente creación.

Toda esta información puede acumularse en un soporte multimedia (CD o sitio web) 


\section{Dinámica de la superficie de conocimiento}

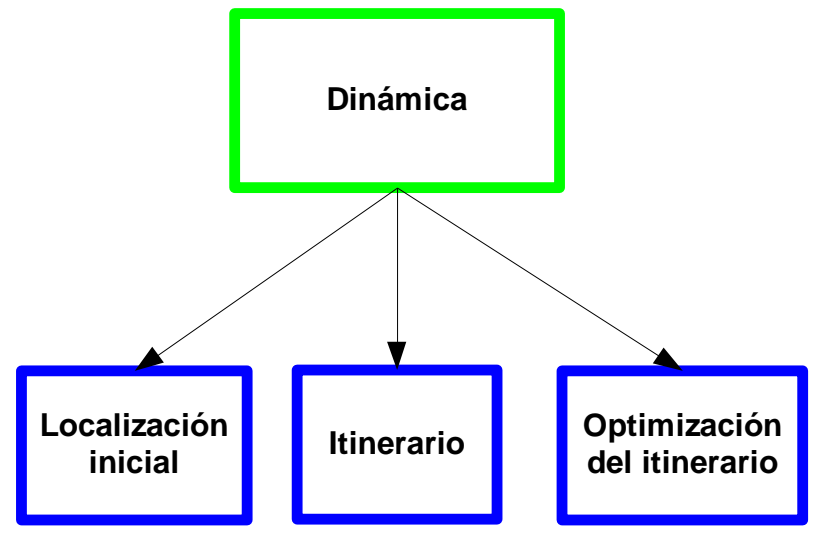

\section{Localización inicial del alumno}

Cada alumno pose un bagaje de conocimientos que es necesario aproximar a través de una encuesta u otras formas de evaluación.

\section{Itinerario sobre la superficie de conocimiento}

A partir de la localización inicial existe -para cada educando- un itinerario que se puede representar por movimientos centrífugos cuyo recorrido podría ser sobre un conjunto de figuras isomorfas, con contorno de la superficie de representación del conocimiento.

Ese itinerario será recorrido a la velocidad del educando, dentro de los límites normales de velocidades de aprendizaje. Cada tramo de esa ruta será complementado con el aporte dosificado de ejemplos y práctica de habilidades, para lograr que los conocimientos se asienten, y resulten una base firme para del recorrido siguiente.

\section{Optimización del itinerario}

Tanto la información básica como el itinerario irán creciendo en eficiencia y eficacia en tanto sea recorrida por los alumnos y optimizada por los docentes que tendrán en cuenta las críticas de los alumnos y las evaluaciones de los resultados efectuadas por la cátedra- de los diversos recorridos realizados por parte de los educando.

Por su lado la cátedra evaluará las características y resultados del uso de los contenidos de la teoría base para optimizar tanto el contenido como la definición de un itinerario óptimo. 


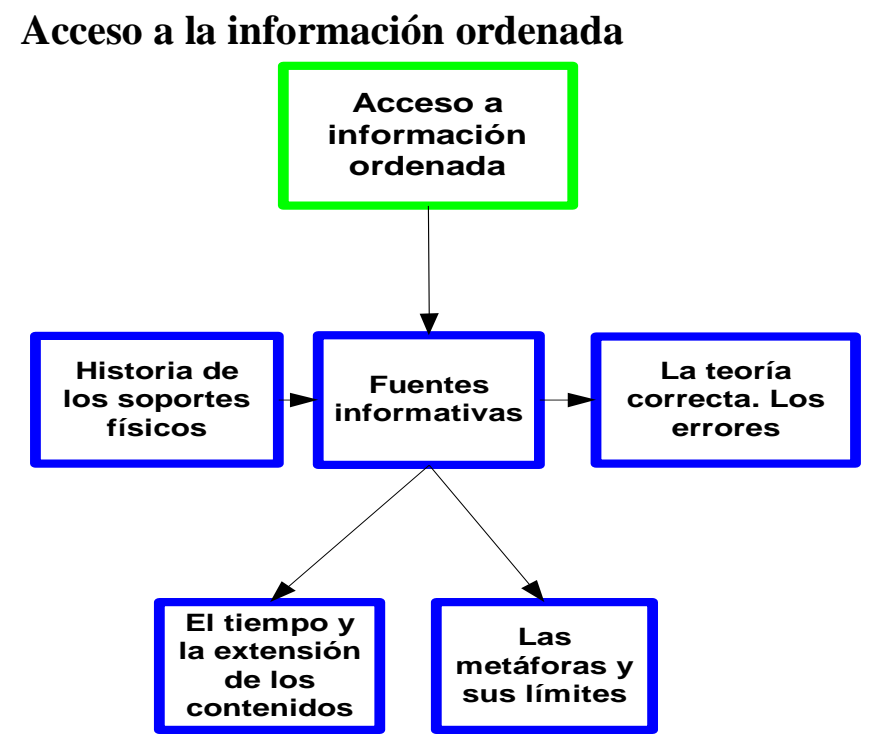

\section{Las fuentes informativas}

Las fuentes informativas multimedia actualmente disponibles no poseen una notación semánticamente coherente y normalizada. En el espacio tiempo compartido por docentes y alumnos sería deseable esa normalización. Eso es posible por las capacidades de edición que permiten los sistemas informáticos.

Vivimos una época de extraordinaria abundancia de información expresada en forma multimedia, es posible replicar -en una aplicación ad hoc - el itinerario de navegación óptimo (en la red de información base teórica) para el educando. El educando debería poder acceder a todo el material puesto a su disposición a cualquier hora del día y desde cualquier lugar de residencia. Lo planteado sugiere la posibilidad de la construcción de un sitio en Internet. Conjuntamente y a efectos de evitar la dispersión que produce la navegación en Internet, es conveniente acotar físicamente el conjunto de la información temática multimedia en el más popular de los soportes vigentes hoy -2003- o sea en un disco compacto. La limitación no tiene porque ser la del soporte físico, sino que tendrá que estar relacionada con la posibilidad de cada educando de recorrer la ruta del acceso al conocimiento en el tiempo normal de acceso que posee.

El contexto de trabajo propuesto se refiere al conocimiento tecnológico con base científica, donde es posible controlar el lenguaje, es decir que es posible seleccionar porciones del lenguaje natural organizándolo y relacionándolo en forma de clasificaciones, tesauros, redes terminológicas, glosarios y diccionarios. Volviendo a la alegoría de la superficie de representación del conocimiento planteada al principio de este capítulo, sería necesario crear la semirrecta el acceso semántico más conveniente desde la ubicación inicial del educando hasta que alcance el contorno actual de la superficie de representación del conocimiento.

\section{La teoría correcta. Los errores}

Existen conceptos que erróneamente comprendidos podrían generar una teoría individual incorrecta y por lo tanto dar lugar a reglas de interpretación y prácticas erróneas. Es necesario acentuar los conceptos teóricos correctos y realizar prácticas de 
lo correcto que permitan concretar correctas aplicaciones, definiendo de este modo el conjunto de ejemplos de referencia, aquellos que con modificaciones en sus planteos signifiquen nuevos esfuerzos a realizar en el camino del aprendizaje.

Los errores que cometa el educando en la actividad práctica, deberían rescatarse en su utilidad, en su conexión con el método científico. Los errores informarán al educando, si se desarrolla un proceso de descubrimiento de su naturaleza errónea, que la teoría ha sido mal comprendido o esta siendo aplicada incorrectamente. Debería evitarse el camino seguido por algunos físicos clásicos respecto de la teoría relativística de generar modelos incompatibles con la realidad que los experimentos muestran. [Thompson, 1981]

\section{Historia de los soportes físicos de la información}

Se ha planteado la posibilidad de crear un ámbito de aprendizaje multimedia, que sirva como continente de la base teórica de la tecnología objeto de estudio.

Desde un punto de vista histórico, se estaría dando continuidad a un proceso de distintos soportes de transmisión de la información relacionada con el conocimiento. Durante muchos siglos el soporte fue oral y el lugar físico de expresión fue el aula; continuó luego con el soporte textual y a fines del siglo pasado con el soporte hipertextual (o para ser más precisos el hipermedial).

Algunas experiencias realizadas por el autor en la construcción y mantenimiento de sitios de dos materias universitarias y varios seminarios, permitieron comenzar a pensar en la posibilidad de construir en un soporte multimedia la información teórica base conectada hipermedialmente, como una expresión práctica de la red de Hempel. Esto se ha concretado en http://sol.info.unlp.edu.ar/topicos2/

\section{EI tiempo y la extensión de los contenidos}

La utilización del tiempo surge de una relación dinámica entre la cátedra y el educando, en la que ya se ha planteado el respeto de la velocidad del educando). La extensión de los contenidos de una sesión de trabajo de acceso a la teoría en cualquier ámbito (desde la clase teórica hasta la multimedia básica) está limitada cuantitativamente por la memoria de corto alcance. Esta memoria puede sostener 7 conceptos, y dar o tomar 2 [Miller, 1956]. Este es el llamado límite de Miller, tomado como referencia permite dividir un módulo en 7 escalones o sub-tópicos, adecuado para la mayoría de los educandos.

En el último capítulo se propondrá una cursada de tiempo variable, como una forma de personalizar el avance del educando.

\section{Las metáforas. Sus límites}

Las metáforas es uno de los caminos de introducción a conceptos nuevos o de difícil aprehensión, así, para explicar la diferencia entre identidad y igualdad entre objetos, metafóricamente -el docente- se puede remitir a una situación popular en una casa de comidas en donde un cliente ve comer a otro una milanesa napolitana y de dice al mozo "quiero lo que él está comiendo" la igualdad significa que el mozo va a la cocina y pide que preparen otra milanesa napolitana, la identidad implicaría que el mozo debería retirar la milanesa del comensal referido por el nuevo cliente y dársela a este último.

Metáforas de estas características ayudan al acceso a conocimientos de confusa interpretación. Luego es necesario recorrer el camino teórico - práctico en la 
tecnología en estudio para que se asiente el conocimiento. Es decir que la metáfora es sólo introductoria de conceptos. Los intentos de reemplazar permanentemente los conceptos por la metáfora, terminan en contradicciones que pueden producir desconcierto, en vez de asentar el conocimiento asociado

\section{Ámbito para el desarrollo de las habilidades}

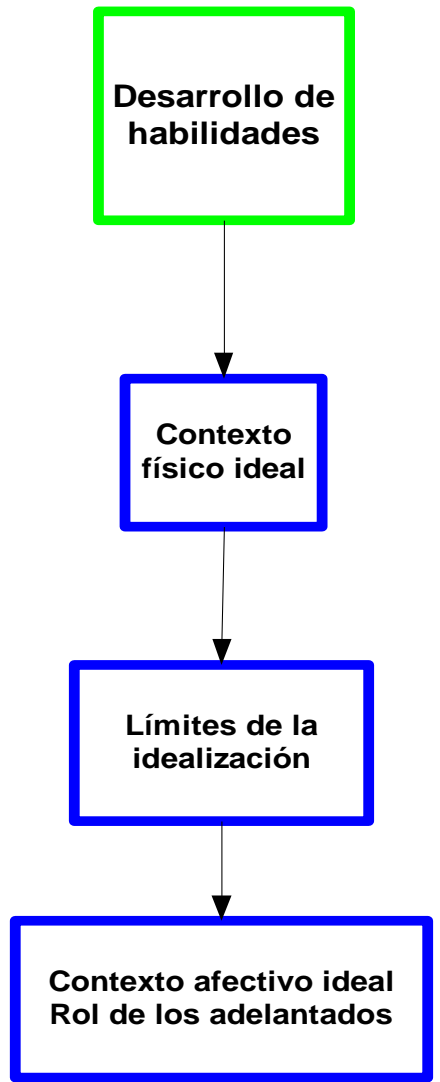

Aprender es crecer en conexiones. Los individuos dan forma a sus ideas, y esas formas, una vez construidas, informan sobre sus ideas. Las expresiones personales y los artefactos culturales se tornaron en cosas con las que pensar, u objetos que permiten la mediación. [Papert, 1981] En nuestra mente, sentidos y cuerpo las ideas se expanden a través del uso personal y cultural de herramientas, entonces estas herramientas tornan a incorporarse, como partes asociadas a nuestra actividad intelectual. Los bordes de nuestras envolturas mentales, sensoriales y corporales se expanden en el mismo sentido que un perro guía de un ciego es una extensión del sistema sensorial del ciego.

Una vez objetivada una experiencia personal puede ser incorporada. El educando puede zambullirse y salir varias veces de la experiencia y este movimiento alternativo es la que nos conecta con el mundo. Las personas terminan habitando sus propias construcciones mentales.

Pensando nuevamente a la superficie de acceso al conocimiento, el educando, cuando llega al taller de producción y aprendizaje se encuentra sobre un contorno interior a la superficie- definido por los puntos alcanzados en cada camino de acceso al conocimiento, y según sus características matéticas personales, se desplazará concretando prácticas sobre semirrectas de acción conectando la teoría con las ejecuciones que realice 
En los siguientes epígrafes se trata de abstraer el contexto ideal que permita recorrer ese camino de desarrollo de habilidades que sea el óptimo para cada educando.

\section{Contexto físico ideal}

Con relación al desarrollo de habilidades es posible crear un lugar de contacto multisensorial entre el alumno y la realidad de la materia en estudio: un mundo de fenómenos físicos para el estudio de la física, un mundo de objetos matemáticos para las matemáticas, o un mundo objetos reales que tengan su correlato con los objetos virtuales de la tecnología de objetos, etc. El equipamiento necesario para crear este particular mundo, cambia dinámicamente al ritmo de la evolución tecnológica y está relacionado con el estado actual de dicha evolución. Se comienzan a ver las posibilidades de un ámbito de robótica que concrete en objetos reales algunos de los objetos de la tecnología homónima.

\section{Contexto ideal para el desarrollo de habilidades. Límites de la idealización}

Este intento de buscar el contexto idealmente perfecto para el desarrollo de las habilidades impone poner los límites que establecen la capacidad de comunicación de las personas y la realidad tecnológica actual.

En el caso de las personas hay un problema inherente a la comunicación que impide que lo que se desea transmitir desde cualquier fuente emisora sea recibido integralmente con el sentido propuesto por el emisor. Los artefactos, en general, son una fuente emisora fiel en tanto repetitiva. En tal sentido tienen una ventaja relativa sobre los humanos, ventaja que de ningún modo puede reemplazar el intercambio inteligente entre profesores y alumnos.

Con referencia a los artefactos es posible prever los cambios que en el futuro nos permitirán interactuar multisensorialmente con objetos de la tecnología objeto de aprendizaje. Más allá de esas previsiones comienza la zona de la ciencia - ficción que eventualmente puede ser fuente de inspiración para quienes trabajan en los laboratorios más adelantados pero que poco pueden aportar hoy, al planteo de un contexto ideal de la formación

\section{Contexto afectivo ideal. EI rol de los adelantados}

Cada educando podría ser supervisado por un adelantado tratándose de desarrollar entre ambos la mejor relación de empatía posible. El adelantado debe compenetrarse de su rol acompañando el itinerario óptimo para el acceso teórico y desarrollo de habilidades. Debe realizar la evaluación continua del avance del educando, verificar el uso correcto del lenguaje y el dominio de los conocimientos informativos y habilidades técnicas, conectando sinérgicamente el aprendizaje con la evaluación a través de la producción, en el ámbito de desarrollo de las habilidades.

\section{La conducción del proceso educativo}

La conducción jerárquica, generalmente de facto, de muchos procesos, esta actualmente en crisis. Tiende a ser reemplazada, en los contextos que lo permiten, por la conducción reticular horizontal. En las relaciones horizontales, la única jerarquía que se puede reconocer -en un ámbito académico- es la de los conocimientos logrados mediante el esfuerzo intelectual.

La horizontalidad de una red está caracterizada por una valorización individual y de conjunto que produce cada incorporación de un integrante a dicha red. Cómo 
alegoría, un fax aislado no tiene ningún valor pero cada incorporación de un nuevo fax a la red valoriza la red y al fax incorporado

Los tres ámbitos pilares del aprendizaje (teoría base, desarrollo de habilidades y formación) deberían contextualizarse para soportar y desarrollar una organización reticular que permita el aporte de cada integrante nuevo, desde el docente que dirige (le da dirección y sentido) incluyendo a los educando pasando y los adelantados.

\section{Composición de la conducción}

La conducción -jerarquizada intelectualmente- estará compuesta por un equipo relacionado reticularmente. Serán universitarios dedicado a la docencia y a la investigación asociada a la tecnología y deberían:

a) Organizar el funcionamiento del contexto propuesto.

b) Formar mediante el desarrollo de seminarios "ad-hoc" a los adelantados y supervisar el trabajo de cada uno de ellos en relación con los educandos.

c) Supervisar la labor del equipo de mantenimiento y actualización de las herramientas tecnológicas dedicadas a la actividad de producción y la formación. Los integrantes de estos equipos deberían involucrarse en el taller realizando tareas docentes, por lo menos en el nivel de adelantados.

d) Actualizarse y actualizar permanentemente los distintos soportes multisensoriales para acceder a los límites del conocimiento en la tecnología.

e) Definir la dinámica de la producción tecnológica.

\section{Evaluación del avance}

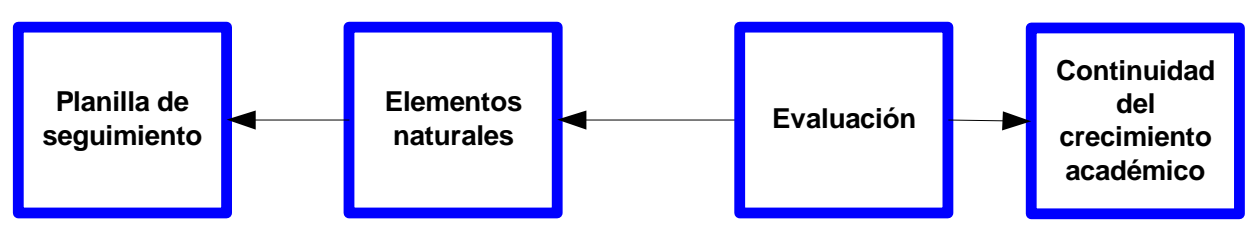

Es otro ámbito en el que se usan -demasiado frecuentemente- criterios de la era industrial como consecuencia inmediata del tipo de enseñanza masiva y no personalizada. La evaluación da lugar a una relación dominante dominado -por lo menos en el espíritu del evaluado- durante exámenes puntuales en el tiempo y el espacio. El evaluado es sometido a una presión psíquica, que limita sus posibilidades de producción intelectual y que se transformará luego en una depresión personal si la calificación del examen es menor que el esperado.

Investigadores de la Universidad del Litoral examinaron a más de cien alumnos antes y después de dar examen y constataron desórdenes inmunitarios, alteraciones del metabolismo y cardiovasculares. Además, el estrés del examen puede perjudicar la memoria. [Lipcovich, 2002]

Quienes han sorteado este tipo de exámenes ven que la preparación de los mismos muchas veces significa un resumen de la información obtenida en el proceso pedagógico. Esta centralización en lo informativo, que ha tenido validez cuando la acumulación de información estaba en el centro de la actividad académica, deja de tener sentido cuando se centra el aprendizaje en el camino plural de acceso al conocimiento planteado en esta tesis. 
Una de las reglas de la matética es: el educando está al mando de los tiempos de acceso al conocimiento [Papert, 1981], tiempos que son aquellos relacionados con su velocidad de aprehensión. Por otra parte es conveniente recurrir a formas de evaluación basadas en la producción del alumno. En este caso es necesario hablar de producciones parciales e individuales de diferente grado de dificultad que acompañen la interacción teórico - práctica y el acceso semántico al contexto de conocimiento. Esto puede complementarse con una producción final, para conservar el valor globalizante (una de las cualidades de los exámenes finales). Los reportes periódicos e individuales de dichas producciones son una pauta importante del avance del educando, denotación que se complementa con el proceso de inserción semántica del propio educando.

Nuevamente este tipo de valuación requiere mayor dedicación docente, motivo adicional para la formación de los adelantados que actúen en el control de las producciones parciales y el asentamiento de los resultados, en las planillas de seguimiento.

\section{Elementos naturales de evaluación}

Las características del contexto planteado -base teórica, taller para el desarrollo de habilidades y la formación integrar- prefiguran la existencia natural de dos elementos de evaluación continua

- La actividad productiva del educando

- Utilización precisa de la semántica asociada a la tecnología.

Los adelantados pueden ver como está localizado el alumno en la superficie de conocimiento, a través de la producción que realiza el alumno y en el uso de la semántica asociada a la tecnología en aprendizaje.

\section{Planilla de seguimiento}

Se dispondrá de una herramienta "ad hoc" que permitirá sobre la base de un conjunto de valoraciones de los docentes, establecer los puntos del itinerario óptimo que ha alcanzado cada educando. Luego sobre el mismo itinerario se podrán establecer los tiempos mínimos y máximos normales de recorrido, en función de la velocidad individual del educando.

El seguimiento se haría con una herramienta de software "ad hoc" que prevea el itinerario óptimo del educando de acuerdo a su situación inicial en la superficie de representación del conocimiento que luego mostraría el itinerario real producto de las modificaciones del itinerario, que automáticamente realizaría, en función de los errores que el educando vaya cometiendo.

\section{La continuidad del crecimiento académico}

La actividad teórico práctica planteada, se aproxima a la aplicación del método científico. Conocer una teoría, interpretar con esa teoría la práctica, descubrir a través de los errores, poder alcanzar la repetitividad de las experiencias

Al lograr conexión entre los conocimientos, habilidades y formación se habilita un paso posible siguiente: una eventual investigación conjunta (profesor, adelantados, alumnos) que permitiría pasar el límite del conocimiento actual y lograr la elaboración de conocimientos nuevos. 


\section{La formación integral}

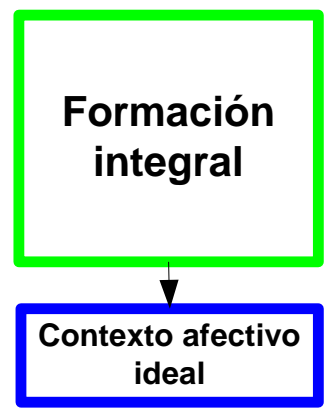

Se planteó en el capitulo II la situación de la universidad dentro del contexto de la más profunda crisis social, política y económica que conoce nuestro país. En el desarrollo de esta crisis la universidad ha estado presente sufriendo sus efectos y algo ausente -sobre todo en la década de 1990- en su análisis científico, técnico y político. Recién en los últimos años de la irrupción neoliberal, se ha planteado algún plan económico como alternativa al saqueo que ha sufrido nuestra nación en manos de gobiernos militares o civiles durante el último cuarto de siglo. Se puede atribuir esta falta de protagonismo de las instituciones universitarias a distintas causas, y probablemente una de ellas sea la falta de formación de los profesionales que habitan en sus claustros. Lo cierto es que como en otros ámbitos de la actividad nacional, la adaptación al mercado ha influido más, que la búsqueda vital de una sociedad mejor.

La universidad forma personas, forma profesionales que tienen en sus manos la vida de otras personas. Esto es muy claro en algunos sectores del saber académico, como el de la salud. Pero los profesionales recibidos en nuestras universidades tienen en sus manos la posibilidad de influir directamente o mediante la emisión de opiniones en decisiones técnico-económicas para transformar nuestro país. Durante muchos años hemos sufrido una cooptación del mercado y un estancamiento en la evolución política que estalló en diciembre de 2001

\section{Contexto afectivo ideal para la formación integral}

Una relación afectiva donde las virtudes preponderen sobre nuestros defectos, permitirá protagonizar entre los docentes, los adelantados y los alumnos, la formación universitaria del conjunto en un ámbito de producción del pensamiento donde la contextualización político social de la realidad pueda ser observada y conectada con la actividad académica. Durante el 2005 proyectamos crear ese ámbito de reflexión con los alumnos de la cátedra Tecnologías en Comunicación Social en la F.P.C.S. a efectos de poder vislumbrar y/o proponer un futuro posible, desde la universidad (completaremos con este ámbito de reflexión los ya existentes de fuentes informativas y desarrollo de habilidades. 


\section{CAPÍTULO 4}

\section{LA TECNOLOGIA DE OBJETOS Y SU APRENDIZAJE}

\section{Resumen}

Se vincula la historia de la tecnología informática con el aprendizaje de la esta tecnología. Se resume la historia del paradigma tradicional, sus virtudes y sus limitaciones; la evolución a partir de dicho paradigma en la búsqueda de soluciones a las crisis de crecimiento del software, que parecen haber encontrado en la tecnología de objetos un camino con clara dirección y sentido.

Se definen los conceptos asociados a la tecnología informática tradicional y de objetos.

Con relación al aprendizaje, se establecen las dificultades del acceso al conocimiento del paradigma de objetos que genera el desafío: la búsqueda del camino personalizado

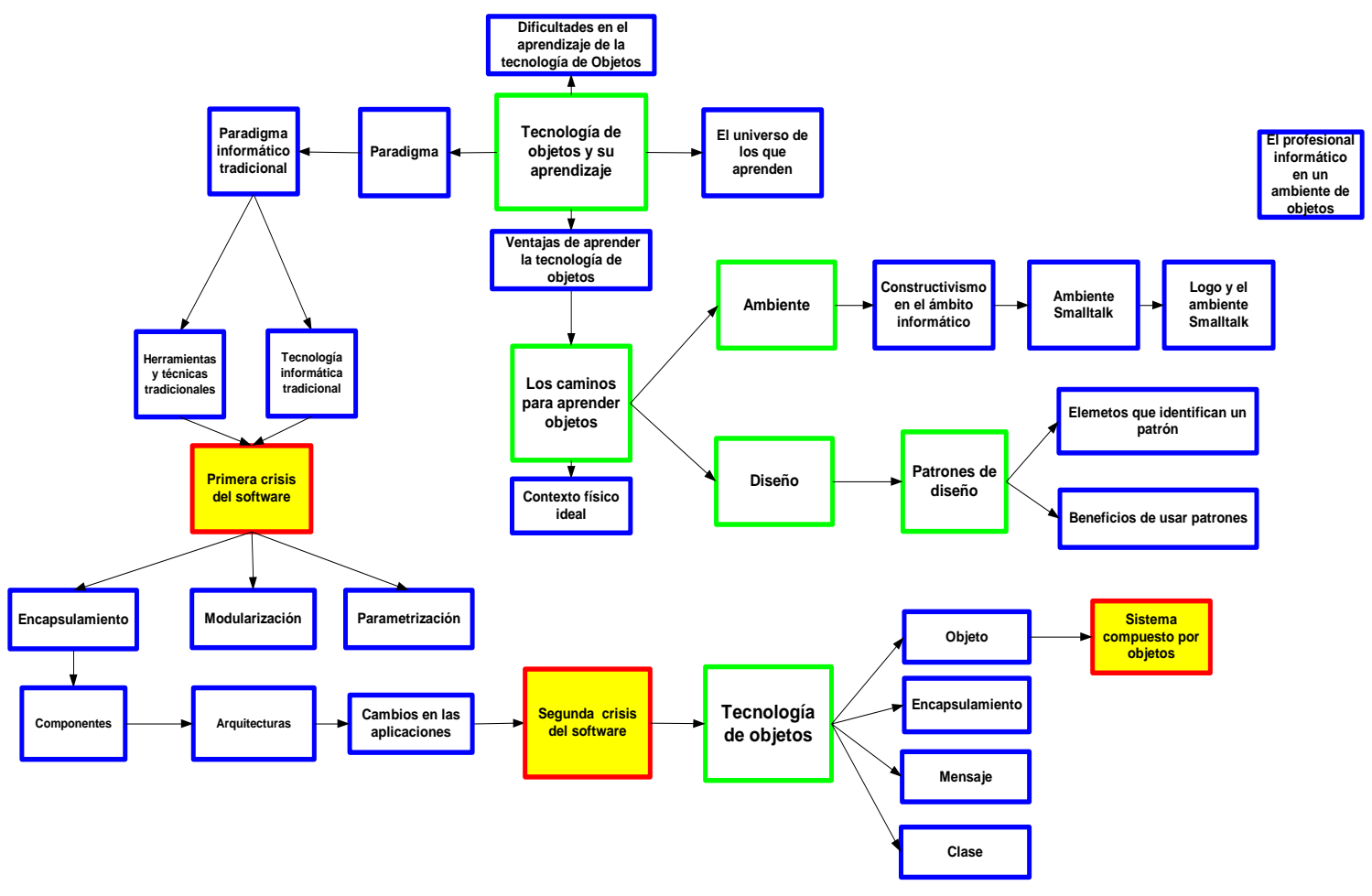




\section{Paradigma}

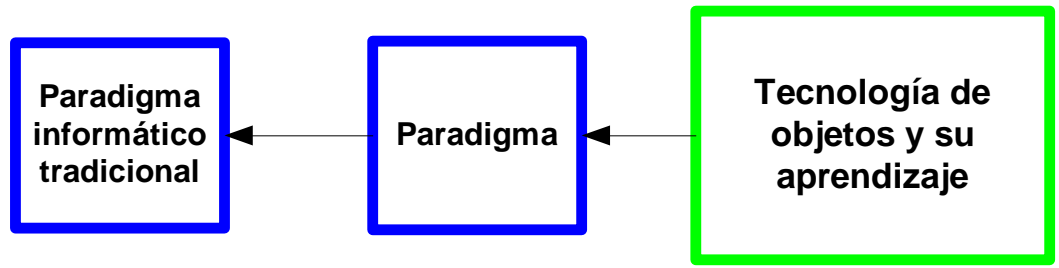

Desde el punto de vista lingüístico se denomina de este modo, al conjunto virtual de elementos de una misma clase gramatical, que pueden aparecer en un mismo contexto. Por extensión -así se usará dentro del ámbito de esta tesis- se denomina paradigma al conjunto de teorías, herramientas y técnicas que conforman el soporte de una tecnología.

\section{Paradigma informático tradicional}

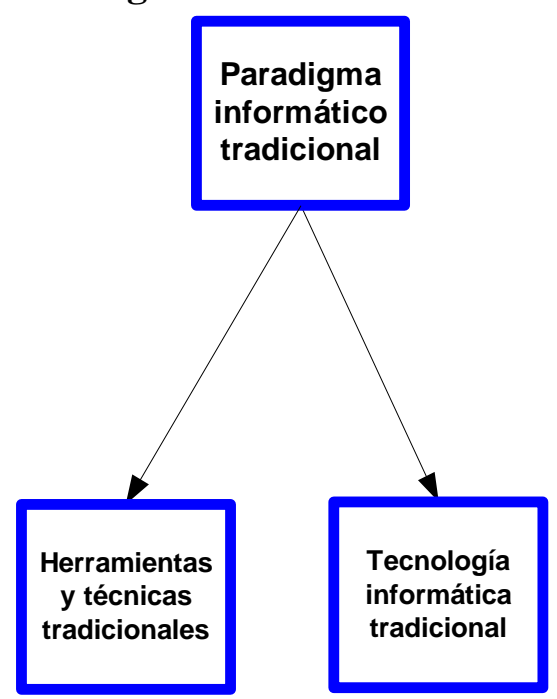

La tecnología utilizada para construir software -con anterioridad a la aparición de la tecnología de objetos- esta basada en un conjunto de elementos básicos bien conocidos actualmente, como lo son el dato y el programa. Un programa puede activarse sobre un conjunto de datos de entrada (input) para producir un conjunto de datos resultantes (output). Esta activación del programa requiere de un determinado tiempo, donde se realiza un trabajo sobre los datos. Al trabajo sobre los datos se lo denomina proceso. Este principio tan simple y elegante sirve para definir cualquier actividad (trabajo) realizada por una máquina. El mismo principio puede ser extendido al asociar varias máquinas para formar una maquina compuesta. De esta manera, acoplando maquinas y "encapsulando" en ellas tareas específicas se logra resolver problemáticas complejas.

\section{Tecnología informática tradicional}

Por tecnología tradicional se entiende aquella que utiliza los lenguajes de programación, como principal herramienta para la resolución de los problemas de informática. (El lenguaje es la herramienta que le permite a esta tecnología expresar un conocimiento). Tiene las siguientes características:

- Existen los programas que son el continente de una solución.

- El programa es activo sobre los datos

- Los datos son pasivos, tienen un contenido a nivel de información, no tienen comportamiento (es equivalente a un 
símbolo en la lingüística tradicional). Un dato cambia en su contenido pero no en su carácter semántico.

- Para escribir la parte activa -el programa- se utilizan lenguajes de programación.

- Es necesario escribir todo lo que se quiere informatizar.

\section{Herramientas y Técnicas tradicionales}

El paradigma tradicional, es simple porque se basa en el concepto de que el dato es pasivo y existe para ser manipulado por un programa durante el desarrollo de un proceso. El programa posee la inteligencia acerca de cómo manipular los datos.

Bajo este enfoque, la computadora provee un soporte para la ejecución de procesos informáticos.

La labor humana consiste en:

1. Definir los objetivos del programa y cómo lo hace.

2. Definir los datos necesarios (iniciales) para la activación del proceso.

Los datos iniciales pueden ser construidos manualmente o como resultado de la activación de otros procesos preliminares.

Para la definición de los objetivos del programa y su forma de resolución, se utiliza un lenguaje de programación. Este lenguaje de programación sirve de nexo entre la parte humana y la máquina.

Los lenguajes de programación utilizados en las últimas décadas fueron definidos para tratar de que fueran universales.

\section{Primera crisis del software}

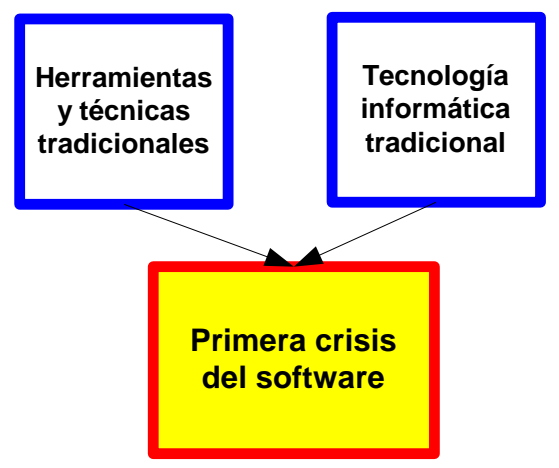

El mayor condicionamiento que sufre el paradigma tradicional es consecuencia de su punto más fuerte: la simpleza. El dato no puede "hacer" pues solo es sustrato sobre el que actúa un programa. Un programa requiere de un esfuerzo creciente a medida que se requiere de mayor cantidad de procesos en sistemas no triviales. La variedad presente en los sistemas contemporáneos -2004- revela claramente que esta estructura "simple" y tradicional no es adecuada para soportar variedad o cambios constantes.

Este paradigma tradicional alcanzó y fue necesario cuando las computadoras eran tan pequeñas que obligaban a expresar los programas en términos de las leyes básicas de la matemática y los lenguajes. Al crecer las expectativas respecto de lo que puede hacer un sistema informático, se produjo la denominada crisis del software, 
caracterizada por la insuficiencia de la mano de obra informática como para mantener todos los programas existentes.

\section{Búsqueda de paliativos a la primera crisis}

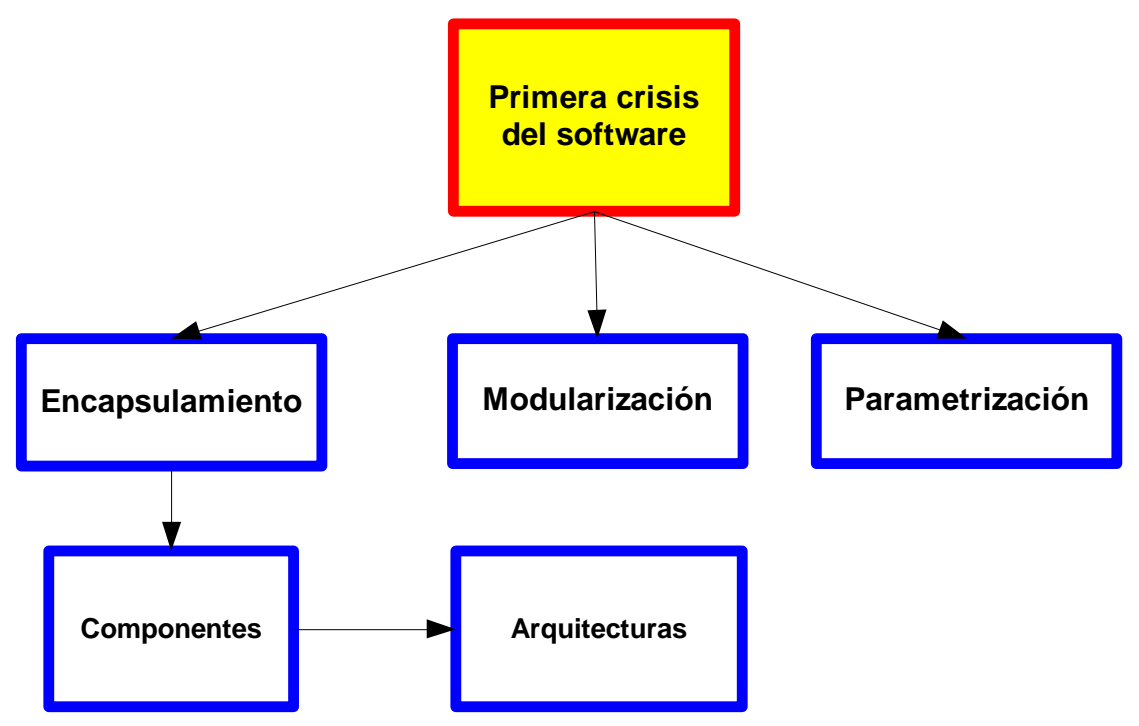

- Parametrización

La primera alternativa que se ensayo para salir de la denominada crisis del software fue la parametrización de los sistemas. Se trató de ubicar en datos externos al programa al conjunto de alternativas posibles para lograr que, durante la ejecución del proceso se determinara que política utilizar para resolver un problema. Esta técnica no alcanzó a cubrir siquiera las necesidades inmediatas.

\section{- Modularización}

Con el lenguaje Pascal en la década del '60 comenzó a definirse una alternativa a la parametrización. Esta alternativa estaba basada en encapsular comportamiento en módulos. El advenimiento de lenguajes como Modula II y Ada, en los '70, fue muy promisorio y estos lenguajes parecieron ser una solución duradera para la construcción de grandes sistemas de software. En esos lenguajes, se logró agrupar funciones aplicables a conjuntos de datos similares (estructuralmente equivalentes) y de esta manera se pudo usar estas funciones como mini-programas existentes en una librería de programas.

\section{- Encapsulamiento de comportamiento}

Los módulos generados mediante la técnica de modularización permitían encapsular un conjunto de funciones aplicables a datos equivalentes; pero los datos seguían siendo pasivos y se necesitaba un programa que los "entendiera".

\section{- Componentes}

Un componente es una pieza de software única (unicidad) que posee una interfaz (protocolo), que define su capacidad de intercambio con otra pieza de idéntica interfaz. Un componente, así definido, posee tres características fundamentales: 
Está encapsulado.

$>$ Es único.

$>$ Posee un "lenguaje" dado por su interfaz.

El encapsulamiento permite definir el componente de manera modular, pudiendo poseer componentes internamente. La unicidad permite focalizar el uso del componente, es decir, procurar un mecanismo de uso selectivo. Finalmente, la interfaz define la capacidad de dialogo que tiene el componente, es decir, como va a ser usado en el futuro. Supuestamente, esa interfaz permitiría ser la "garantía" de funcionamiento del componente, aunque es bien conocido hoy (en teoría y práctica) lo poco acertado que fue esta afirmación. En la práctica el mantenimiento de esta interfaz tiene un costo muy alto y es el mayor límite para el mantenimiento de sistemas de componentes. En realidad la interfaz solamente da una certeza sintáctica de funcionamiento, pero no garantiza de manera alguna la seguridad semántica de un sistema de componentes.

El encapsulamiento permitió plantear nuevas alternativas en las que los datos. Se logró facilitar el acceso a los datos, al ubicarlos en librerías de funciones (ligándolos estructuralmente a dichas librerías). Así fue planteado que un dato unido a su comportamiento podía ser utilizado como piedra fundamental de una obra de software.

\section{Arquitecturas}

Los componentes dieron lugar a nuevas extrapolaciones, ahora no con datos y programas, sino con esos mismos componentes representando los ladrillos con los que se construyeron la "arquitectura de un sistema informático". Correlativamente la construcción de software comenzó a aparecer como un área de la ingeniería (ingeniería de sistemas o de software).

Los resultados de aplicar componentes para construir software han sido pobres y con el pasar de los años se hizo cada vez más evidente que nuevamente se había cometido el error de extrapolar técnicas y herramientas útiles en contextos simples pensando que serían igualmente ventajosos en sistemas de otras magnitudes. $\mathrm{O}$ sea, nuevamente se cometió el mismo error que 30 años antes: suponer que un sistema grande es la suma de sistemas pequeños (componentes).

Con el pasar de los años se puede cambiar de herramientas, pero es necesario plantear si la herramienta es válida (cuando se tiene un martillo, es posible todo lo que se vea sean clavos)

Luego de medio siglo de usar lenguajes de programación y programas, se ha tratado de alterar los datos para que tengan programas asociados, pero nunca se ha planteado (masivamente) la validez del uso de un lenguaje de programación universal. [Reimondo, 2000]

\section{Cambios en las aplicaciones}




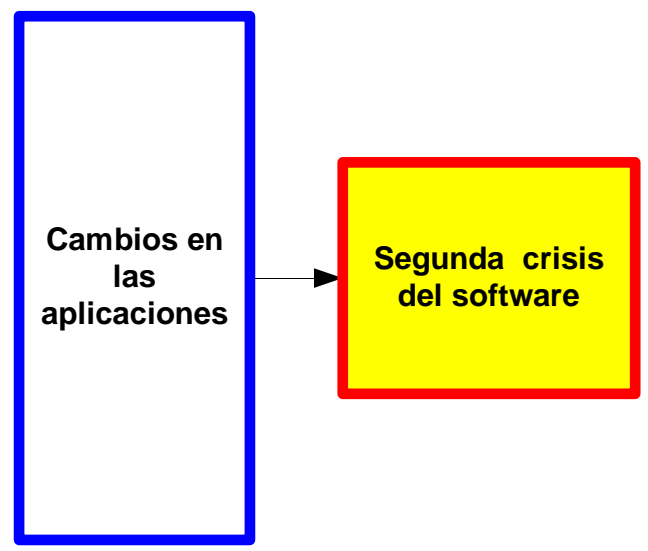

Las aplicaciones comenzaron a cambiar muy rápidamente, se comenzaron a producir hechos inesperados, se requirieron y se requieren cambios con urgencia, etc. El error del 2000 fue un buen ejemplo de desarrollar pensando en las restricciones (entre 1970 y 1980, por la restricción de memoria disponible, se manejaban los años de las fechas con dos dígitos).

El problema es que las técnicas tradicionales de desarrollo de software hacen que la fecha se vea como la representación de la fecha (independientemente de la cantidad de dígitos). Si la representación de la fecha fuera algo secundario y lo importante fuera "para que se quiere la fecha", no hubiera habido problemas. Cualquier persona que desarrolla con objetos correctamente no tiene forma de encontrarse con un problema de ese tipo (aunque se hayan usado dos dígitos, string, etc.) Si la aplicación ha sido desarrollada correctamente con TO, corregirlo es tan simple como la realización de cualquier otro cambio de implementación en una estructura de datos. Más aun, en un sistema de objetos no es necesario cambiar las fechas viejas pues pueden convivir con una nueva representación de forma transparente; no sólo se le puede enseñar a las instancias viejas que son de la clase vieja (la implementación vieja), sino que una nueva implementación toma partido y empiezan a usarse instancias nuevas sin tener que cambiar la enorme cantidad de fechas viejas que se tienen repartidas en la mayoría de los sistemas.

Quienes desarrollan software, usando el paradigma tradicional, cometen permanentemente errores semejantes a los del "2000", debido a simplificaciones durante el análisis, a especificaciones incorrectas de parte del cliente, etc.

Las técnicas anteriores a objetos, no tiene manera de resolver este fenómeno de cambio permanente del software de una manera racional.

Las aplicaciones son cada vez más complejas y hay que desarrollarlas en menos tiempo. Es imposible, en cada caso, empezar desde cero. Sin embargo eso es lo que ocurre inevitablemente, cuando se desarrolla usando variantes de la tecnología tradicional.

Lo que se necesita, es resolver estos problemas concibiendo un adecuado modelo de desarrollo de software y que además garantice algún tipo de transición razonable de los sistemas existentes. En este ultimo aspecto, el paradigma de objetos, además de revolucionar la forma en que se desarrolla software, tiene que aplicarse para adaptar los sistemas que hoy están funcionando. [Rossi, 1999] 


\section{La segunda crisis del software}

Con la popularidad de los equipos personales aparece nuevamente una crisis en informática, aunque esta vez ya no se le presta tanta atención, pues la existencia de un medio como Internet requiere de soluciones menos comprometidas con informática (y más con el área de negocios). Esta situación ha dado más tiempo para madurar las técnicas en la construcción de sistemas. Los sistemas desarrollados para su uso en Internet no son materia de las ciencias exactas, pero esa vulgarización de la informática esta permitiendo contar con más tiempo para promover cambios más profundos en los profesionales del área informática.

Un cambio paradigmático es muy profundo y requiere de mucho esfuerzo para ser adoptado globalmente, pues es un cambio tecnológico. Se le pide a las personas renunciar al uso de un conjunto de habilidades que les ha costado mucho esfuerzo alcanzar, para cambiarlas por otras en las cuales no tiene porqué creer "a priori”.

Es irreal pensar que un cambio tecnológico se puede realizar por medio de la difusión de material escrito o por transferencia horizontal. Todo cambio tecnológico requiere de la concreción de experiencias fundamentales en el área de la nueva tecnología. Es por ello que en el caso de la informática, requerirá bastante tiempo el adoptar una nueva tecnología que resuelva el problema actual.

Posiblemente la división en soporte informativo teórico, área de desarrollo de habilidades prácticas y la formación de docentes y alumnos ayuden a crear un ámbito que permeabilice el acceso a la tecnología que en las últimas décadas muestra claramente la dirección más prometedora: la Tecnología de Objetos.

\section{Tecnología de objetos}

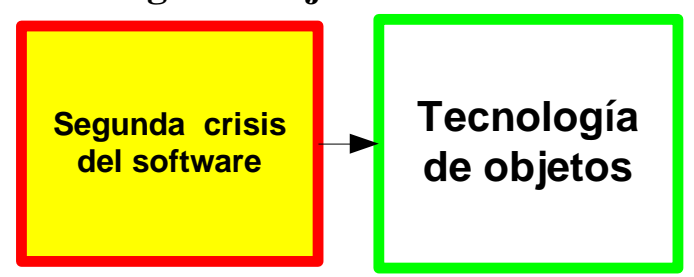

La tecnología para el desarrollo de sistemas de información con objetos, parte del principio paradigmático que asevera que toda unidad informática se caracteriza por ser única y acotada, esta unidad se denomina "objeto informático". Esta unicidad permite tratar a cada objeto informático con un carácter único en el espacio que lo contiene.

Los límites que tiene un objeto informático admite analogías con los objetos reales (físicos); y gracias a esto permite el uso de herramientas de conceptualización básicas como la focalización, manipulación, introspección e incluso reflexión.

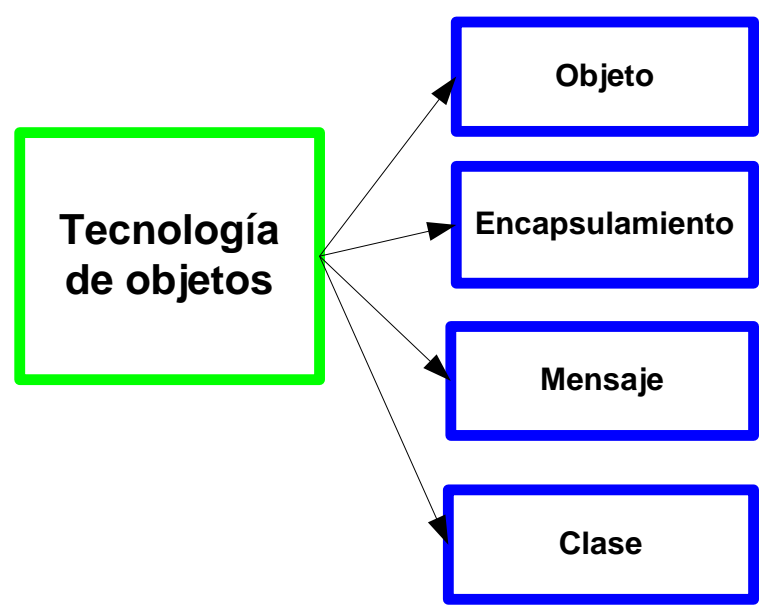




\section{Objeto}

Es un elemento de software único, capaz de asumir la responsabilidad de resolver una problemática, entendiendo y resolviendo los mensajes que recibe, lo que permite atribuirle un comportamiento (concepto central en la Tecnología de Objetos). Ese comportamiento está expresado por el conjunto de métodos que el objeto es capaz de ejecutar al responder a los mensajes.

\section{Mensaje}

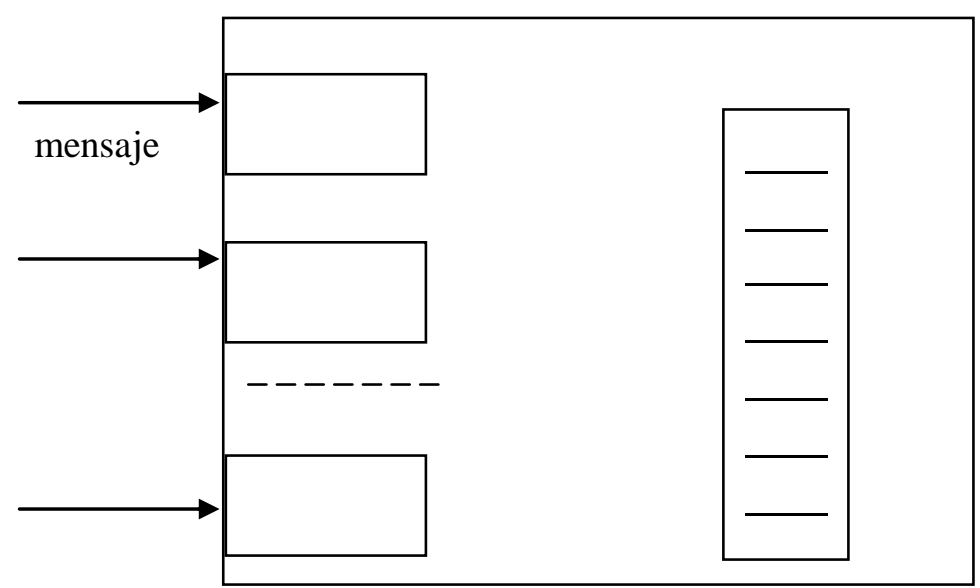

Un mensaje se le manda a un objeto para pedirle que haga algo, que ejecute una operación. Está en la naturaleza del objeto que recibe el mensaje la reacción que pueda desencadenar el envío de dicho mensaje.

\section{Interfaz de un objeto}

Se denomina interfaz de un objeto al conjunto de mensajes que un objeto puede cumplir (o conjunto de operaciones que puede realizar). En un momento dado de la vida del sistema, un objeto tiene una interfaz que lo caracteriza.

\section{Clase}

Es el molde que permite crear objetos (objetos de esa clase). Contiene la definición simplificada de las características comunes de un conjunto de objetos semejantes, o sea que comparten el mismo comportamiento y estado interno.

Se especifica en la clase:

a) el comportamiento mediante la descripción de las operaciones que un objeto instancia de esa clase puede desempeñar mediante los métodos de instancia). El comportamiento de un objeto depende de su clase y esta al ser un objeto más, puede cambiar mientras el sistema esta en funcionamiento.

b) el estado interno mediante las variables de instancia (que apuntan a distinto tipo de objetos) donde las instancias de la Clase, guardan su información.

\section{Sistema compuesto por objetos}

Un Sistema en Tecnología de Objetos es una red de objetos cooperantes (que en aplicaciones reales pueden ser decenas de miles) que interactúan entre sí (eso es la cooperación) enviándose mensajes (comunicándose entre ellos). Esta interacción provoca un cambio continuo en el estado del sistema. 


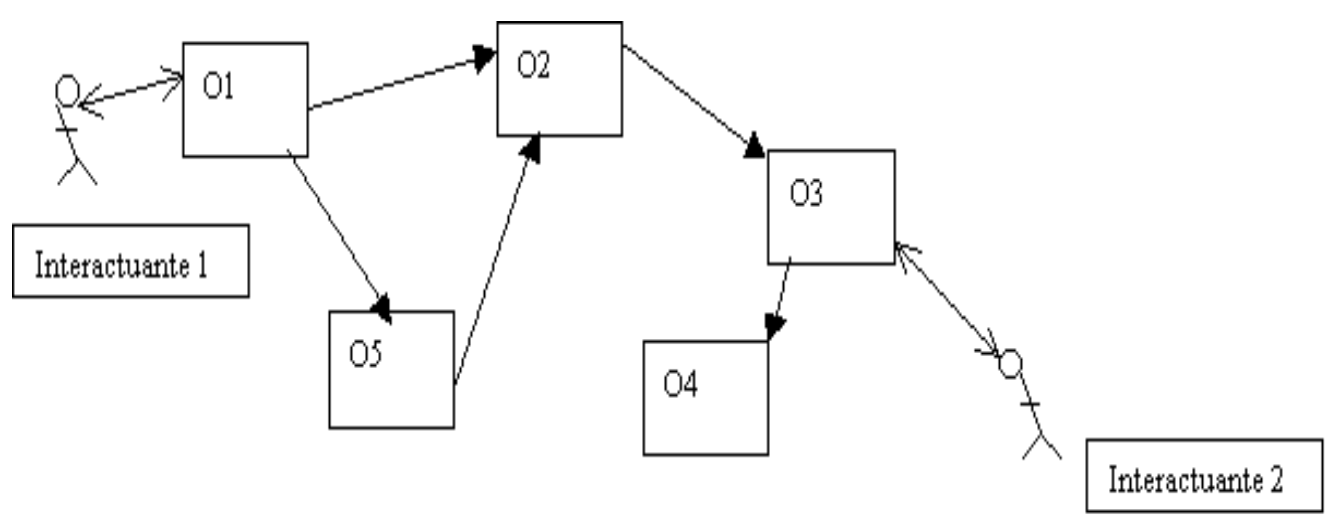

La comunicación entre objetos se realiza por medio de diálogos formulados mediante el envío de mensajes en el lenguaje definido por los objetos que intervienen en este intercambio. Un sistema de objetos es entonces un conjunto de objetos que se relacionan generando un ambiente estable, el cual realiza un trabajo (producto de la naturaleza de los objetos contenidos). El comportamiento es también un objeto, permitiendo la denominada meta-programación (programación de la programación) y reflexión del sistema en sí mismo. Es decir, un sistema de objetos puede desarrollar o absorber (en su funcionamiento) nuevo comportamiento expresado por un operador humano o por un objeto cualquiera del sistema. De otro modo, en los sistemas de objetos es posible que un objeto aprenda nuevos comportamientos según sus experiencias. El desarrollo de un sistema es un caso en particular donde el comportamiento es aportado por agentes humanos.

En un sistema de objetos existen por lo menos, las mismas garantías que en un sistema tradicional, pero además es posible prepararlo para los cambios pudiendo evolucionar mientras el sistema esta funcionando. [Rossi, 1999]

\section{Ejemplo que permite apreciar la diferencia entre los dos paradigmas informáticos}

Supongamos que se pretende cambiar el código postal de cuatro dígitos en una aplicación, para acomodar un código alfanumérico. Con tecnología tradicional aparecen tres de fuentes de ineficacia evidentes:

a) Un cambio único (modificación del código postal) tiene que ser reprogramado en dos de ubicaciones (estructura de base de datos y el código del procedimiento). Sería mejor que los datos estuvieran estrechamente conectados con el código que realiza el cambio

b) Dado que es muy probable que varios procedimientos manejen códigos postales, por ejemplo en la rutina de validación del código, habrá que expandir el cambio a esos procedimientos. En un sistema ideal todos estos cambios se tendrían que producir simultáneamente.

c) Aunque solo la porción de procedimiento que pertenece al código postal es afectado por el cambio, el procedimiento entero y sus conexiones con el resto del sistema, tiene que ser examinado por el programador y debe ser recompilado.

Seguramente quienes primero pensaron en la tecnología de objetos vieron que tendría que haber una manera para aislar los cambios más inteligentemente. 
En un el lenguaje de programación ideal, cada campo en la base de datos sería una entidad separada a los efectos de cambiar sus atributos. Cada parte de una la rutina en un programa debería ser una entidad separada a efectos de mantener el código. Tendríamos un conjunto de elementos atómicos de datos y un conjunto de procedimientos atómicos.

Los procedimientos se agrupan muy naturalmente alrededor los datos. Entonces el procedimiento para validar un código postal es algo que únicamente necesita saber el objeto código postal. Entonces se puede construir cada objeto dato con la "inteligencia" suficiente como para realizar operaciones útiles únicamente para él, sin aislarlo de estos procedimientos.

Esta simple estrategia de hacer "inteligente" al dato es el corazón del ambiente Smalltalk. Una aplicación no es más un conjunto de procedimientos que trabajan sobre las bases de datos sino un conjunto de objetos que cooperan entre sí con rutinas incorporadas a ellos denominadas "métodos". El lenguaje resulta orientado a un objeto y no orientado a un procedimiento.

Además, como en Smalltalk las variables no son tipadas no se requiere que los programas cambien si, por ejemplo, es necesario cambiar un número por una "string".

En conclusión, para cambiar la definición de un código postal en Smalltalk, todo lo que se necesita hacer es cambiar el método de validación del código postal del objeto código postal. Cuando otro objeto, tal como el objeto cliente, necesita saber si un el código postal es válido, pasa el valor propuesto al objeto código postal, que usa sus mecanismos incorporados -método de validación- para hacer la prueba.

\section{Aprendizaje de la tecnología de objetos}

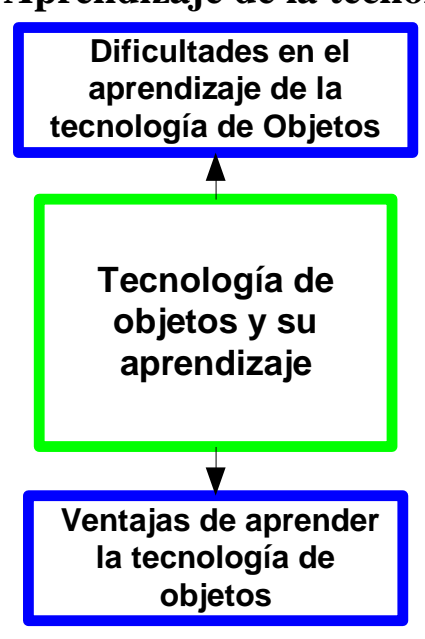

\section{Dificultades en el aprendizaje de la tecnología de Objetos}

Aprender la tecnología de objetos requiere un esfuerzo intelectual importante, realizable por cualquier persona, que impulsada por el interés o la necesidad de aprender pueda dedicar el tiempo -personal- que demanda el acceso a este conocimiento. Este tiempo personal está vinculado con el perfil personal del aprendizaje -cuestión importante en esta tesis- es decir las características personales de quien pretende acceder a una tecnología determinada.

Aunque la promesa de los objetos es atractiva, aquellos profesionales de la informática que han recorrido el camino del desarrollo de sistemas sobre la huella de otros paradigmas, sienten una humana resistencia al cambio. El dominio de dichas 
técnicas pretéritas les ha demandado mucho tiempo de capacitación. Entonces, a los requerimientos para aprender cualquier tecnología, se suma las emociones contradictorias que supone transitar caminos del conocimiento asociados a un nuevo paradigma.

Cuando se comienza a estudiar la TO es casi inevitable la referencia a la tecnología tradicional, referencia que puede agregar un elemento más de confusión. En este sentido la posibilidad es, conectar la tecnología tradicional -en su característica procedural- con la estructura de los métodos, cuyo contenido es semejante al de un "procedimiento".

Inmediatamente y como nexo entre lo viejo y lo nuevo debe recordarse que conceptual y funcionalmente, se debe considerar la "programación" de los métodos como una red de objetos cooperantes. De otro modo, para facilitar los primeros encuentros con el paradigma de objetos, quienes provienen de la programación tradicional, pueden, en área del desarrollo de habilidades, concretar pequeñas aplicaciones semejantes al esquema procedural, realizadas directamente en un espacio de trabajo de Smalltalk. Desde el punto de vista teórico será necesario remarcar que se trabaja con un conjunto de objetos cooperantes, no existiendo instrucciones sino objetos a los cuales se les están mandando mensajes que saben resolver.

\section{Ventajas de aprender la tecnología de objetos}

A las característica evolutiva ya mencionada, se puede resaltar la posibilidad de un sistema de objeto se construye coherentemente con el sistema real. Esto permite que los emergentes reales (aquellas cuestiones no previstas) tengan un paralelo en el sistema virtual. Esto sólo se logra usando objetos, permitiendo superar muchas de las trabas que la tecnología pretérita imponía a los desarrolladores.

Asimismo se desarrolla verdadera ingeniería de software a través del conocimiento acumulado en los patrones de diseño. Por último es posible lograr una documentación automáticamente actualizada a través de los patrones de implementación.

Al comienzo de la década de los '90, aparece con fuerza el paradigma de objetos en la comunidad internacional; muchos pronostican que será el paradigma de escala para el desarrollo futuro de software.

El lenguaje Java, junto al uso de Internet ha producido en los '90, un movimiento económico sin precedentes, ha popularizado la terminología de objetos. La aparición de Java trae aparejado la comprensión por parte de la comunidad de desarrolladores de software que la plataforma Internet es una plataforma de desarrollo plausible, a punto tal que en buena parte de la industria, por la presión corporativa de las empresas Sun, Oracle e IBM (javistas), y de Microsoft como contrapresión, existe una tendencia a hacer reingeniería para pasar a Intranet, o de buscar que las aplicaciones corran con interfaz semejante a la de los productos de Internet. Buena parte de esa presión tiene que ver con que Java tiende a ser una buena plataforma de desarrollo para producir aplicaciones Intranet. Erróneamente, puede suceder se crea que al estar programando en Java, se está aprendiendo objetos.

Uno de los efectos negativos del súbito interés de buena parte de la industria por la TO es el convencimiento de gran cantidad de profesionales en el sentido de que aprender objetos es aprender una notación. La notación estándar Unified Modeling Lenguage (UML) es probablemente la más utilizada. Pero usar esa notación y creer que se conoce la tecnología TO es equivalente a decir que para aprender a diseñar bases de datos hay que aprender la graficación del diagrama Entidad/Relación. Aprender la 
notación es solo una parte, lo más importante es aprender a usarla correctamente. Como UML es notablemente amplia, cuesta aprenderla y se cree que si se sabe ya se conoce la tecnología de objetos; UML como cualquier otra estrategia para acceder tecnología de objetos es útil si se aprende integralmente el paradigma de la tecnología de objetos.

La realidad intelectual es que desde fines de los ' 80 no se publica nada con tecnología anterior a objetos. No hay metodologista en el mundo que pueda ayudar a alguien que quiera hacer una aplicación interactiva -por ejemplo- en Internet- usando técnicas estructuradas. Todos los metodologistas que trabajaban con técnicas estructuradas migraron a objetos a principio de los '90. [Rossi, 1999]

\section{Los caminos para aprender tecnología de objetos}

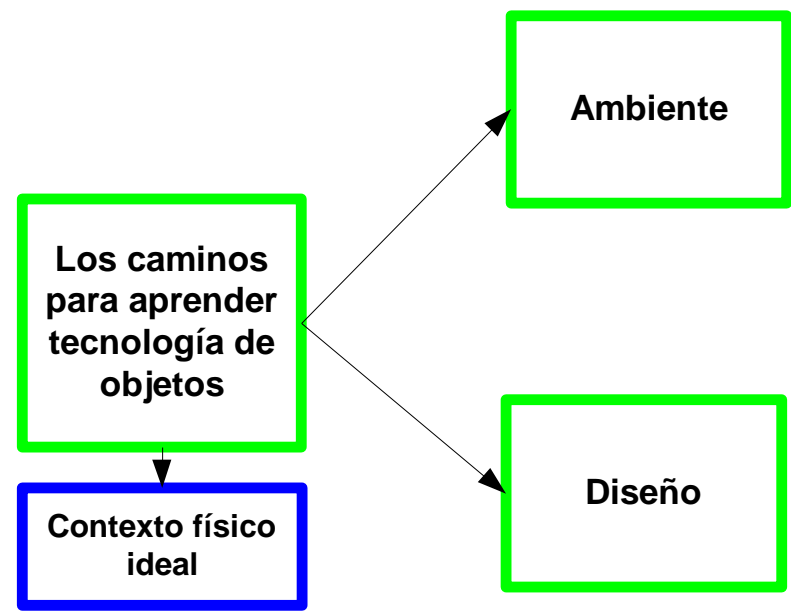

Se ha planteado en los capítulos anteriores los criterios generales para el aprendizaje de tecnologías de base científica. Se trata aquí de lograr que los conceptos allí planteados sean soporte y base para el aprendizaje de la tecnología de objetos. Se puede agregar que el eje tecnológico del aprendizaje de la tecnología de objetos es aprender técnicas que permiten la acumulación de software que funciona y que pueden aplicarse a los sistemas de información evolutivos en general.

Del conjunto de caminos posibles y simultáneos propuestos por esta tesis, dos son soportes principales (generando criterios de acceso al conocimiento que esta tesis reconoce como complementarios pero cuya complementariedad no ha dado lugar aún a una práctica claramente establecida). Estos dos caminos toman como preponderantes los caminos del

- Ambiente de objetos

- Diseño

\section{Ambiente de objetos (un camino)}

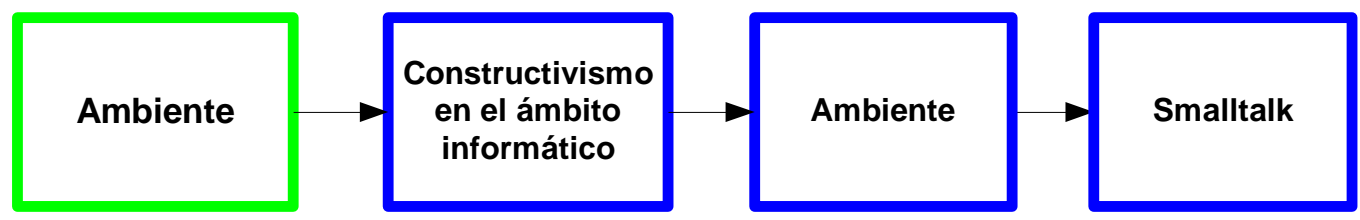




\section{Constructivismo en el dominio informático}

El aprendizaje mediante el uso exclusivo de la prueba y error resulta, en cualquier ámbito del conocimiento, muy difícil. Respecto de la tecnología de objetos, tal forma de acceso al conocimiento es imposible.

En el estado pretérito de avance de la informática, con lenguajes procedurales de pequeña cantidad de instrucciones, fue posible desarrollar habilidades adecuadas al desarrollo informático vigente mediante la asistencia de tutoriales e interactuando con una computadora.

El grado de complejidad para el dominio del arte y técnica de construir sistemas con tecnología de objetos usando el extenso ambiente Smalltalk, define una imposibilidad real de colocar al educando frente a una computadora pretendiendo lograr un aprendizaje interactivo, mucho menos en el estado actual de "inteligencia" de las computadoras. Se analiza a continuación el ambiente, particularizando en Smalltalk.

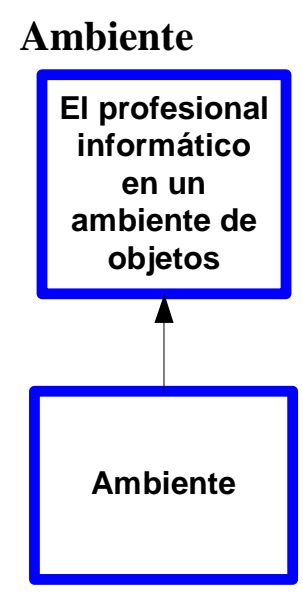

El conjunto de objetos informáticos define un espacio informático denominado "ambiente de Objetos", que sirve de soporte a cualquier conjunto de nuevos objetos informáticos que compongan un sistema. Un ambiente de objetos define los límites accesibles a los objetos que contiene. Uno o más sistemas informáticos pueden estar contenidos en un ambiente de objetos.

La existencia de este ambiente hace innecesario empezar a construir cada sistema desde cero. Normalmente se parte de un Ambiente de Objetos existente y se construyen dentro del mismo, otros objetos que resuelven la problemática del sistema informático específico de un dominio.

Los límites de un Ambiente de Objetos vienen dados por la capacidad de actuar que tienen los objetos contenidos en este. A los objetos informáticos que no tienen representación real se los denomina objetos virtuales (o virtualizados). La Tecnología de Objetos es el conjunto de herramientas y técnicas que permiten trabajar sobre objetos contenidos en un Ambiente.

En el paradigma de objetos, no es necesario el concepto de programa, pues cada objeto tiene una razón de ser para el ambiente que lo contiene y su comportamiento viene dado por su naturaleza.

En el trabajo en ambiente de objetos la tarea de construcción de sistemas esta gobernada por técnicas de carácter evolutivo. La concreción de un sistema de información es el resultado de una evolución del ambiente hasta alcanzar el grado de satisfacción y estabilidad necesario. [Reimondo, 2000] 
En el paradigma de objetos, se define solo lo que es un objeto. Esto parece dejar de lado la inteligencia (que antes era cubierta por el "programa"), aunque si se reflexiona un poco se ve que la "inteligencia de un sistema" es parte de su esencia y no debe estar fuera de este, sino más bien es su sustento. En la Tecnología de Objetos, el comportamiento de un objeto es también un objeto. Es decir, si un objeto sabe comportarse de una manera, es porque posee en su naturaleza ese conocimiento. Este conocimiento también es un objeto y puede ser compartido, por ejemplo, por objetos de la misma especie.

Esta facilidad de permitir la manipulación de la inteligencia (comportamiento) de un sistema por el sistema mismo permite construir sistemas evolutivos y que crecen por interacción constante con entrenadores humanos.

\section{El profesional informático en un ambiente de objetos}

El profesional informático en un ambiente de objetos tiene un rol nuevo. No es la definición de las tareas (o rutinas) de un sistema, sino que es una tarea más constructiva (construcción de objetos) y centrada en la manipulación y evolución del sistema en sí mismo, expresado en el lenguaje del sistema y no en un lenguaje "universal". El profesional informático se encuentra trabajando en el sistema (ya no solo es alguien que define un sistema y lo traduce al lenguaje de programación).

\section{Smalltalk}

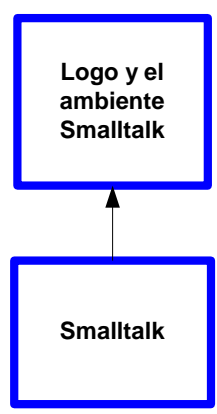

El ambiente de objetos de uso comercial más utilizado se denomina Smalltalk. El primer Smalltalk fue construido entre los años 1972 y 1976, desde entonces, este ambiente viene evolucionando hasta nuestros días, funcionando sobre distintos soportes de hardware y sistemas operativos.

Esta evolución ha permitido la maduración de objetos y herramientas para permitir construir sistemas de información evolutivos, que permitan cambios de comportamiento a bajo costo.

Se necesita algo más que un Ambiente de objetos para la buena construcción de un sistema informático. Es necesario el desarrollo de la experticia en el uso de las nuevas herramientas y en la creación de sistemas evolutivos (que evolucionan a partir del ambiente). Esta es una de las razones por las que no se utiliza Smalltalk masivamente, pues requiere de un aprendizaje basado en la adquisición de experiencia en la nueva tecnología. No basta aprender una sintaxis o el uso de las opciones de los menús de una herramienta. 


\section{Lenguaje Logo y ambiente Smalltalk}

El acceso a la desarrollo en el ambiente Smalltalk implica un salto conceptual demasiado grande tanto para las personas del área de sistemas que ya programan proceduralmente como aquellos que se inician en la tarea de codificar.

Durante la década del ' 80 he trabajado en la enseñanza y aplicación del lenguaje informático Logo que tiene un escalón de acceso pequeño, uno de los motivos que hicieron atractivo para que muchas personas pudieran comenzar a trabajar con él, en su introducción a la actividad computacional. El programa ejecutable que permite realizar esta actividad queda oculto para la persona que comienza a trabajar con Logo.

Contrariamente a lo que sucede en Logo, el ambiente Smalltalk aparece en toda su enorme extensión en cuanto se consulta el conjunto de clases construidas en los últimos 30 años.

Esta tesis pretende traducir las características de acceso del lenguaje Logo en el ambiente Smalltalk como soporte de implementación de la tecnología de objetos, teniendo en cuenta la diferente magnitud de problema. El conjunto de caminos a recorrer -que esta tesis propone- resulta una posibilidad para aquellos que comienzan su actividad informática a través de la tecnología de orientación a objetos y Smalltalk.

\section{Diseño (un camino)}

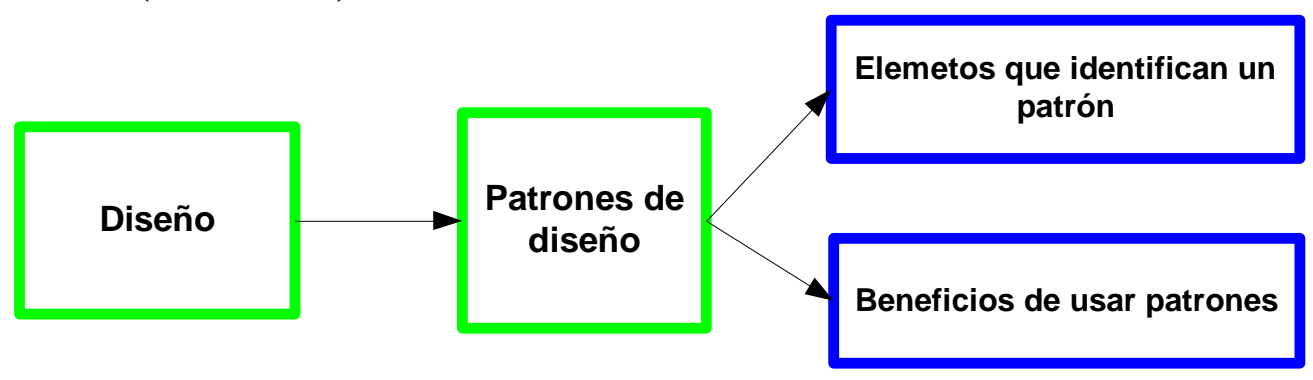

Durante el diseño se definen

- Las clases iniciales o clases del problema

- La relación entre las clases

- Conocimiento entre los objetos que las clases generarán

- Interacciones entre los objetos

Para el diseño del sistema se parte de la especificación de requerimientos y en base a la misma se pueden construir

- Casos de uso.

- Se establecen el o los diagramas de secuencia que incluyan los casos alternativos

- Definir las clases que instanciarán a los objetos encontrados.

- Relacionar las clases.

- Agregarle a las clases atributos y operaciones (básicamente los mensajes que los objetos de esas clases pueden recibir)

- Establecer la lista de responsabilidades de cada clase y las colaboraciones

- Definido el diagrama de clases se itera con el diagrama de secuencia hasta conseguir el diseño inicial.

[Thompson, 2003] 


\section{Patrones de diseño}

Un patrón de diseño es una descripción de objetos comunicantes y clases personalizadas para resolver un problema de diseño que aparece una y otra vez, en un contexto determinado.

Los patrones de diseño no se refieren a la forma en que codifica ni tampoco hacen referencia diseños de dominios específicos.

Un patrón de diseño identifica los aspectos claves de la estructura de un diseño permitiendo que sea más sencillo diseñar software orientado a objetos reutilizable. Básicamente identifica las clases e instancias participantes, sus roles, colaboraciones y responsabilidades.

\section{Elementos que identifican un patrón}

Los elementos más importantes que identifican un patrón son:

- Nombre: identifica en una o dos palabras el problema de diseño, su solución y consecuencias.

- Problema que resuelve: describe cuando aplicar el patrón, explica el problema y su contexto.

- Solución: describe los elementos que componen el diseño, sus relaciones, responsabilidades y colaboraciones. La solución no describe un diseño o implementación particular ya que un patrón puede ser aplicado en muchas situaciones diferentes.

- Consecuencias: son los resultados y compromisos provenientes de la aplicación del patrón. Son importantes para evaluar alternativas de diseño y para conocer los costos y beneficios de aplicar el patrón.

\section{Beneficios}

El conocimiento de los patrones afecta la manera en que se diseña software orientado a objetos basado en la experiencia obtenido al trabajar con los mismos. Podemos decir que entre los beneficios encontramos:

- Se obtiene un vocabulario de diseño común, útil para que los diseñadores puedan comunicarse con otros, para documentar y explorar alternativas de diseño.

- Ayudan a documentar y aprender al mismo tiempo, haciendo más sencillo entender sistemas orientados a objetos existentes.

- Representan una alternativa adicional para trabajar junto con los métodos existentes promoviendo mejores diseños y estandarizando la manera en que los diseños son desarrollados.

- Simplifican la refactorización ayudando a determinar como reorganiza un diseño, reduciendo la cantidad refactorización posterior.

- Ayudan a difundir la reutilización de las arquitecturas de software y facilitan el diseño a nivel arquitectura. 


\section{Comparación con otro cambio de paradigma informático}

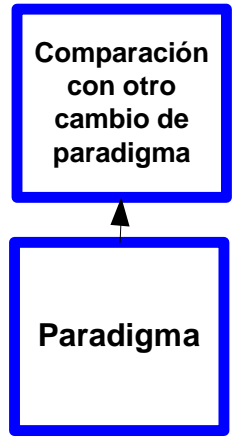

Es interesante comparar el fenómeno de la transición al paradigma de objetos con otro fenómeno de cambio tecnológico: el pasaje del uso de archivos secuenciales a bases de datos relacionales. Actualmente nadie hace seriamente un desarrollo de una base de datos sin usar el modelo relacional. Sin embargo la transición de archivos secuenciales a bases de datos relacionales -cuyo origen tuvo lugar en la década del '60terminó siendo muy lenta. Más aún, en nuestro país la transición se completó con poca profundización conceptual de los especialistas de la industria. (Se construyen todavía muchas tablas de pocos atributos o pocas tablas de demasiados atributos). [Rossi, 1999]

El acceso a los conocimientos necesarios para bases de datos relacionales y modelado Entidad/Relación no requiere demasiado esfuerzo. Con objetos pasa algo semejante, pero aprender objetos es más difícil, es necesario aprender de otra manera, requiere un esfuerzo intelectual importante. Fundamentalmente diseñar con objetos es muy diferente a diseñar de cualquier otra manera.

\section{Uso y Re-uso}

Los componentes permitieron su uso varias veces sin modificación. El re-uso es el resultado de tomar una cosa, refinarla y luego usar el resultado de ese refinamiento.

En los Ambientes de Objetos es común tomar una clase y, a partir de la misma obtener una nueva refinándola, de manera tal que pueda instanciarse en objetos más aptos para un domino dado (etapa básica de la evolución)

\section{Precisión semántica}

En el campo del diseño los patrones han logrado la solución de problemas que se presentan una y otra vez; en el campo de la implementación el ambiente Smalltalk presenta desde hace 30 años un software estable y evolutivo, algo inédito hasta que se creó dicho ambiente.

Entonces, el problema de la precisión semántica que aparece en el desarrollo de la ingeniería de software, y que se manifiesta con mayor fuerza en el área de aprendizaje puede resolverse con un acceso continuo un lenguaje normalizado y común en cierto espacio y tiempo. Para lograr ese acuerdo en el uso del lenguaje se pueden articular los términos de la tecnología de objetos como una red terminológica. 


\section{El universo de los que aprenden}

Existen, por lo menos dos poblaciones: quienes ya han programado tradicionalmente y quienes recién comienzan a programar. Para ambos casos es necesario que el acceso a Smalltalk represente un salto conceptual posible (lo suficientemente pequeño como para que pueda efectuarlo cualquier educando).

Para aquellos que han programado en algún lenguaje procedural es conveniente reconocer a Smalltalk como un repertorio de código estable, que respeta los principios del paradigma de objetos. Un análisis un poco más profundo permite ver que un método, necesita para su ejecución, el servicio de otros objetos cooperantes. Debido al estado de transición actual -para este conjunto que se ha formado en el paradigma tradicional- resulta casi inevitable la referencia al paradigma procedural

Para los que recién ingresan en el área de los desarrollos informáticos, los ejemplos de complejidad creciente, pueden ser la forma más conveniente de acceder al paradigma y a la tecnología de orientación a objetos.

En la mayoría de la literatura sobre programación con objetos se enfatiza en las diferencias que tiene esa programación con la tradicional. Ciertamente es diferente en muchos aspectos. Trabajar con objetos implica una nueva forma de pensar.

En un lenguaje convencional de programación un procedimiento realiza múltiples operaciones y maneja varios ítems de datos. Por ejemplo, cuando un cliente registra un depósito en un sistema de ahorro, ejecuta un comando, que invoca un procedimiento para que valide varios campos de información en el registro del cliente.

En relación al segundo conjunto de estudiantes (aquellos que ingresan al conocimiento informático a través de la tecnología de orientación al objetos), es una carga muy pesada conocer usos semánticos no normalizado aun, o sea acceder a un grupo de términos completamente nuevos. Para aliviar este esfuerzo, se puede utilizar la red terminológica de la tecnología de objetos (acercamiento hipertextual a la red teórica de Hempel) y seguir los siguientes patrones de enseñanza y aprendizaje.

a) Objetivos: el docente debe tener objetivos y explicarlos. Si se desea motivar a los estudiantes, los objetivos de la actividad serán precisos y clara la explicación de como se alcanzan. Asimismo debe abandonarse cualquier acción que no contribuya a alcanzar esos objetivos. El educando entenderá la razón de esos objetivos y podrá probar y probarse que los ha alcanzado.

b) Estructurar la actividad: presentando los sub-tópicos comenzando con lo más simple y se avanzando hacia lo más complejo. Contraejemplo de la aplicación este patrón sería intentar "estudiar" el amplísimo código contenido en el ambiente Smalltalk.

c) Concretar antes de abstraer: dar siempre ejemplos antes que reglas, realidad antes de los modelos. Así, por ejemplo, es imposible factorizar dos métodos si antes no se han escrito y probado cada uno de ellos.

d) Conectar lo nuevo con algo conocido por el alumno: antes de usar una expresión, primero explicarla, por ejemplo: la herencia biológica como antecedente de la herencia de clases. Explicar claramente el léxico de la tecnología de orientación a objetos, con claras traducciones cuando se trate de términos en inglés u otro idioma, por más habitual que sea su uso entre los expertos

e) El desafío de encontrar un modo sintótico de conocer los objetos o sea conocer a los objetos como conoce a una persona, [Papert 1981], puede resolverse gracias a la visión antropomórfica de los objetos en el uso de los expertos, cuyos límites temporales y conceptuales de uso, en general no están bien 
definidos, y que deberán establecerse hábilmente por el educador a cargo del taller (encontrando los límites de la alegoría).

\section{El código, los patrones de implementación y la documentación}

En el caso particular de desarrollos informáticos, los docentes, constructores y lectores de software poseen un lenguaje acotado de uso común que es el código. La sintaxis y gramática de ese código también puede -en el caso de la tecnología de objetosexpresarse mediante un lenguaje de patrones de codificación, resultando una posibilidad real de tener una documentación permanentemente actualizada: el mismo código

\section{Contexto físico ideal}

La propuesta del contexto físico ideal -en lo que a equipamiento se refiere- es dinámica pues va cambiando con la evolución tecnológica y está relacionado con el estado actual de dicha evolución. Actualmente podría plantearse un taller dedicado exclusivamente a esta actividad y provisto de computadoras de última generación, con un soporte de software de base confiable, con acceso a la red local e Internet, con todos los accesorios actualmente disponibles para mejorar la interacción sensorial entre el educando y los objetos de aprendizaje (por ejemplo con robots-objetos a los cuales se les pueda enviar mensajes de cumplimiento físico).

Se dispondría herramientas (programas) que permitan seguir en forma multimedia y rastreable todo el desarrollo del software desde el análisis mediante los casos de uso hasta su implementación en código Smalltalk, desde los objetos del problema hasta los objetos de la solución. 


\section{CAPITULO 5 \\ APLICACIÓN DE LA FORMACIÓN PERSONALIZADA EN UN ÁMBITO APRENDIZAJE REAL}

\section{Resumen}

Se vincula los capítulos anteriores con los intentos de concreción en el aprendizaje de la tecnología de objetos.

Presenta una versión concreta de la superficie de conocimiento, en forma de una planilla "ad hoc"

Propone la posibilidad de una cursada extendida que atenúe los efectos de los límites temporales y espaciales del acceso al conocimiento.

Describe un contexto real actual -del que participa el autor-para la aplicación de las ideas centrales de esta tesis en ámbitos universitarios.

Queda para futuras experiencias del autor y otros que puedan aplicar los conceptos planteados en esta tesis llevar la actividad lo más cerca del nivel ideal planteado en el capitulo 4.

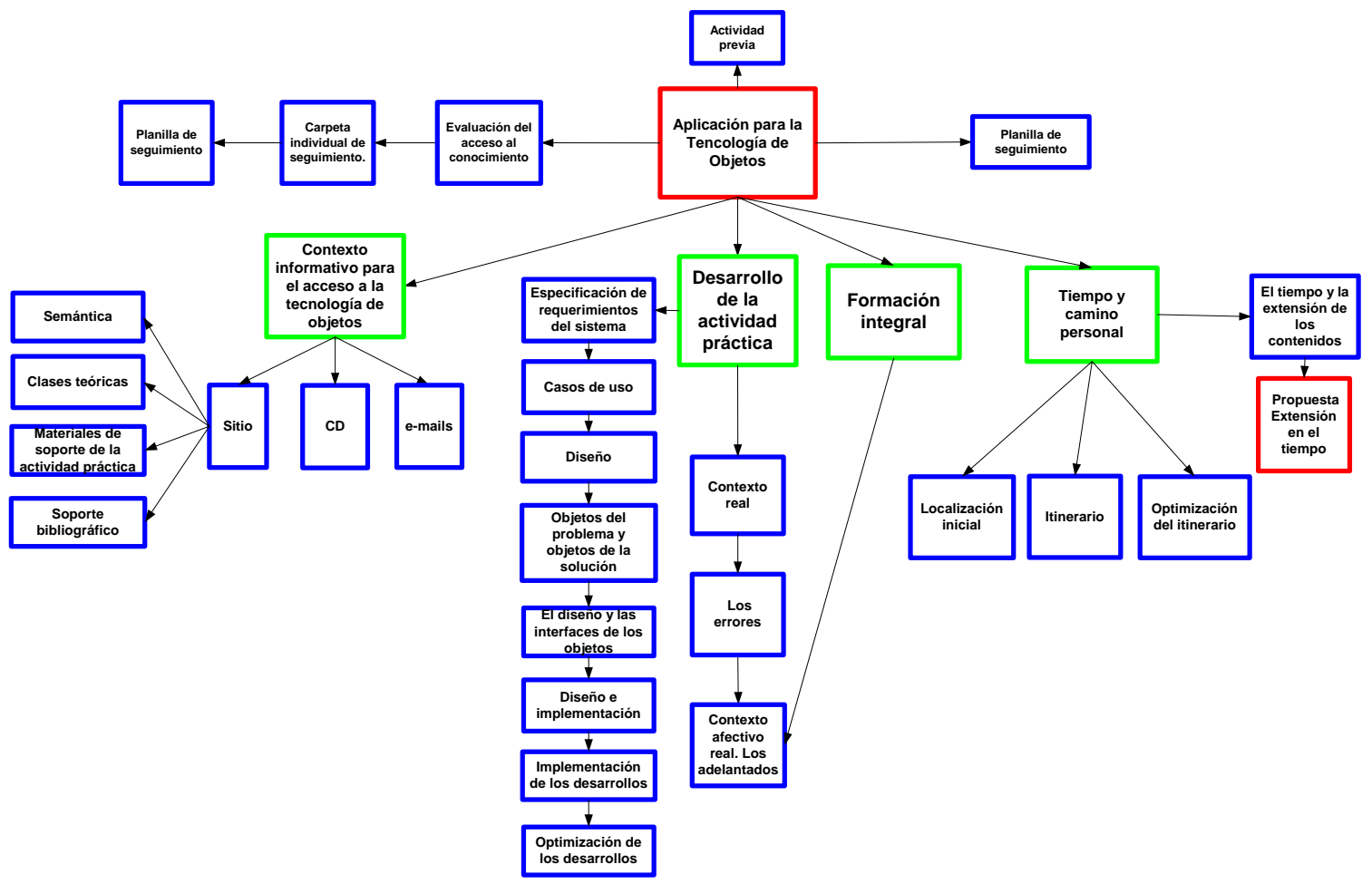




\section{Aplicaciones iniciales de los conceptos relevantes de esta tesis}

La aplicación más importante de los conceptos desarrollados en esta tesis tiene lugar, como ya se ha dicho, en una materia de la maestría de Ingeniería de software de la Facultad de Informática de la UNLP, dedicada al aprendizaje de la tecnología de objetos. También se han realizado aplicaciones más avanzadas en la cátedra taller Tecnologías en comunicación, de la que el autor es titular.

Las características de esta aplicación están dadas por la transición desde una cursada común a la búsqueda de personalizar el avance en la aprehensión de los conocimientos a la velocidad del educando y siguiendo los múltiples caminos propuesto.

Durante 2003 se contó por primera vez con un soporte multimedia, que puede considerarse como una versión inicial del buscado soporte informativo básico.

\section{Actividad previa. Encuesta}

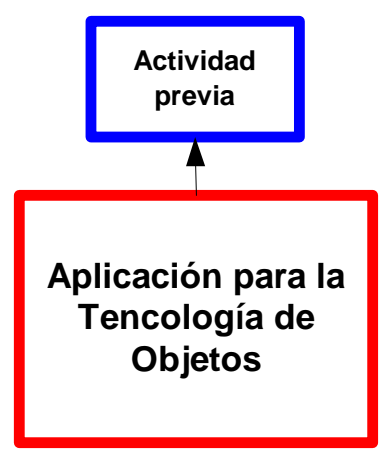

Cada alumno llega a cursar una materia con una comprensión variable, con un grado diferente de avance en la superficie de conocimiento. Esto hace necesario realizar una encuesta o algún otro procedimiento de evaluación entre todos lo cursantes para saber cual es el conocimiento de la tecnología y lenguajes de implementación, para definir si se encuentra en el estado de conocimiento mínimo como para cursar la materia en el tiempo disponible. Nuevamente y desde el comienzo el aprendizaje se puede personalizar. Asimismo se puede aprovechar ese momento para integrar al alumno a esta práctica diferente, que sepa que estamos tratando de personalizar el aprendizaje.

En nuestro ámbito real -aprendizaje de la tecnología de objetos en la Maestría de Ingeniería de software- se ha usado inicialmente una encuesta. Esta encuesta trata de ubicar al alumno en un punto la superficie de conocimiento. Luego a través del desarrollo de un ejercicio se va completando este perfil del cursante y se avanza con él a su propia velocidad dentro de los límites administrativos. La encuesta en uso tiene el siguiente contenido: 


\section{CÁTEDRA TECNICAS Y HERRAMIENTAS_ ENCUESTA}

\section{APELLIDO Y NOMBRE:}

DOMICILIO COMPLETO ESPECIFICANDO LOCALIDAD:

TELEFONO

CORREO-ELECTRÓNICO:

CONCURRE A CLASES TEÓRICAS

SU AREA DE TRABAJO ACTUAL:

\begin{tabular}{|c|l|l|l|l|}
\hline $\begin{array}{c}\text { SU CONOCIMIENTO SOBRE } \\
\text { LOS SIGUIENTES ASPECTOS } \\
\text { DE LA TECNOLOGÍA DE } \\
\text { OBJETOS ES }\end{array}$ & NULO & $\begin{array}{c}\text { INTRODUC } \\
\text { TORIO }\end{array}$ & MEDIO & COMPLETO \\
$\begin{array}{c}\text { (MARCAR CON UNA "X" LO } \\
\text { QUE CORRESPONDA) }\end{array}$ & & & & \\
\hline $\begin{array}{l}\text { CONOCIMIENTO TEÓRICO DE } \\
\text { LA TECNOLOGÍA DE OBJETOS }\end{array}$ & & & & \\
\hline $\begin{array}{l}\text { TERMINOLOGIA USADA EN LA } \\
\text { TECNOLOGÍA DE OBJETOS }\end{array}$ & & & & \\
\hline $\begin{array}{l}\text { REPRESENTACION UML DE } \\
\text { SISTEMAS DE OBJETOS }\end{array}$ & & & & \\
\hline $\begin{array}{l}\text { DISEÑO DE SISTEMAS CON } \\
\text { TECNOLOGÍA DE OBJETOS }\end{array}$ & & & & \\
\hline $\begin{array}{l}\text { ALGUN LENGUAJE } \\
\text { ORIENTADO A OBJETOS }\end{array}$ & & & & \\
\hline AMBIENTE SMALLTALK & & & & \\
\hline
\end{tabular}

TIPO DE ACCESO A INTERNET

MARCAR CON UNA "X"

IRRESTRICTO ON LINE

IRRESTRICTO TELEFONICO

TELEFONICO RESTRINGIDO

POR EL COSTO DE USO 
Planilla de conocimiento: concreción de la superficie de conocimiento

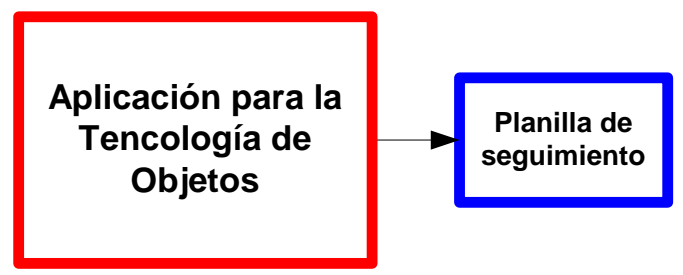

A efectos llevar al uso práctico la superficie de conocimiento presentada en el capítulo anterior se ha tomado una planilla en la que en las filas se establece una secuencia posible de acceso al conocimiento de la tecnología de objetos y algunos de los caminos posibles quedan asignados en las columnas

Se considera la posibilidad de recorrer los siguientes caminos posibles:

\section{SEMÁNTICA}

\section{TEORIA}

\section{EJEMPLOS E IMPLEMENTACIÓN DISEÑO y UML}

Con estas simplificaciones se logró la siguiente muestra

\begin{tabular}{|c|c|c|c|c|}
\hline Fecha & SEMÁNTICA & TEORIA & $\begin{array}{l}\text { EJEMPLOS e } \\
\text { IMPLEMENTACIÓN }\end{array}$ & DISEÑO y UML \\
\hline & sistema / programa & $\begin{array}{l}\text { análisis } \\
\text { conceptual }\end{array}$ & $\begin{array}{l}\text { ejemplo de sistema OO } \\
\text { funcionado }\end{array}$ & $\begin{array}{l}\text { diagrama de } \\
\text { interacción }\end{array}$ \\
\hline & objeto / object & $\begin{array}{l}\text { análisis } \\
\text { conceptual }\end{array}$ & $\begin{array}{l}\text { creación de un objeto } \\
\text { en el Transcript }\end{array}$ & $\begin{array}{l}\text { Representación de un } \\
\text { objeto } \\
\text { Diagrama de un } \\
\text { objeto con su estado } \\
\text { actual }\end{array}$ \\
\hline & $\begin{array}{l}\text { estado interno / } \\
\text { estructura }\end{array}$ & $\begin{array}{l}\text { análisis } \\
\text { conceptual }\end{array}$ & inspección de un objeto & $\begin{array}{l}\text { representación de los } \\
\text { atributos o estado } \\
\text { interno }\end{array}$ \\
\hline & $\begin{array}{l}\text { comportamiento / } \\
\text { behavior }\end{array}$ & $\begin{array}{l}\text { análisis } \\
\text { conceptual }\end{array}$ & $\begin{array}{l}\text { mandar mensajes a un } \\
\text { objeto en el transcript e } \\
\text { inspeccionar la } \\
\text { devolución }\end{array}$ & $\begin{array}{l}\text { representación de los } \\
\text { métodos de un objeto }\end{array}$ \\
\hline & $\begin{array}{l}\text { encapsulamiento / } \\
\text { encapsulation }\end{array}$ & $\begin{array}{l}\text { análisis } \\
\text { conceptual }\end{array}$ & & \\
\hline & método / method & $\begin{array}{l}\text { análisis } \\
\text { conceptual }\end{array}$ & codificar un método & $\begin{array}{l}\text { representación de los } \\
\text { métodos de un objeto }\end{array}$ \\
\hline & selector & $\begin{array}{l}\text { análisis } \\
\text { conceptual }\end{array}$ & identificar el selector & \\
\hline & mensaje / message & $\begin{array}{l}\text { análisis } \\
\text { conceptual }\end{array}$ & $\begin{array}{l}\text { enviar mensajes a } \\
\text { literales }\end{array}$ & $\begin{array}{l}\text { representación de los } \\
\text { mensajes }\end{array}$ \\
\hline
\end{tabular}




\begin{tabular}{|c|c|c|c|}
\hline $\begin{array}{l}\text { mensajes unarios, } \\
\text { binarios y de palabra } \\
\text { clave }\end{array}$ & $\begin{array}{l}\text { análisis } \\
\text { conceptual }\end{array}$ & $\begin{array}{l}\text { enviar distintos tipos de } \\
\text { mensajes a objetos }\end{array}$ & \\
\hline clase / class & $\begin{array}{l}\text { análisis } \\
\text { conceptual }\end{array}$ & $\begin{array}{l}\text { implementar la clase } \\
\text { CuentaBancaria }\end{array}$ & $\begin{array}{l}\text { representación de una } \\
\text { clase }\end{array}$ \\
\hline $\begin{array}{l}\text { instancia / instance/IC / } \\
\text { Instancia de la Clase } \\
\text {........ }\end{array}$ & $\begin{array}{l}\text { análisis } \\
\text { conceptual }\end{array}$ & $\begin{array}{l}\text { crear un objeto e } \\
\text { inspeccionarlo }\end{array}$ & $\begin{array}{l}\text { representación de una } \\
\text { instancia en los } \\
\text { distintos diagramas. } \\
\text { particularmente en los } \\
\text { de secuencia }\end{array}$ \\
\hline $\begin{array}{l}\text { interfaz de un objeto } \\
\text { /object interface }\end{array}$ & $\begin{array}{l}\text { análisis } \\
\text { conceptual }\end{array}$ & & \\
\hline $\begin{array}{l}\text { jerarquia de clases / } \\
\text { taxonomia de clases / } \\
\text { class hierarchy }\end{array}$ & $\begin{array}{l}\text { análisis } \\
\text { conceptual }\end{array}$ & $\begin{array}{l}\text { visualizar las distintas } \\
\text { jerarquías de } \\
\text { Visualwork y la de } \\
\text { CuentaBancaria } \\
\end{array}$ & $\begin{array}{l}\text { Diagrama de Clases } \\
\text { Representación de la } \\
\text { jerarquía } \\
\text { CuentaBancaria }\end{array}$ \\
\hline $\begin{array}{l}\text { polimorfismo / } \\
\text { polymorphism }\end{array}$ & $\begin{array}{l}\text { análisis } \\
\text { conceptual }\end{array}$ & $\begin{array}{l}\text { comprobar el } \\
\text { polimorfismo la } \\
\text { jerarquía de colecciones }\end{array}$ & \\
\hline herencia / inheritance & $\begin{array}{l}\text { análisis } \\
\text { conceptual }\end{array}$ & $\begin{array}{l}\text { verificar el mecanismo } \\
\text { de herencia en la } \\
\text { jerarquía Number }\end{array}$ & Notación de herencia \\
\hline $\begin{array}{l}\text { herencia de } \\
\text { comportamiento }\end{array}$ & $\begin{array}{l}\text { análisis } \\
\text { conceptual }\end{array}$ & & \\
\hline herencia de estructura & $\begin{array}{l}\text { análisis } \\
\text { conceptual }\end{array}$ & $\begin{array}{l}\text { verificar la herencia del } \\
\text { la variable saldo }\end{array}$ & \\
\hline subclase & $\begin{array}{l}\text { análisis } \\
\text { conceptual }\end{array}$ & $\begin{array}{l}\text { uso de una subclase del } \\
\text { comportamiento y } \\
\text { estructura de la } \\
\text { superclase }\end{array}$ & \\
\hline superclase & $\begin{array}{l}\text { análisis } \\
\text { conceptual }\end{array}$ & & \\
\hline clase abstracta & $\begin{array}{l}\text { análisis } \\
\text { conceptual }\end{array}$ & $\begin{array}{l}\text { verificar el carácter } \\
\text { abstracto de Collection }\end{array}$ & $\begin{array}{l}\text { Representación de } \\
\text { una clase abstracta }\end{array}$ \\
\hline clase concreta & $\begin{array}{l}\text { análisis } \\
\text { conceptual }\end{array}$ & $\begin{array}{l}\text { verificar el carácter } \\
\text { concreto de } \\
\text { OrderedCollection }\end{array}$ & \\
\hline asociación de clases & $\begin{array}{l}\text { análisis } \\
\text { conceptual }\end{array}$ & & $\begin{array}{l}\text { Representación de } \\
\text { una asociación }\end{array}$ \\
\hline sobreescribir / override & $\begin{array}{l}\text { análisis } \\
\text { conceptual }\end{array}$ & $\begin{array}{l}\text { sobreescribir el método } \\
\ldots \ldots\end{array}$ & \\
\hline $\begin{array}{l}\text { binding dinamico } \\
\text { /atadura dinamica }\end{array}$ & $\begin{array}{l}\text { análisis } \\
\text { conceptual }\end{array}$ & & \\
\hline variable & análisis & & \\
\hline
\end{tabular}




\begin{tabular}{|l|l|l|l|l|} 
& & conceptual & \\
\hline & $\begin{array}{l}\text { variable de instancia } \\
\text { I instance variable }\end{array}$ & $\begin{array}{l}\text { análisis } \\
\text { conceptual }\end{array}$ & $\begin{array}{l}\text { agregar una variable } \\
\text { de instancia a una clase }\end{array}$ & \\
\hline & métodos de acceso & $\begin{array}{l}\text { análisis } \\
\text { conceptual }\end{array}$ & $\begin{array}{l}\text { codificar los métodos de } \\
\text { acceso a una variable }\end{array}$ & \\
\hline
\end{tabular}

La elección de estos caminos -en esta muestra de la planilla de representación de la superficie de conocimiento- no excluye otros caminos posibles. De hecho durante el año 2004, usamos un swiki (wiki implementado en Smalltalk) para las páginas personales de cada alumno en Internet y el chat como herramienta de consulta, donde todos los caminos anteriores pueden realimentarse.

En el ámbito real experimental presentado al comienzo de este capitulo, se concretan clases teóricas, existe un taller de desarrollo de habilidades (para los alumnos que no cursan a distancia o aquellos que concurren periódicamente a La Plata). Nuestra web -en permanente crecimiento- recorre los caminos de la teoría, ejemplos, diseño, conceptos básicos de la tecnología de objetos y la implementación en Smalltalk. Todo este contenido, en el estado correspondiente al inicio de un curso, se envía en un disco compacto al conjunto de cursantes.

\section{Extensión del tiempo disponible}

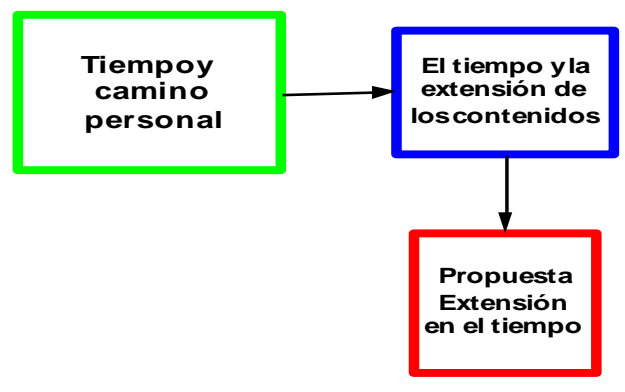

\section{Necesidad}

Los límites físicos de los edificios universitarios y los límites temporales de los ciclos lectivos no pueden ni podrán atender la necesidad de la formación terciaria en general y universitaria en particular

Sucede en un momento histórico, de importancia vital para el acceso al conocimiento. O sea que estas limitaciones tienen una trascendencia particular en momentos en que el empleo desaparece y la necesidad de la masificación del acceso al conocimiento es prioritarias para las comunidades que quieran entrar en la era posindustrial o era del conocimiento. Está claro que existen problemas en las áreas primarias y secundarias de la educación. Esto no debería ser una limitación para buscar estos caminos de expansión de la enseñanza universitaria 


\section{Propuesta}

Se plantea una propuesta para atenuar el efecto de los límites temporales impuestos por la administración universitaria tradicional. La propuesta permitiría respetar la velocidad individual del educando en un contexto presencial o no presencial.

Para el caso de la tecnología que estamos considerando y probablemente para todas las de base científica, es normalmente necesario el acceso paulatino al conocimiento - en rigor en base a los conocimientos comprendidos ya por el educandopara hacer posible la acomodación de los conceptos nuevos. La búsqueda de esta acomodación se logra respetando la velocidad de avance diferente de cada educando, velocidad que -como ya se ha planteado- es función de muchas variables.

La propuesta plantea -en la transición- dos tipos de cursadas

Tiempo fijo: establecido por las prácticas universitarias de cursar durante un período (cuatrimestre, año académico, etc.). Tiempo limitado del que se dispone y que acota la extensión de los conocimientos que pueden ser comprendidos por del educando. Se establecen para este lapso los objetivos mínimos a alcanzar.

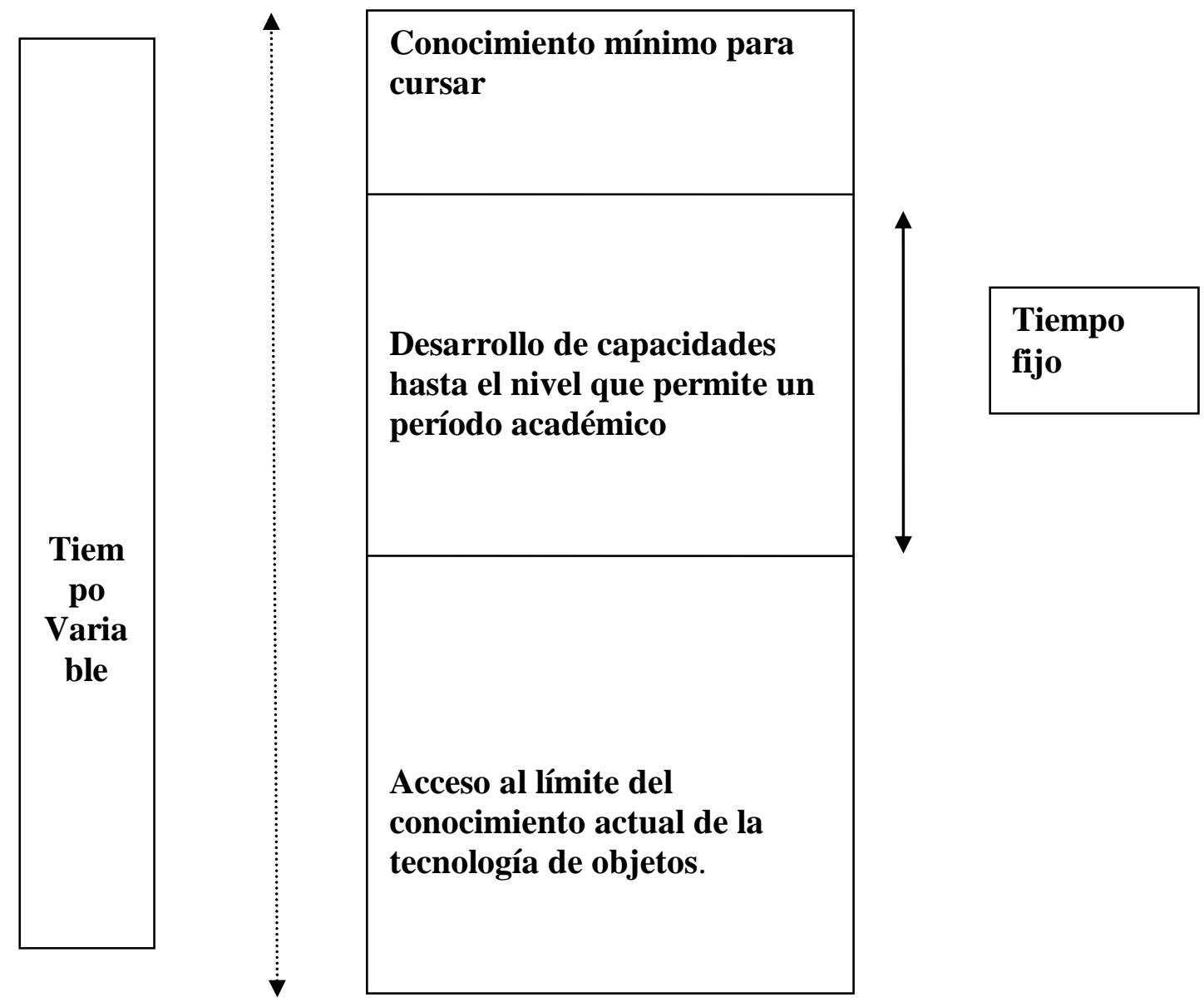

Tiempo variable compuesto por tres etapas:

a) Primera etapa: cada alumno llega al nivel de conocimientos necesario para acceder a la cursada de tiempo fijo. Esta actividad puede desarrollarse en forma presencial, con el soporte teórico 
multimedia o a distancia a través de la web e intercambio de correo-electrónico, con un número limitado de entrevistas con el docente. Esta actividad sería obligatoria para quienes -vivan o no en la localidad donde se realiza la cursada de tiempo fijo- no posean los conocimientos suficientes como para comenzar a cursar la materia, y por lo tanto necesitarán un tiempo variable para comenzar la cursada de tiempo fijo y llegar al nivel de conocimientos pretendido.

b) Etapa de tiempo administrativo establecido

c) Última etapa: quienes deseen en el futuro desarrollar la labor de adelantados o se interesen puedan desarrollar sus capacidades, teniendo en este último caso el objetivo llegar al límite actual de conocimientos dentro de la tecnología.

Se logra de este modo:

a) Atenuar la limitación temporal

b) Tener en cuenta el perfil del cursante

c) Cada educando avance a su propia velocidad para llegar a los objetivos de conocimiento.

d) Extender el límite de conocimientos a alcanzar que pueden ser establecidos por le propio educando.

En nuestro ámbito real actual (de transición); concientes de que se debe competir con las otras actividades del cursante (o sea el tiempo que el cursante dispone) establecemos un cronograma cuya rigidez cambia según las circunstancias. Buscamos asegurar que todo alumno que desee acceder al conocimiento de la tecnología de objetos pueda hacerlo poniendo su cuota de tiempo y voluntad. Cuando alguno de ellos tiene algún contratiempo que, circunstancialmente le impide dedicarse a su aprendizaje, la rigidez temporal se convierte en flexibilidad.

\section{Extensión del alcance físico de actividad académica}

La actividad de la formación en Internet o tele-formación está en desarrollo, también sus bases pedagógicas y matéticas.

Lo que hoy se puede ver, es que se ha potenciado la enseñanza a distancia donde hay una posibilidad de atenuar los efectos del límite espacial del aula; también se logra aumentar el tiempo de contacto docente-alumno usando herramientas virtuales, como el chat. Es decir, se va generado una alternativa para quienes residen en zonas alejadas de la localización física de la unidad académica. Paralelamente como ha sucedido con la misma Internet, ha aparecido un campo de negocios reales, virtuales y legítimos; también hay otros que a veces hacen lo viejo con herramientas nuevas.

También ha nacido un campo de investigación de interés epistemológico, donde estamos recorriendo un camino que, seguramente, dará nacimiento a nuevas teorías. 


\section{Contexto informativo para el acceso a la tecnología de objetos}

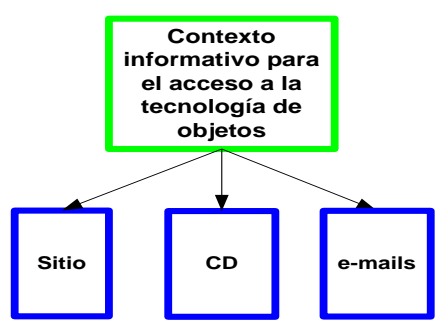

Dado el acceso limitado a Internet -que existe en esta transición- la información base para el cursante ha sido almacenada hipermedialmente en un soporte como los discos compactos (CD). La web de la materia sería una forma de actualización permanente y de contacto en cuanto al desarrollo de un sistema que es la forma de interacción en entre la teoría de la tecnología de objetos y la realidad.

\section{Contenidos del Sitio (o CD)}

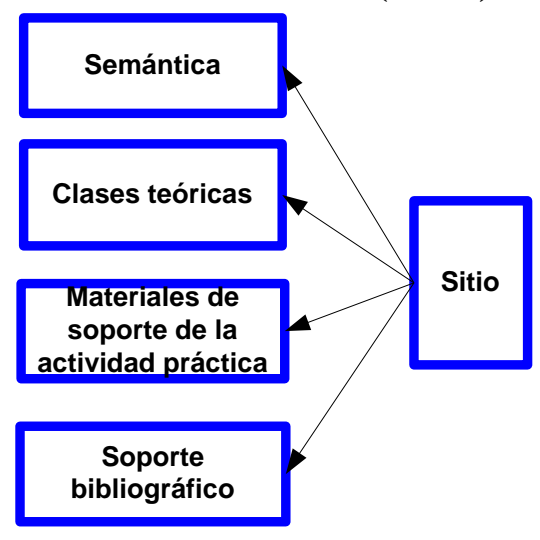

\section{Semántica}

Se ha tomado -en el ejemplo de planilla de conocimiento- la semántica utilizada en la tecnología de objetos como primera columna en la planilla de conocimiento. En realidad, cualquiera de los caminos posibles puede ser tomado como referencia y luego completar los demás caminos congruentemente. Esta semántica asociada a la tecnología de objetos queda expresada mediante la red terminológica que es una expresión concreta aproximada a la red teórica del esquema de Hempel y permite mejorar el uso de una semántica común en un ámbito que por sus características de crecimiento crea o modifica términos cotidianamente tanto en su expresión como con relación a su significado y significante. Esta red hipertextual permite que en un espacio y tiempo acotado se pueda usar una terminología común. El contenido de este hipertexto red terminológica puede ser accedido desde cualquier buscador de Internet (del tipo Netscape o Explorer), se encuentra ordenada alfabéticamente y conceptualmente según los siguientes conceptos:

- Conceptos de ingeniería de software

- Conceptos teóricos

- Conceptos aplicados de Objetos o conceptos Smalltalk. 


\section{Clases teóricas}

La actividad teórica -para los alumnos que cursan en forma presencial- se desarrolla con la periodicidad necesaria en un aula donde se explican y discuten los conceptos de la TO con los concurrentes, realizando conexiones con la práctica mediante el planteo de problemas, que sirven de realimentación inmediata para el docente sobre el estado de comprensión de los alumnos. Existe en este ámbito una limitación dada por la existencia de velocidades diferentes de comprensión de los concurrentes. Esta actividad intenta lograr las conexiones con los diferentes caminos propuestos en la superficie de conocimiento.

Las primeras conexiones se logran vinculando los temas nuevos con los conocimientos existentes en la mente de los educando, realizando discusiones con los mismos a fin de evitar que la actividad se acerque a un monólogo, para la transmisión de información al concurrente.

Para realizar las conexiones con los ejemplos se concretan desarrollos completos -interactuando con los concurrentes- en dominios conocidos por el conjunto de los concurrentes, por ejemplo dominio bancario, reserva de pasajes aéreos o comercio electrónico.

Se publican en la web la trascripción de cada una de las clases teóricas que ha sido grabadas en audio -el video es una aspiración a concretar- y se envían a los cursantes a distancia. Como alternativa a este soporte se realiza una trascripción a texto en el sitio de la materia.

\section{Materiales de soporte de la actividad práctica}

Los diferentes materiales provistos para el desarrollo del soporte teórico informativo base y de la actividad práctica se pueden ver en su sitio http://sol.info.unlp.edu.ar/topicos2/

\section{Soporte bibliográfico}

La sobreabundancia bibliográfica puede producir un atosigamiento informativo y una dispersión del educando. Sobre la base de la bibliografía propuesta será necesario asociar los particulares textos que la conectan con cada fila de la planilla de conocimiento.

La solución propuesta para el futuro es la construcción de la base teórica dinámica, soportada multimedialmente

\section{Desarrollo de la actividad práctica}

La actividad práctica - para los alumnos presenciales- se desarrolla en una sala taller que cuenta con suficiente equipamiento como para disponer uno o a lo sumo dos concurrentes por computadora. En general se trata de acompañar los conceptos vertidos contemporáneamente en las clases teóricas, con prácticas conectadas a dichos conceptos.

A los cursantes a distancia se les pide la especificación de un sistema que se desarrollará utilizando la tecnología de objetos. Luego de la especificación se pasa a la actividad más importante del desarrollo: el diseño, respetando la norma de represtación UML, finalmente se recurre a la implementación en Smalltalk. Toda esta actividad de enseñanza aprendizaje es evaluada por el titular de la cátedra mediante un examen final. 
Actividad de desarrollo de un sistema a realizar por los cursantes

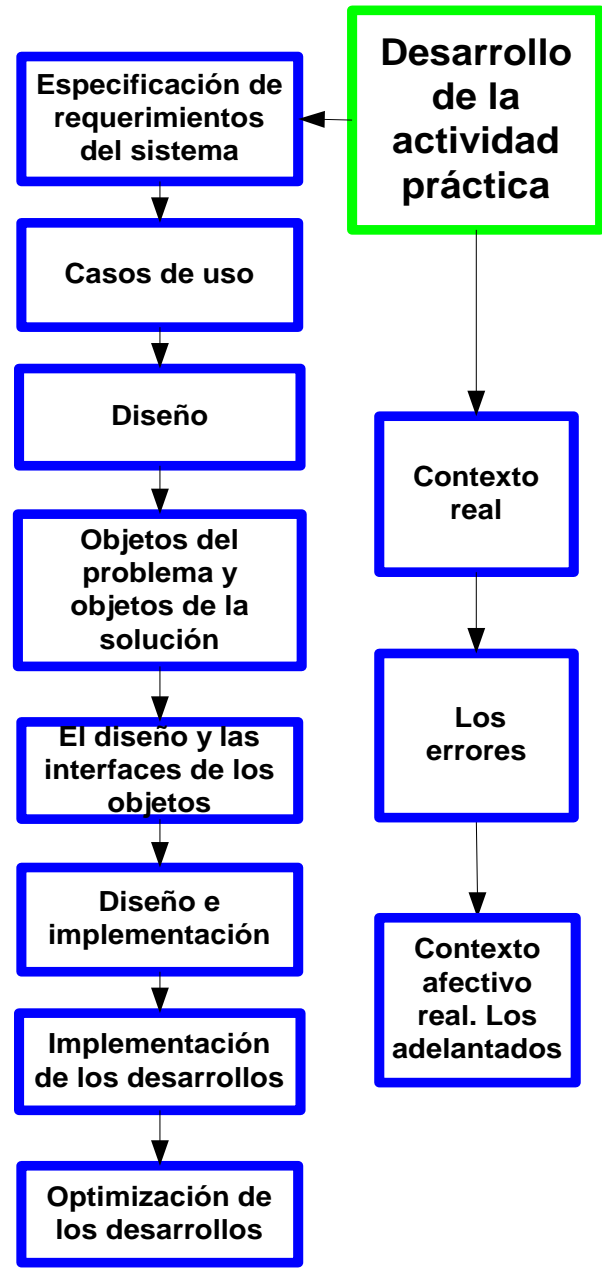

\section{Especificación de requerimientos del sistema}

Se planteará a los cursantes la elección de un dominio de actividad de características tales que le den sentido al uso de la TO una especificación de requerimientos. La realización de esta especificación crea un ámbito de aprendizaje al encontrarse el alumno con la necesidad de definir los siguientes elementos

a) Limitar la extensión textual de la especificación a efectos de evitar la dispersión.

b) Identificación del dominio y del proyecto en pocas palabras

c) Objetivo del sistema o ¿Qué es lo que hace el sistema?

d) Funcionalidad esperada

e) Conectar el objetivo del sistema con la funcionalidad principal del sistema mediante el mensaje fundamental del dominio (o sea el mensaje inicial para probar luego la implementación)

f) Enumerar los objetos que colaboran (con sus responsabilidades)

La elección del dominio deberá ser tal que dé lugar a comportamiento notable. Es posible que por una continuidad con el trabajo pretérito en el área informática se elijan dominios donde solo se trabaje con registros que almacenan datos. 
Es necesario especificar claramente la funcionalidad del sistema, qué es lo que se espera que el sistema haga. En este sentido son válidos, por ejemplo, los juegos y simuladores, ya que en ellos existe mucha interacción entre objetos del problema.

\section{Cuidados a tener en cuenta cuando se escribe la especificación}

De la especificación del sistema se pueden extraer los objetos iniciales para modelar la aplicación, objetos que tienen su contrapartida en el mundo real. Se deben tener los siguientes cuidados:

a) Usar un solo término para cada concepto. Si redundan usar el más significativo.

b) Ser cuidadoso con los adjetivos. Un adjetivo puede sugerir un tipo diferente de objeto, un uso diferente del mismo objeto o ser irrelevante. Si el adjetivo señala que la conducta del objeto es diferente, entonces produce una nueva clase.

c) Ser cuidadoso con las sentencias en voz pasiva o de aquellos sujetos que no son parte del sistema. Reconstruir la sentencia en voz activa.

d) Modelar categorías de clases para facilitar que luego deriven en clases abstractas.

e) Modelar los valores de los atributos de los objetos, pero no los atributos en sí.

\section{Diseño}

El diseño en la tecnología de objetos es la parte relevante de un desarrollo. Esta actividad está teniendo su proyección a través de los patrones de diseño que permiten una standardización en la resolución de los problemas de diseño que aparecen una y otra vez

La representación gráfica se realiza según la norma UML. Se estarán recorriendo dos radios de la superficie de conocimiento (Diseño y UML). Nuevamente es conveniente efectivizar en la mente de los cursantes las conexiones con los otros radios mediante la comunicación presencial o virtual. (Estas conexiones tienen una propuesta concreta de ejecución en la planilla de conocimiento)

\section{Casos de uso}

A partir de la especificación, se trabaja con la funcionalidad establecida, para la que se grafica el caso de uso.

a) Definir los actores.

b) Definir los la relación entre los actores y las funcionalidades de cada caso de uso.

c) Escribir las conversaciones para cada Caso de Uso

d) Se toma el o los caso de uso y se establece cuáles son los objetos necesarios para cumplir con la función asociada a ese caso de uso. Esos objetos del problema tendrán una distribución a priori de responsabilidades individuales y colaboraciones, para un primer intento de cumplimentar la funcionalidad del sistema en desarrollo.

e) Se establecen el o los diagramas de secuencia que incluyan los casos alternativos para cada una de las conversaciones de cada caso de uso, encontrando qué objetos pueden interactuar para resolver la conversación.

f) Se definen las clases que instanciarán a los objetos encontrados. Dichas clases tiene responsabilidades que deben ser identificadas: 
- Responsabilidades de cada clase: las responsabilidades de cada clase (o de los objetos que instancia) se cumplimentan básicamente a través de su comportamiento que va cambiando su estado interno. Las responsabilidades de un objeto son los servicios que provee. Cuando un objeto cumple una petición realizada por otro objeto juega el rol de servidor. Un contrato entre dos clases representa una lista de servicios que una clase solicita a otra clase.

- Como identificar responsabilidades: a través de la especificación se listan los verbos y se determina si representan acciones que algún objeto debe ejecutar. A partir de las clases encontradas y sus nombres, lo cual sugiere una responsabilidad al menos y esta deriva en otras y así sucesivamente. También pueden analizarse las relaciones "es_tipo_de", "es_análoga_a" y "es_parte_de" para identificar superclases y/o subclases que determinen responsabilidades.

- Para determinar las colaboraciones: si es una clase servidora se debe preguntar qué hace, que conoce y que clases necesitan el resultado de su comportamiento. Si es una clase cliente se debe preguntar qué otras clases necesita para cumplir sus responsabilidades

g) Una clase puede cumplir una responsabilidad sola o puede requerir asistencia de otras clases. Aquellas clases que colaboran definen un contrato donde una clase que juega el rol de cliente y otra clase juega el rol de servidor. Analizando colaboraciones se pueden detectar responsabilidades mal asignadas en la etapa previa.

h) Se relacionan las clases.

i) Se agregan a las clases atributos y operaciones (básicamente los mensajes que los objetos de esas clases pueden recibir.)

j) Se establece en el diagrama de clases la lista de responsabilidades de cada clase y las colaboraciones. Junto con el nombre de la clase se puede poner un estereotipo que sugiere ciertas responsabilidades generales de la clase. En su forma más simple, un estereotipo se representa con un nombre encerrado por pico-paréntesis o comillas francesas (por ejemplo, <<nombre $\rangle>$ ) y se coloca arriba del nombre de un elemento. En el caso particular de una clase por ejemplo. puede indicar que es <<abstracta〉> o que instancia objetos <<de control>>

k) Una vez definido el diagrama de clases se itera con el diagrama de secuencia hasta conseguir el diseño definitivo.

[Thompson, 2003]

\section{Análisis y diseño}

No hay un límite preciso entre análisis y diseño, cuando se hace el análisis se va construyendo un modelo y cuando se pasa a diseño lo que se hace es evolucionar ese modelo, se pueden eliminar objetos superfluos o agregar objetos de la solución.

\section{Relación entre objetos del problema (análisis) y objetos de la solución (diseño)}

En el análisis se trabaja con los objetos del problema (aquellos que tienen contrapartida en el mundo real), al pasar al diseño pueden aparecer nuevos objetos: los objetos de la solución. Por ejemplo, si se está modelando un juego de fútbol: en el análisis aparecen como objetos del problema: jugador, campo de juego y pelota que 
darán lugar a un diagrama de secuencia para el caso de uso de un gol, en que el jugador acciona sobre la pelota y de alguna manera el sistema se de cuenta de que hubo un gol; cuando se pasa a la etapa de diseño se le comienza a poner más inteligencia a los objetos, así se le pondría a la pelota la "inteligencia" de saber cuando entró en el arco. Esta aparición de objetos de la solución con mayor inteligencia es típica en los Patrones de Diseño

Una vez desarrollados los diagramas de secuencia se pueden construir los diagramas de clases.

\section{El diseño y las interfaces de los objetos}

La interfaz de un objeto es el conjunto de las signaturas definidas para los mensajes que un objeto puede responder, donde cada signatura especifica, para un mensaje dado, el nombre del método que cumple el mensaje, los argumentos que eventualmente acompañan al selector, y el valor devuelto luego de la ejecución de método.

Se diseña en función de las interfaces de objeto, o sea de la forma en que se puede comunicar con el objeto (los mensajes que entiende).

\section{Diseño e implementación}

Toda etapa de diseño se debe realizar sin pensar cómo va a ser la implementación concreta, sólo se expresa en términos de los mensajes que se van a mandar a los objetos.

No se puede guiar el diseño por la forma en la que se va a implementar, lo que permite hacer diseños lo suficientemente genéricos cómo para implementarse en cualquier lenguaje.

\section{Implementación de los desarrollos}

La implementación es la conexión con el mundo de la experimentación que establece el esquema de Hempel. Simultáneamente con los demás caminos (semántico, teórico, etc.), se aprende a interactuar con el ambiente Smalltalk, las clases básicas, las estructuras de control, las de datos, etc.

Como ha quedado claro en párrafos anteriores, en este campo donde se produce parte del paso de una tecnología informática a una ingeniería de software. En el ambiente Smalltalk se logra la acumulación de conocimiento en forma de software estable y evolutivo.

Por su parte a través de los patrones de diseño se acumulan soluciones para problemas de diseño que aparecen una y otra vez, cuestión que las ingenierías tradicionales fueron realizando en el pasado.

En contra de este camino de crecimiento la imposición comercial del lenguaje Java es una de las trabas a esta posibilidad de concretar una difusión del uso y re-uso racional del software. La otra traba es la dificultad que el aprendizaje de la tecnología de objetos tiene y que esta tesis trata de atenuar.

\section{Contexto afectivo real y adelantados en el taller de aprendizaje de Objetos}

Los docentes a cargo del taller cumplen durante el primer año de actividad el rol de adelantados, tratando de acercarse al ideal planteado en el capítulo 4. Inicialmente serán una fuente de consulta dedicada a salvar los obstáculos de acceso al 
lenguaje Smalltalk, para luego analizar, diseñar e implementar los problemas planteados. Al hacerlo se pueden resolver problemas de conceptualización.

Un caso típico de actividad relacionado con el acceso conceptual al paradigma de TO y que difícilmente se llegue a resolver en la mente del alumno si no hay una actividad práctica relacionada con la producción de dentro del ambiente Smalltalk, está relacionado con planteos como "¿cómo le mando un mensaje a un objeto?, ¿existe el objeto? ¿Es necesario crearlo? ¿cómo se crea un objeto?”

Durante cada período académico se seleccionan los colaboradores de la materia para los años siguientes; serán aquellos que cumplan con lo especificado oportunamente.

La práctica de taller permite que las conexiones se afirmen al interactuar en el campo de la implementación y apelando a un uso sensorial más amplio que el posible en el ámbito teórico. Al darse una interacción más completa, existe una realimentación continua entre lo que pensaba el educando y lo que la realidad corrobora o contradice. Lo corroborado tiene alta probabilidad de ser conocimiento instalado (acomodado). El rol de los adelantados es ayudar a salvar las contradicciones entre la teoría vigente en la mente del educando y lo que la experiencia muestra.

\section{Conexión adicional: Modelado E/R del paradigma de TO}

Si previamente es conocido por el educando el modelo entidad-relación es posible poder conectar, esquemáticamente, lo conocido con lo nuevo, mediante el siguiente modelo desarrollado por quien escribe.

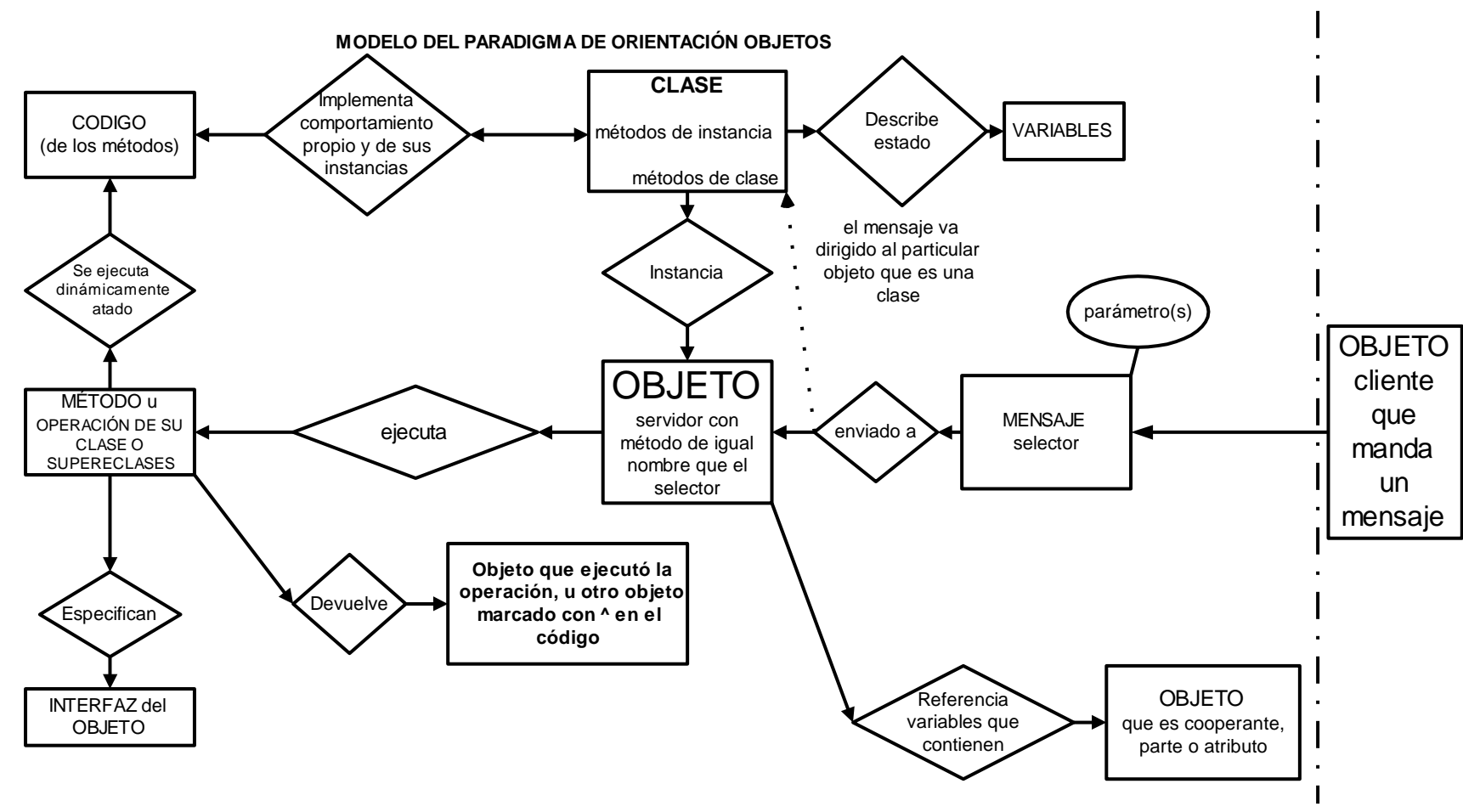




\section{Optimización de los desarrollos}

En palabras de Hilario Fernández Long "todo proceso de optimización se debe tener en cuenta que siendo lo mejor enemigo de lo bueno, los esfuerzos deben limitarse. En cualquier obra artística $99 \%$ perfecta, para llevarla al $100 \%$ perfecta hay un esfuerzo que solo el artista genial puede realizar, el artista normal no puede."

La optimización de desarrollos en el software, ha significado en la tecnología tradicional lograr la mayor velocidad de ejecución (performance) siendo en realidad esta sólo una variable a considerar.

Dentro de la tecnología de objetos existen varios conceptos de optimización. Uno de ellos consiste en reordenar de distintas formas el diseño y la implementación para lograr mayor reusabilidad e ir ganando en eficiencia $y$ mantenibilidad.

Un área especial de optimización se denomina refactorización.

Esta actividad esta relacionado con un nivel de conocimientos que se considera necesario plantear: es el horizonte actual de la tecnología de orientación a objetos en el que se puede ver el nacimiento de una verdadera ingeniería de software en el sentido de logra desarrollos de calidad constante o de mejoras de la calidad según los conceptos de Richard Gabriel en su libro Patrones de software:

"Todavía no se puede decir que es la calidad, pero se pueden decir algunas cosas de software que la poseen:

No fue escrito con una fecha límite irreal.

Sus módulos y sus abstracciones no son demasiado grandes - si así lo fuesen, su tamaño y su inflexibilidad hubiesen creado fuerzas que gobernarían en exceso la estructura total del software; cada módulo, función, clase, y abstracción es pequeña y tiene nombre de modo tal que se sepa que es cada cosa sin mirar a sus implementaciones.

Cualquier parte mala fue reparada durante el mantenimiento o está siendo reparada ahora.

Si es pequeño, fue escrito por una persona extraordinaria, alguien que yo quisiera tener como amigo; si es grande, no fue diseñado por una persona, pero si a través del tiempo de forma lenta, cuidadosa e incrementada.

Si miro a cualquier pequeña parte de él, puedo ver lo que está pasando no necesito referirme a otras partes para entender lo que algo está haciendo. Esto me dice que las abstracciones tienen sentido por ellas mismas - ellas son completas.

Si miro a cualquier parte grande en un vistazo general, puedo ver lo que está pasando - no necesito conocer todos los detalles para comprenderlo.

Es como un fractal, en el que cada nivel de detalles es tan localmente coherente y tan bien pensado como cualquier otro nivel.

Cada parte del código es transparentemente clara - no hay secciones que sean obscuras con el objeto de ganar eficiencia.

Todo acerca de él parece familiar.

Puedo imaginar cambiarlo, añadir alguna funcionalidad.

No le temo, lo recordaré." 


\section{Evaluación del acceso al conocimiento}

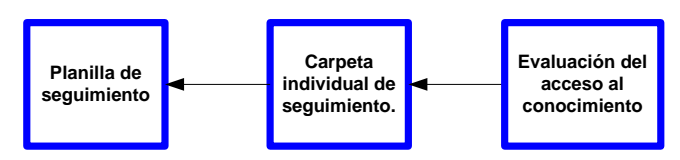

La evaluación de cualquier acceso al conocimiento, resulta de la evidencia presentada activamente por el educando, en el sentido de dominar la teoría asociada al conocimiento y de la aplicación de dicha teoría mediante reglas de interpretación tanto para explicar la experiencia como para crear nuevas realidades que resuelvan los nuevos problemas que se planteen. Es una evaluación que solo puede realizar quien acompaña periódicamente al educando en su proceso de la formación.

\section{Carpeta individual de seguimiento.}

Se planteo como elemento principal de evaluación del educando su producción. En el caso del desarrollo de cada proyecto -hasta disponer de herramientas más elaboradas- se deberá habilitar una carpeta de archivos para cada cursante dentro de la cual se guardaran la especificación de requerimientos, el diseño, la implementación del caso de uso elegido y la conexión con la interfaz de usuario que permite su visualización y uso. 


\section{CAPITULO 6 \\ APORTES, CONCLUSIONES Y ACTIVIDAD A FUTURO}

Se resumen las conclusiones del trabajo y se propone como actividad a futuro se propone continuar investigando los efectos de aplicar profundamente las propuestas de esta tesis en la actividad del aprendizaje de tecnología de objetos: instalando un ámbito de reflexión sobre la actualidad y el futuro, produciendo sistemas e ideas por parte de los alumnos: un sistema con tecnología de objetos y un trabajo de análisis de la situación actual y propuesta para futuro.

\section{APORTES}

De la lectura de los capítulos anteriores surgen como aportes de esta tesis

- Redefinición de los dos ámbitos tradicionales -teórico y práctico- proponiendo un tercer ámbito académico de reflexión entre docentes y alumnos.

- Concepto de superficie de conocimiento que permite ubicar al alumno en el origen de su conocimiento para lograr a través del camino de aprendizaje, llegar a los límites del conocimiento actual.

- Propuesta de tiempo variable de cursada, asociado al tiempo variable de aprendizaje normal de la personas.

- Concepto de adelantado: posibilidad de mejorar la relación cuantitativa y cualitativa entre quienes enseñan y quienes aprenden (sin necesidad de disponer de nuevos los recursos económicos).

\section{CONCLUSIONES Y ACTIVIDAD A FUTURO}

Aplicando exhaustivamente la metodología científica, recurriendo al conocimiento conectado, en base a información ordenada, prácticas productivas, y considerando el perfil matético del cursante es posible redefinir el ámbito de aprendizaje de modo que:

a) La información necesaria este disponible de un modo eficiente y evolutivo

b) La actividad práctica se vincule con la producción.

c) Prolongar -dentro de límites normales- el tiempo de aprendizaje- permitiendo adaptar -el tiempo disponible- a la particular velocidad de cada cursante

d) Incorporar a parte de los ex cursantes como docentes auxiliares logrando simultáneamente un ámbito de capacitación adicional de los mismos.

e) Crear un ámbito de reflexión sobre el presente y el futuro para

\section{De este modo se logra}

- Redefinir las actividades teóricas y prácticas.

- Tener presente la situación social, económica y política para analizar los efectos del cambio tecnológico sobre el presente y el futuro.

- Lograr un aprendizaje de la tecnología soportada en conceptos científico

- Personalizar el aprendizaje tecnológico en sus fases teóricas y prácticas según el perfil de de cada educando.

- Aplicar estos criterios al caso particular de la tecnología de objetos

- Aplicar las experiencias en cualquier materia tecnológica de base científica. 
- Objetivos del ambiente académico propuesto

Buscar una forma más inteligente de habitar el planeta, propuestas que eventualmente podrán ejecutar como profesionales egresados de esta Universidad o como futuros ciudadanos formados en una mayor inteligencia social.

- Influenciar la búsqueda del conocimiento liberando la mente de las creencias que dieron base a la era industrial (consumo ilimitado, emanaciones contaminantes ilimitadas, etc.).

- Capacitación de los profesionales que se reciben en el área informática para relacionarla con el pensamiento crítico en su profesión y en su actitud como ciudadanos.

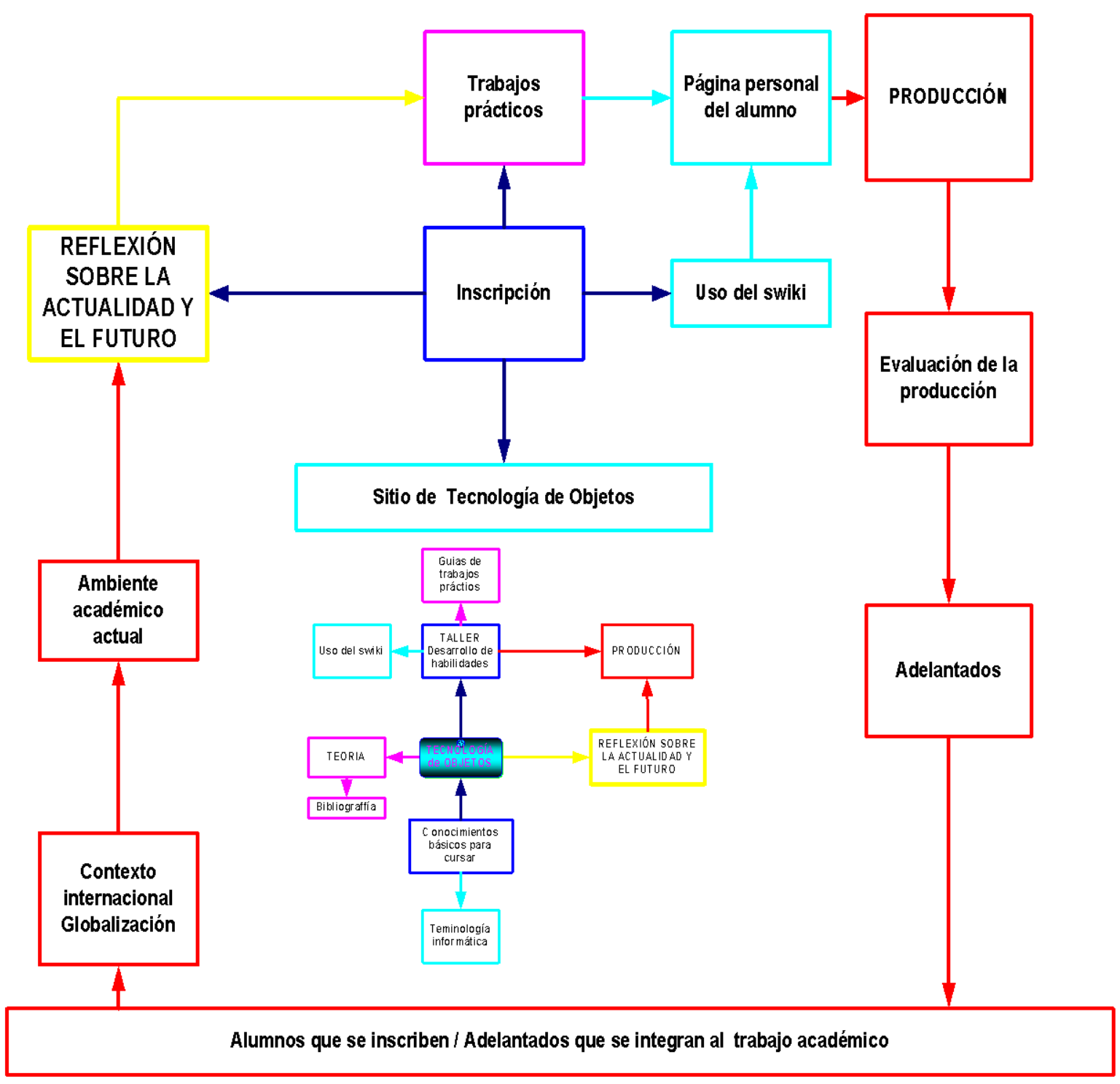

El "ámbito de reflexión sobre la actualidad y el futuro" se podrá establecer la temática a tratar abarcando temas que van desde el contexto mundial hasta el sentido de la vida, pasando por la realidad nacional y local.

Se busca que emerja de nuestra inteligencia conjunta algo profundamente humano, que sea alternativa al materialismo global, comunicarlo para su optimización y 
concreción (en la cual nos incluiríamos), mediante su desarrollo en la comunidad argentina.

Se tratará de plantar semillas de pensamiento conjunto usando reticularmente las capacidades intelectuales, para tratar los problemas que -influyendo en nuestro planeta $\mathrm{u}$ hogar común- nos afectan a todos y cada uno de nosotros.

\section{Continuidad en el desarrollo de e-learning}

Se ha practicado e-learning hasta ahora con el correo electrónico, el sitio de la cátedra y herramientas como el swiki, el chat, etc. Estos instrumentos permiten un contacto continuo con los alumnos

E-learning es el aprovechamiento de nuevas herramientas para ayudar al trabajo interpersonal entre docentes y alumnos.

\section{Sitio evolutivo de la cátedra}

La tecnología de la Web permite asentar conocimiento e ir evolucionando continuamente.

Los alumnos, tendrán en el sitio evolutivo su fuente de consulta informativa. El sitio la cátedra acompaña a los alumnos cursantes a través de los materiales que se incorporen y a través de la presencia virtual de los docentes.

Se buscará planificar el sitio para que tenga un portal con un límite de información diferenciada, que puede ser captada por la memoria de corto alcance por el alumno interactuarte.

Tratar de establecer criterios ergonómicos para la Web, que tengan en cuenta el punto de vista del usuario, o sea que el sitio pueda ser recorrido en forma ergonómica y normalizada, como un libro del cual sabemos que tiene una tapa, un prólogo, un índice, etc.

\section{Red conceptual del sitio}

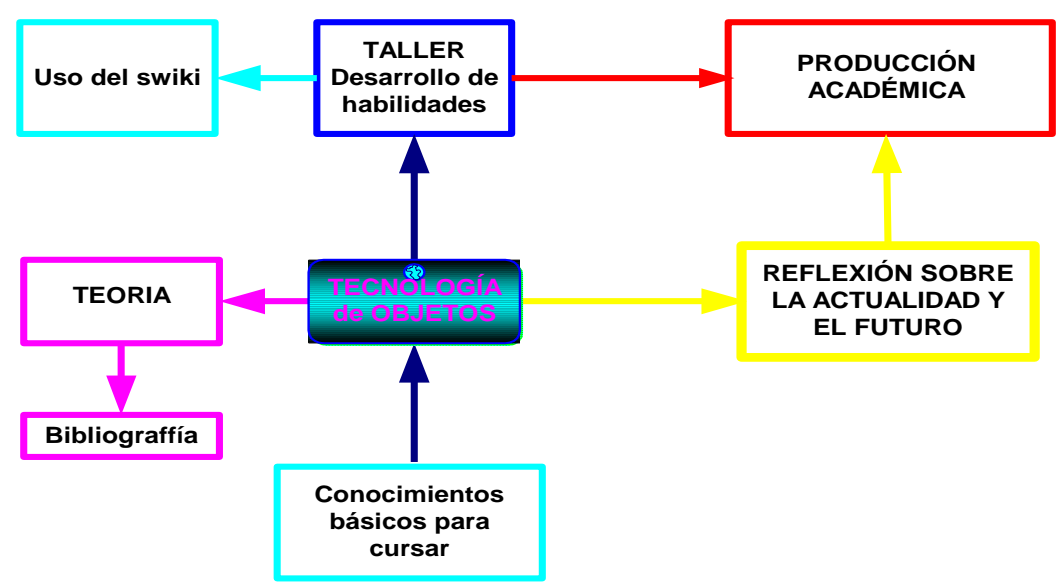




\section{Contenido del sitio}

\section{Información teórica}

Contiene la base teórica de la cátedra.

Toda la información teórica que pretendemos se conozca y toda la información base para la aplicación práctica:

- Conocimiento previo que deben tener para cursar (quienes se inscriban y no lo tengan tendrán tiempo desde la inscripción hasta que comience el curso para acceder a dicho conocimiento): Se logra a través del glosario de términos.

- Toda otra información que se espera que los alumnos sepan o puedan aprender interactuando con el sitio

\section{Ámbito virtual de publicación de la producción de los cursantes}

La herramienta que se utilizará será un editor de acceso controlado denominado swiki donde los alumnos pueden publicar su producción en su página personal.

\section{Inscripción de los cursantes}

La inscripción de los cursantes de la materia será una instancia importante desde el punto de vista cualitativo en la medida que, podrá comunicar a los alumnos que quieran cursarla, qué es y qué no es Tecnología de Objetos.

\section{Comunicación a los alumnos en el momento de inscripción}

- Asistencia obligatoria al ámbito de reflexión. Aquellos que cursen a distancia integrarán un ámbito virtual

- Luego del horario de reflexión un profesor ayudará a definir los temas de trabajo, el sistema de objetos y el tema socioeconómico que será discutido durante las reuniones de reflexión.

Asimismo se comunicará que la materia posee tres áreas

- Informativa teórica

- Desarrollo de habilidades y producción

- Formación integral.

Se exhibirá gráficamente la red de ideas planteada en el comienzo de este capítulo, un organizador que permite definir los ejes de trabajo a simple vista.

Red de actividad con los alumnos y ex alumnos: intentaremos retener en una red de actividad permanente a los alumnos que se interesen en integrarla, trataremos de estar atentos para detectarlos. Luego durante el siguiente año podrán ser los adelantados. 


\section{BIBLIOGRAFÍA}

Alexander, Christopher y otros, “A Pattern Language”, Oxford University Press Inc. 1997

Bohr, Niels "Atomic Physics and Human Knowledge”, John Wiley \& Sons, New York, 1958.

Bell, John S., Lo decible y lo indecible en la mecánica cuántica, Alianza Universidad, Madrid, 1990

Bosch, Mela "Hablamos en prosa sin saberlo" Seminario Interdisciplinario "El futuro de Internet: análisis de contenido de información en red" F.P.C.S U.N.L.P. 1999

Beck, Kent "Smalltalk Best Practice Patterns", Prentice Hall PTR, 1997.

Calvin, Willam H. "How Brains Think”, Basics Books, 1996

Contini de González, Norma "Inteligencia de los unos y los otros" Pagina12. Suplemento Psicología, 23 diciembre 1999

Cromer, Alan “Connected Knowledge”, Oxford University Press Inc. 1997

Freire, Pablo “Pedagogía del oprimido" SIGLO XXI, ISBN: 987-98701-5-8

Gamow, George "One Two Three . . Infinity: Facts and Speculations of Science", Dover, ISBN: 0486256642

García del Cid, Lamberto "La paradoja Einstein-Podolsky-Rosen y el teorema de Bell", 2004

http://www.fcgjung.com.es/art_19.html

Gardner, H., y Hatch, T. (1989). "Multiple intelligences go to school: Educational implications of the theory of multiple intelligences". Educational Researcher, 18 (8), 4-10.

Kapra, Fritjof, "El Tao de la Física”, Editorial Sirio, Málaga, 1975,1983 ISBN: 847808-175-5

Kuhn, T. S., "The structure of the scientific revolutions", Chicago University Press, Chicago, 1962

Landow, George P. "Hipertexto”, Paidos 1995 
LaLonde, Wilf R. and Pugh, John R., "Inside Smalltalk” Prentice-Hall, 1990, ISBN 013-468414-1

Lipcovich, Pedro "Dar examen es perjudicial para la salud", Página 12, 2002 http://pagina12.feedback.net.ar/diario/sociedad/3-13871-2002-12-07.html

Miller, George A., "The Magical Number Seven, Plus or Minus Two: Some limits on our Capacity for Processing Information." Psychological Review, 63 (1956):81-97 ó http://www.well.com/user/smalin/miller.html

Oppenheimer, Julios Robert, "Science and the Common Understanding" Oxford University Press, Londres, 1954

Popper, K., "Conjeturas y Refutaciones”, Paidós, Buenos Aires, 1967.

Gabriel, Richard, "Patterns of Software: Tales from the Software Community", Oxford University Press; ISBN: 0195121236, 1996.

Papert, Seymour "Desafío a la mente", Ediciones Galápagos, 1981

Papert, Seymour "La máquina de los niños", Paidós, 1995

Reimondo, Alejandro "Porqué objetos", Smallltalking, 2000

http://www.smalltalking.net/Papers/why/PorqueObjetos.htm

Rossi, Gustavo "Teóricas maestría Ingeniería de Software”, 1999

http://sol.info.unlp.edu.ar/topicos2/Teoria/indice.htm

Thompson, Héctor. “T y H 2003”, 2003

http://sol.info.unlp.edu.ar/topicos2/

Thompson, Héctor, y otros “Computación clínica y espacio creativo", Editorial Tekne, 1988

Thompson, Héctor, y otros "Computación en el colegio", Ed. Informática Educativa, 1984

Thompson Héctor "Energía e información, ¿escasez o abundancia?, Revista Virtual Question, FPCS, UNLP, 2000

Turkle, Sherry, "The second self"Computers and the Human Spirit, NY, Simon and Schuster, 1984 